Florida International University FIU Digital Commons

$11-8-2012$

\title{
Tin Oxide Based Composites Derived Using Electrostatic Spray Deposition Technique as Anodes for Li-Ion Batteries
}

Abirami Dhanabalan

Florida International University, adhan001@fiu.edu

DOI: $10.25148 /$ etd.FI12121003

Follow this and additional works at: https://digitalcommons.fiu.edu/etd

\section{Recommended Citation}

Dhanabalan, Abirami, "Tin Oxide Based Composites Derived Using Electrostatic Spray Deposition Technique as Anodes for Li-Ion Batteries" (2012). FIU Electronic Theses and Dissertations. 801.

https://digitalcommons.fiu.edu/etd/801 


\section{FLORIDA INTERNATIONAL UNIVERSITY}

Miami, Florida

TIN OXIDE BASED COMPOSITES DERIVED USING ELECTROSTATIC SPRAY DEPOSITION TECHNIQUE AS ANODES FOR LITHIUM-ION BATTERIES

A dissertation submitted in partial fulfillment of the requirements for the degree of DOCTOR OF PHILOSOPHY

in

MATERIALS SCIENCE AND ENGINEERING

by

Abirami Dhanabalan

2012 
To: Dean Amir Mirmiran

College of Engineering and Computing

This dissertation, written by Abirami Dhanabalan, and entitled Tin Oxide Based Composites Derived Using Electrostatic Spray Deposition Technique as Anodes for LiIon Batteries, having been approved in respect to style and intellectual content, is referred to you for judgment.

We have read this dissertation and recommend that it be approved.

$\begin{array}{r}\text { W. Kinzy Jones } \\ \hline \text { Norman D.H. Munroe } \\ \hline \text { Surendra K. Saxena, Co-Major Professor } \\ \hline \text { Chunlei Wang, Major Professor }\end{array}$

Date of Defense: November 8, 2012

The Dissertation of Abirami Dhanabalan is approved.

$\begin{array}{r}\text { Dean Amir Mirmiran } \\ \text { College of Engineering and Computing } \\ \hline \begin{array}{r}\text { Dean Lakshmi N. Reddi } \\ \text { University Graduate School }\end{array}\end{array}$

Florida International University, 2012 
(C) Copyright 2012 by Abirami Dhanabalan

All rights reserved. 


\section{DEDICATION}

I dedicate this dissertation to my loving and supportive family and friends. 


\section{ACKNOWLEDGMENTS}

It has been a long journey since I started my PhD. I began the program, just after completing my bachelor's degree, knowing little, and may I dare to say, I have learned quite valuable lessons by the time I completed. Several things happened and my personal views have changed after I started my PhD. I was completely at a loss when my cousin, with whom I grew up as a child, passed away quite suddenly. Due to the personal struggles, dissertation could not always be my first priority. But I have persisted and completed, thanks to the support of my advisor, parents and friends. I am really fortunate to have Dr. Chunlei Wang as my advisor and deeply grateful for her guidance, vision and her academic, financial \& emotional support throughout the course of my $\mathrm{PhD}$ research. I appreciate her patience and understanding of my personal struggles. She believed in me and motivated me at a time when I was not so sure of myself. I sincerely thank her for reviewing my research works and for the suggestions to improve the quality of my research.

I am grateful to all the members of my dissertation committee, Dr. Surendra K.Saxena, Dr. W. Kinzy Jones, Dr. Norman D.H. Munroe and Dr. Wenzhi Li for their willingness to serve on my dissertation committee, for their academic support, valuable inputs and encouragement. I thank Dr. Giri Narasimhan, Dr.Cesar Levy and Dr. Arvind Agarwal for their generous support and encouragement during my studies.

I sincerely thank my past and present research group members: Dr. Yan Yu, Dr. Xifei Li, Dr. Wei Chen, Yamini Parikh, Kevin Bechtold, Varun Penmatsa, Chunhui Chen, Majid Beidaghi, Yin Song, Tae Kwon Kim, Yong Hao, and Richa Agarwal, for making my time at FIU memorable. I still vividly remember the days I spent learning 
about lithium batteries from Dr. Yan Yu and later from Dr. Xifei Li. They set a very good example of how a researcher ought to be. I am grateful for all the valuable technical lessons I learned from them and their help in reviewing my papers.

My gratitude is extended to Mr. Neal Ricks, Dr. Yanqing Liu, and Mr. Tom Beasley for their support to carry out my experiments. I had an opportunity to learn a lot from them about different characterization techniques and they were always ready to help going beyond their limits.

I acknowledge the University Graduate School at FIU for supporting me through Dissertation Evidence Acquisition (DEA) award.

I'd like to thank all my friends especially Chandan Pulletikurthi, for enduring me for $4+$ years. She listened to me \& supported me through all the tough times. I thank Dori Glaser for all the support, encouragement and for believing in me. I see myself as a confident and intelligent person through her eyes. I am truly indebted to both of you for all the happy memories.

I am forever grateful to my parents, sister, and brother-in-law for their unwavering support and love. I am proud of them and love them very much. They are so patient with my long absence from home. I thank them for supporting me to pursue my dream against all the odds. I also would like to thank my nephew Manoj for regarding in such high esteem. I hope that one day I can support him the way my parents supported me.

It would not have been possible to write this dissertation without all the support from the people I mentioned here. For any errors or inadequacies remaining in this work, the responsibility is entirely mine. 


\title{
ABSTRACT OF THE DISSERTATION \\ TIN OXIDE BASED COMPOSITES DERIVED USING ELECTROSTATIC SPRAY \\ DEPOSITION TECHNIQUE AS ANODES FOR LI-ION BATTERIES
}

\author{
by
}

\author{
Abirami Dhanabalan \\ Florida International University, 2012 \\ Miami, Florida \\ Professor Chunlei Wang, Major Professor
}

Recent advances in the electric \& hybrid electric vehicles and rapid developments in the electronic devices have increased the demand for high power and high energy density lithium ion batteries. Graphite (theoretical specific capacity: $372 \mathrm{mAh} / \mathrm{g}$ ) used in commercial anodes cannot meet these demands. Amorphous $\mathrm{SnO}_{2}$ anodes (theoretical specific capacity: $781 \mathrm{mAh} / \mathrm{g}$ ) have been proposed as alternative anode materials. But these materials have poor conductivity, undergo a large volume change during charging and discharging, large irreversible capacity loss leading to poor cycle performances.

To solve the issues related to $\mathrm{SnO}_{2}$ anodes, we propose to synthesize porous $\mathrm{SnO}_{2}$ composites using electrostatic spray deposition technique. First, porous $\mathrm{SnO}_{2} / \mathrm{CNT}$ composites were fabricated and the effects of the deposition temperature $(200,250,300$ $\left.{ }^{\circ} \mathrm{C}\right) \&$ CNT content $(10,20,30,40 \mathrm{wt} \%)$ on the electrochemical performance of the anodes were studied. Compared to pure $\mathrm{SnO}_{2}$ and pure CNT, the composite materials as anodes showed better discharge capacity and cyclability. $30 \mathrm{wt} \% \mathrm{CNT}$ content and 250 ${ }^{\circ} \mathrm{C}$ deposition temperature were found to be the optimal conditions with regard to energy capacity whereas the sample with $20 \% \mathrm{CNT}$ deposited at $250{ }^{\circ} \mathrm{C}$ exhibited good capacity 
retention. This can be ascribed to the porous nature of the anodes and the improvement in the conductivity by the addition of CNT. Electrochemical impedance spectroscopy studies were carried out to study in detail the change in the surface film resistance with cycling. By fitting EIS data to an equivalent circuit model, the values of the circuit components, which represent surface film resistance, were obtained. The higher the CNT content in the composite, lower the change in surface film resistance at certain voltage upon cycling. The surface resistance increased with the depth of discharge and decreased slightly at fully lithiated state.

Graphene was also added to improve the performance of pure $\mathrm{SnO}_{2}$ anodes. The composites heated at $280{ }^{\circ} \mathrm{C}$ showed better energy capacity and energy density. The specific capacities of as deposited and post heat-treated samples were 534 and 737 $\mathrm{mAh} / \mathrm{g}$ after 70 cycles. At the $70^{\text {th }}$ cycle, the energy density of the composites at $195{ }^{\circ} \mathrm{C}$ and $280{ }^{\circ} \mathrm{C}$ were 1240 and $1760 \mathrm{Wh} / \mathrm{kg}$, respectively, which are much higher than the commercially used graphite electrodes $(37.2-74.4 \mathrm{Wh} / \mathrm{kg})$. Both $\mathrm{SnO}_{2} / \mathrm{CNT}$ and $\mathrm{SnO}_{2} /$ grapheme based composites with improved energy densities and capacities than pure $\mathrm{SnO}_{2}$ can make a significant impact on the development of new batteries for electric vehicles and portable electronics applications. 


\section{TABLE OF CONTENTS}

CHAPTER

PAGE

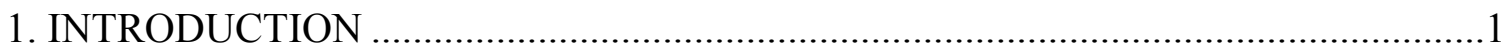

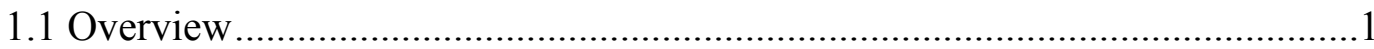

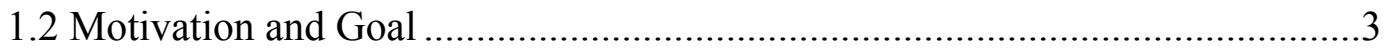

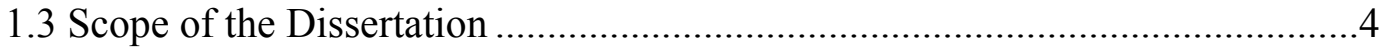

2. BACKGROUND AND LITERATURE REVIEW ................................................

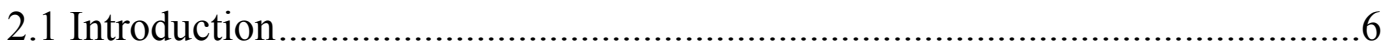

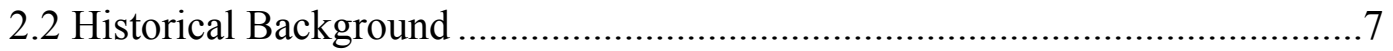

2.3 General Working Principle of Lithium-ion Batteries...................................

2.4 Electrode Materials for anodes .................................................................... 10

2.4.1 Intercalation/De-intercalation Anodes: Carbon based Anodes .........11

2.4.1.1 CNT anodes ............................................................... 13

2.4.1.2 Graphene anodes..................................................... 16

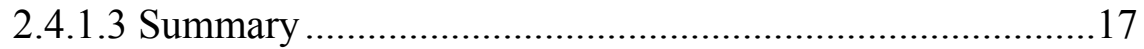

2.4.2 Alloying/ dealloying anode: $\mathrm{SnO}_{2}$ anodes ..................................18

2.5 Experimental technique-Electrostatic Spray Deposition ...............................23

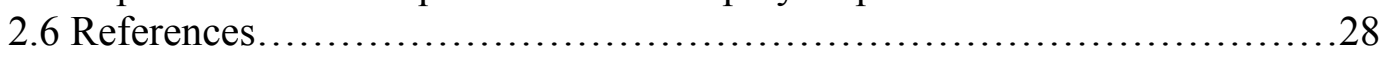

3. POROUS TIN OXIDE/CNT COMPOSITE ANODES: INFLUENCE OF

COMPOSITION AND DEPOSITION TEMPERATURE

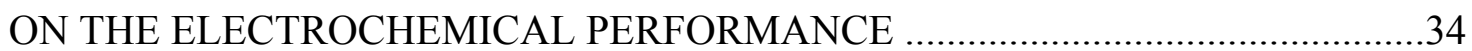

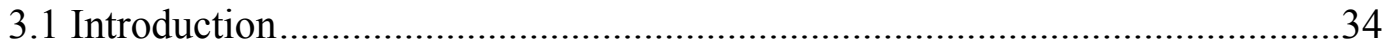

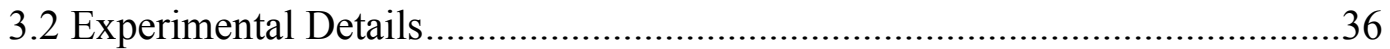

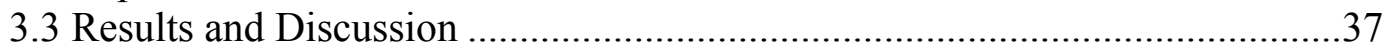

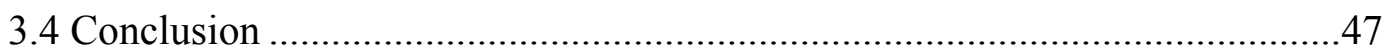

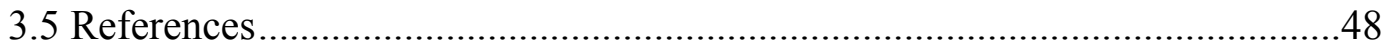

4. INVESTIGATION OF ELECTROCHEMICAL IMPEDANCE SPECTROSCOPY OF TIN OXIDE/CARBON NANOTUBE COMPOSITE ANODES FOR

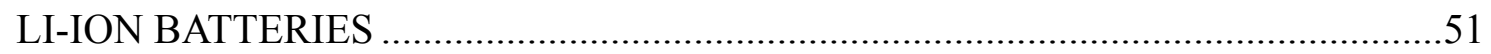

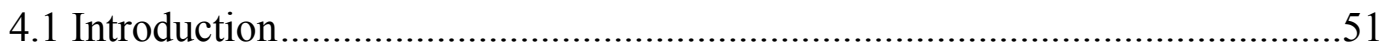

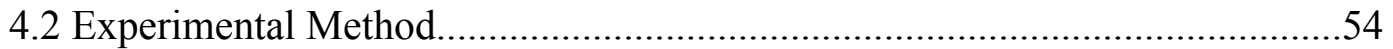

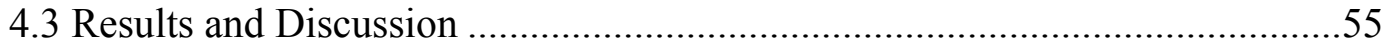

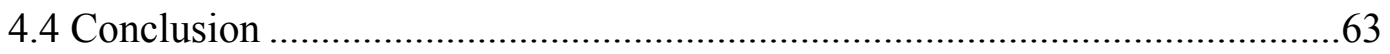

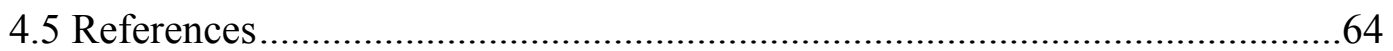

\section{FABRICATION AND CHARACTERIZATION OF TIN OXIDE/GRAPHENE}

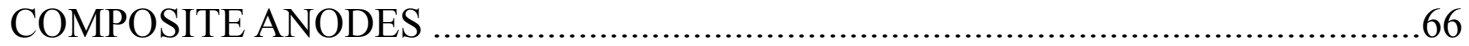

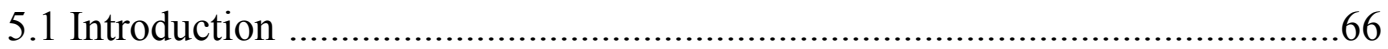

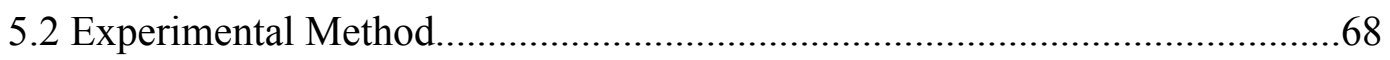

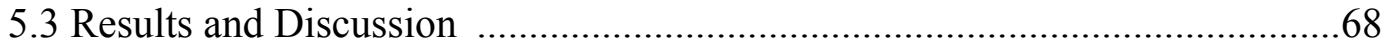

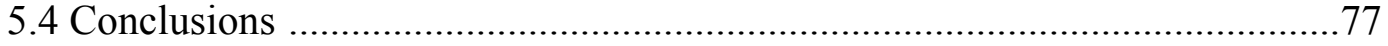


6. FABRICATION OF TIN-CARBON COMPOSITE ANODE MATERIAL BY ELECTROSPINNING AND ELECTROSTATIC SPRAY DEPOSITION FOR LITHIUM RECHARGEABLE BATTERY

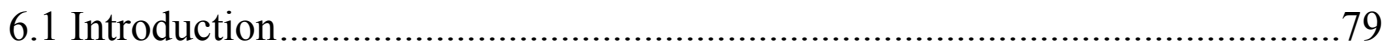

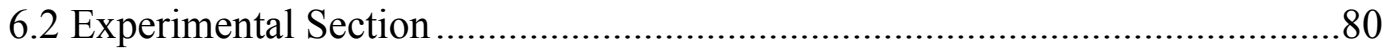

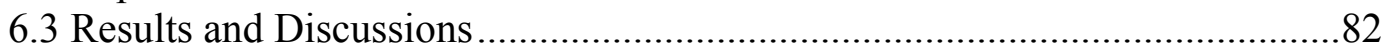

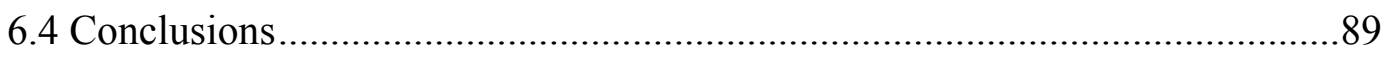

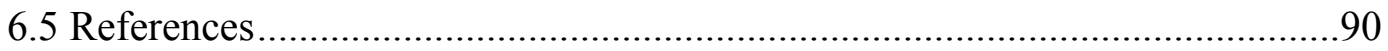

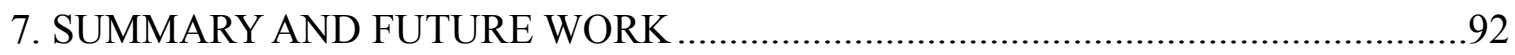

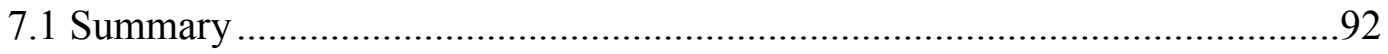

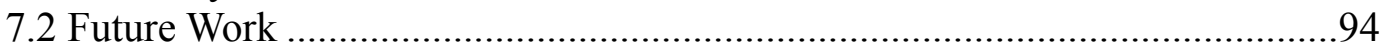

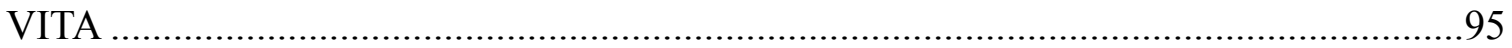




\section{LIST OF FIGURES}

\section{FIGURE}

PAGE

Figure 1.1 Flow chart of the research plan......................................... 5

Figure 2.1 Ragone plot of specific power versus specific energy for various batteries.....7

Figure 2.2 Representation of charge storage mechanisms in a lithium-ion battery........9

Figure 2.3 Schematic of the ESD experimental set-up showing the processes involved in ESD: (i) spray formation; (ii) droplet transport, evaporation, disruption; (iii) preferential landing; (iv) discharge, droplet spreading; (v) film formation by decomposition and drying of the precursor salt

Figure 3.1 (a) X-ray Diffraction pattern, (b) Raman Spectroscopy of as-deposited $\mathrm{SnO}_{2} / 10 \mathrm{CNT}$ on Ni substrate at $200{ }^{\circ} \mathrm{C}$.

Figure 3.2 SEM images of the as-deposited $\mathrm{SnO}_{2} / 20 \mathrm{CNT}$ samples at (a) $200{ }^{\circ} \mathrm{C}$, (b) 250 ${ }^{\circ} \mathrm{C}$, (c) $300{ }^{\circ} \mathrm{C}$, (d) $\mathrm{SnO}_{2} / 10 \mathrm{CNT}$ samples deposited at $250{ }^{\circ} \mathrm{C}$, (e) $\mathrm{SnO}_{2} / 30 \mathrm{CNT}$ samples deposited at $250{ }^{\circ} \mathrm{C}$, (f) $\mathrm{SnO}_{2} / 40 \mathrm{CNT}$ samples deposited at $250{ }^{\circ} \mathrm{C}$, (g) Pure CNT deposited at $250{ }^{\circ} \mathrm{C}$, and (h) pure $\mathrm{SnO}_{2}$ deposited at $250{ }^{\circ} \mathrm{C}$

Figure 3.3 (a) Typical TEM image, and (b) elemental mapping of $\mathrm{SnO}_{2} / 30$ CNT sample deposited at $250^{\circ} \mathrm{C}$. (c) HRTEM of CNT with arrows indicating open ends.

Figure 3.4 First and second cycle charge-discharge profiles of (a) pure CNT at $250{ }^{\circ} \mathrm{C}$, (b) pure $\mathrm{SnO}_{2}$ at $250{ }^{\circ} \mathrm{C}$, and (c) $\mathrm{SnO}_{2} / 30 \mathrm{CNT}$ at $250{ }^{\circ} \mathrm{C}$. D1, D2 are the first and second discharge cycles, respectively. C1, C2 are the first and second charge cycles, respectively

Figure 3.5 Variations in the discharge capacity versus cycle number for (a) different deposition temperatures of $\mathrm{SnO}_{2} / 30 \mathrm{CNT}$ composites, (b) different compositions of CNT in $\mathrm{SnO}_{2} / \mathrm{CNT}$ composites deposited at $250{ }^{\circ} \mathrm{C}$. The samples were tested at a current density of $0.1 \mathrm{~mA} / \mathrm{cm}^{2}$ between $0.02-1.5 \mathrm{~V}$.

Figure 3.6 Comparison of theoretical and practical discharge capacity for different weight percent of CNT in the composite anodes deposited at 200, 250 and $300{ }^{\circ} \mathrm{C}$ after 25 cycles.

Figure 4.1 (a) Charge-discharge profile of a) Pure tin oxide, b) pure CNT and c) tin oxide $/ 30 \%$ CNT.. 
Figure 4.2 Cycle performance of pure tin oxide, pure CNT and tin oxide/30\% CNT......57

Figure 4.3 SEM images of Tin oxide $/ 30 \% \mathrm{CNT}$ a) before cycling and, b) after cycling for 50 cycles .58

Figure 4.4 EIS data and simulation results for tin oxide/30\% CNT at different voltages during a) $1^{\text {st }}$ cycle, b) $2^{\text {nd }}$ cycle and c) $20^{\text {th }}$ cycle. Lines indicate the simulation data and dots indicate the EIS experimental data. Inset: Equivalent circuit used to fit impedance data. Rs, R1 are solution resistance and surface resistance, respectively. R2 is the resistance due to phase transformation. Q1 and Q2 are the capacitance of surface film and phase formation. $\mathrm{W}$ is Warburg impedance due to diffusion

Figure 4.5 a) Change in R1 with \%CNT in the composite and cycling. b) Change in Q1 with $\% \mathrm{CNT}$ in the composite and cycling....

Figure 5.1 SEM images of a) pure tin oxide, b) pure graphene, and c) Tin oxide/graphene deposited at $195^{\circ} \mathrm{C}$ by ESD method.

Figure 5.2 X-ray diffraction patterns of a) pure tin oxide, and b) tin oxide/graphene.......70

Figure 5.3 Charge-discharge characteristics of tin oxide/graphene composite at a) $195^{\circ} \mathrm{C}$, b) $280{ }^{\circ} \mathrm{C}$

Figure 5.4 Comparison of a) cycle performance, and b) energy density of tin oxide /graphene composites and tin oxide

Figure 5.4 a) Rate capability of tin oxide /graphene composites, b) Normalized capacity versus rate of discharge of tin oxide /graphene composites.

Figure 6.1 Schematic of co-axial electrospinning set-up

Figure 6.2 XRD patterns of Sn-C porous film and Sn@C encapsulated in C hollow fiber prepared by ESD and electro spinning, respectively..

Figure 6.3 a) SEM images of as prepared TBT/PAN nanofibers b) SEM image showing porous $\mathrm{SnO}_{2} / \mathrm{PVP}$ composite.

Figure 6.4 TEM of pyrolysed carbon coated tin inside hollow carbon fibers a) Bright field zero loss filtered image $b$ ) high magnification of an isolated carbon coated tin particle inside hollow carbon fiber.

Figure 6.5 Charge-Discharge cycle of a) Porous Sn-C film at $0.2 \mathrm{~mA} / \mathrm{cm}^{2}$ in the voltage range of $0.02-3.0 \mathrm{~V}$, and b) $\mathrm{Sn} @ \mathrm{C}$ encapsulated in carbon hollow fibers anodes at $\mathrm{C} / 10$ rate in the voltage range of $0.01-3.0 \mathrm{~V}$.. 
Figure 6.6 Charge-Discharge cycles of Sn@C encapsulated in hollow carbon fiber and commercial tin nanopowder at $0.5 \mathrm{C}$ in the voltage range of $3.0-0.01 \mathrm{~V}$. Sn-C porous film was tested between $0.02-3.0 \mathrm{~V}$ at $0.2 \mathrm{~mA} / \mathrm{cm}^{2}$. 


\section{INTRODUCTION}

\subsection{Overview}

Lithium ion batteries (LIBs) are one of the secondary batteries in which Li-ion moves between the positive and negative electrodes during charge/discharge process, so-called "rocking-chair batteries". Commercialized LIBs use graphite negative electrodes with theoretical capacity of $372 \mathrm{mAhg}^{-1}$ and $\mathrm{LiCoO}_{2}$ positive electrodes with $140 \mathrm{mAhg}^{-1}$. The demand for LIBs has increased over the last decade due to its high energy density, relatively lightweight, slow self-discharge rates, no memory loss and less environmental concern. Some of the current and projected applications of LIBs include portable electronic devices such as mobile phones, laptop, camera, medical devices, sensors, memory devices, electric vehicles, telecommunications, satellites, etc. Nevertheless, it is necessary to address the issues of the complexity of storing high capacities and delivering high power densities for longer period of time, for use in complex portable devices as well as larger applications. According to their electrochemical mechanism with lithium during cycles, anode materials can be divided into three groups: intercalation/de-intercalation (e.g., Graphite), alloying/dealloying (e.g., $\mathrm{SnO}_{2}, \mathrm{Si}$ ), and conversion reaction (e.g., $\mathrm{Fe}_{2} \mathrm{O}_{3}$ ). For example, theoretical capacity of $\mathrm{Sn}$ is $993 \mathrm{mAhg}^{-1}, \mathrm{SnO}_{2}$ is $782 \mathrm{mAhg}^{-1}, \mathrm{Fe}_{2} \mathrm{O}_{3}$ is $1005 \mathrm{mAhg}^{-1}, \mathrm{SnSb}$ is 611 $\mathrm{mAhg}^{-1}$, etc., which is several times higher than graphite. Due to the low capacity of graphite, the last two group anodes with high specific capacities have been intensively investigated. But these materials undergo a large volume change during charging and discharging leading to poor cycle performances and hence, severely hinder their application in lithium ion batteries. 
$\mathrm{SnO}_{2}$ as a high capacity anode material has been extensively investigated since $1997 . \mathrm{SnO}_{2}$ reacts irreversibly with $\mathrm{Li}$ to form $\mathrm{Sn}$ and $\mathrm{Li}_{2} \mathrm{O}$ leading to large irreversible capacity loss. In the subsequent reaction, $\mathrm{Li}$ reacts with $\mathrm{Sn}$ to form $\mathrm{Li}_{4.4} \mathrm{Sn}$ (maximum $\mathrm{Li}$ uptake), such large atomic uptakes $(440 \%$ rise in the number of atoms) can induce large volume change ( $300 \%$ ). The repeated huge expansion/contraction causes great stress in Sn lattice, which results in the cracking, crumbling and pulverization of Sn particles and the consequent loss of electrical contact between anode and current collector. Also, these Sn nanoparticles aggregate during cycling causing poor capacity retention. $\mathrm{SnO}_{2}$ is an n-type semiconductor and has poorer conductivity than the commercial graphite anodes. Also, the charge transfer kinetics has to be improved to obtain high rate capability. Many significant research efforts have been devoted to improve the cycle performance of $\mathrm{SnO}_{2}$ anodes. One of the methods is to use different morphologies to buffer the volume change. Electrostatic Spray Deposition (ESD) technique provides a simple and versatile method for generating from rich variety morphology thin-films of multi-component metal oxides. In this technique, an electrostatic force is used to atomize the droplets forming a cone-jet spray, which deposits on the substrate. It has many advantages, such as easy film-morphology control, high deposition rate, and the capability for deposition in ambient atmosphere. Samples can be tested without any further addition of binder. Moreover, the porous structure can buffer the stress, allowing easy percolation of electrolytes, thereby improving the Li-ion diffusion in addition to increasing the surface area. The other method used to improve the performance of $\mathrm{SnO}_{2}$ involves the use of a composite or alloy to buffer the stress. Improvements in cyclability and conductivity have been achieved using tin based composite anodes where one of the constituent materials mainly acts as a buffer while the other reacts with lithium. It is 
possible to overcome several inter-related problems associated with $\mathrm{SnO}_{2}$ anodes that can be related with poor conductivity, large volume change, large irreversible capacity loss, aggregation of tin particles, poor capacity retention and cycle life by fabricating novel $\mathrm{SnO}_{2}$ composite anodes with improved morphology.

\subsection{Motivation and Goal}

The main motivation for this work is to develop and characterize $\mathrm{SnO}_{2}$ based composite material as an anode for Li-ion battery with high capacity and cyclability. To solve the issues related with $\mathrm{SnO}_{2}$ anodes, it is proposed to synthesize porous $\mathrm{SnO}_{2} / \mathrm{CNT}$ composites and $\mathrm{SnO}_{2} /$ Graphene composites. In porous $\mathrm{SnO}_{2} / \mathrm{CNTs}$, CNT in the composite can improve the conductivity, act as a binder and also improve the capacity. CNT can also buffer the stress and hence increase the cyclability. Porous structure has been reported to provide the void space needed to buffer the volume change. Improving the charge transfer kinetics for high rate capability using porous structure and CNT that allows for shorter Liion and electron diffusion paths. Electrochemical Spray Deposition (ESD) technique can be used to synthesis different morphologies in a simple and efficient way. Moreover, the thinfilms of $\mathrm{SnO}_{2}$ with CNT prepared using ESD can be used as an electrode material without any further additives.

It is necessary to understand the mechanisms that affect the electrochemical performance such as surface film formation, internal resistance of the electrode at different voltages and phase transitions during alloying and de-alloying, in order to efficiently design and optimize the anode. This can be achieved using electrochemical impedance spectroscopy. The impedance of $\mathrm{SnO}_{2} / \mathrm{CNT}$ composites were studied and evaluated. 
In another approach, this dissertation aims to develop $\mathrm{SnO}_{2} /$ graphene composites using ESD method. Graphene, with its outstanding properties such as chemical stability, high electrical conductivity, large surface area and high theoretical capacity, can improve the conductivity and also contribute to the capacity of the anodes. Since graphene is a nanomaterial, it can also improve the kinetics of the lithium ion diffusion by providing shorter pathways.

In order to compare our tin oxide based composites with tin composites $\mathrm{Sn} / \mathrm{C}$ composites were prepared. Though tin has a higher theoretical capacity and good conductivity than tin oxide, it is expected that tin oxide composites can perform as well as the tin composites due to the synergetic effect of the constituents in the composites. Figure 1.1 presents the flowchart of the research plan.

\subsection{Organization of the Dissertation}

Chapter 2 provides the background of the dissertation and discusses the properties and applications of lithium ion battery anodes. The types of anodes, relevant to this dissertation, both from a materials point of view and an architectural view are discussed. Chapter 3 details the synthesis and characterization of $\mathrm{SnO}_{2} / \mathrm{CNT}$ composites. The studies on influence of deposition temperature and CNT content on improving the performance of lithium ion battery anodes are presented. Chapter 4 explains the electrochemical impedance spectroscopy (EIS) of $\mathrm{SnO}_{2} / \mathrm{CNT}$ composites. EIS investigations were carried out to study

the surface film resistance of $\mathrm{SnO}_{2} / \mathrm{CNT}$ composite anodes. Equivalent circuits were proposed and the values of the components were obtained. Chapter 5 explains fabrication and evaluation of $\mathrm{SnO}_{2} /$ graphene electrodes. The electrochemical performance of the composite anodes subjected to different heat treatment during synthesis is discussed. 
Chapter 6 details the related work on $\mathrm{Sn} / \mathrm{C}$ composites. $\mathrm{Sn} / \mathrm{C}$ composite with porous morphology and Sn encapsulated in a carbon nanofiber were synthesized. The evaluation of these composites indicated that both composites show similar performance results. The results are comparable with the tin oxide anodes discussed in the previous chapters. Chapter 7 provides a summary of the dissertation and proposes future works.

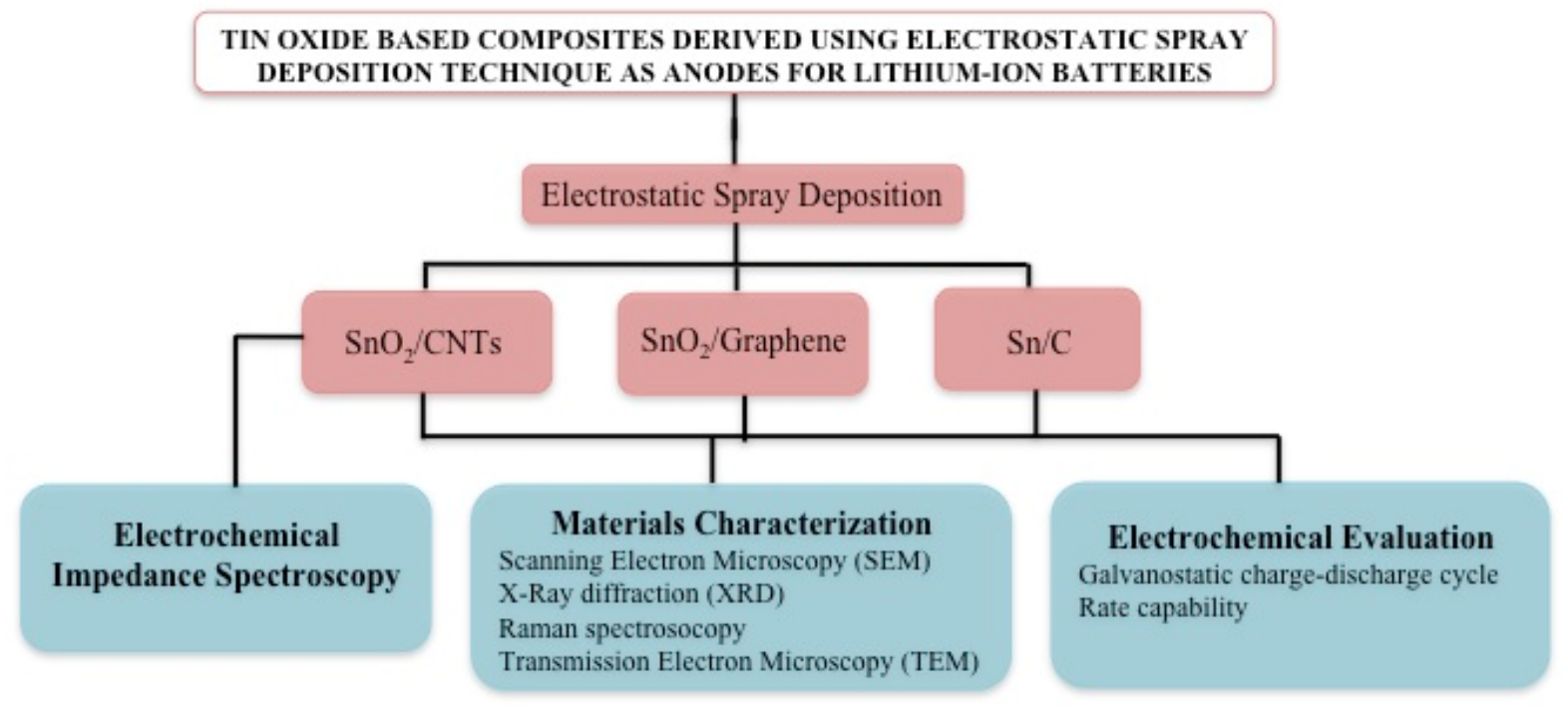

Figure 1.1 Flowchart of the research plan. 


\section{BACKGROUND AND LITERATURE REVIEW}

\subsection{Introduction}

The design of rechargeable battery systems has long been the most challenging issue in energy applications for high energy density and high power density requirements. In comparison to lead acid batteries, Ni-Cd batteries and Ni-MH batteries, lithium ion batteries (LIBs) show many advantages such as high working voltage (3.6 V of the nominal voltage),

high energy density (125 $\mathrm{Whkg}^{-1}$ ), long cycling life (more than 1000 cycles), ecofriendliness and no memory effect [1-4]. Therefore, LIBs have been widely used as a convenient power source for various electronic devices, such as mobile phones, laptops, MP3 and MP4 players, digital cameras, etc [1]. In particular, LIBs are also considered ones of the most promising energy storage technologies for application of low fuel consumption hybrid electrical vehicles (HEVs) and zero fuel consumption pure electrical vehicles (EVs). The development and commercialization of HEVs and EVs have been the major driving force for the development of LIBs [5].

Figure 2.1 illustrates the "Ragone plot" in terms of specific power and specific energy of different battery chemistries compared to other energy storage devices [6]. In terms of both specific power and specific energy the lithium-ion batteries exceed the other battery chemistries. This particular ragone plot includes the discharge time and energy goals for electric vehicles. The diagonal lines in the plot indicate the time to discharge. The asterisk denotes the maximum desired energy goals of various electric vehicles. 


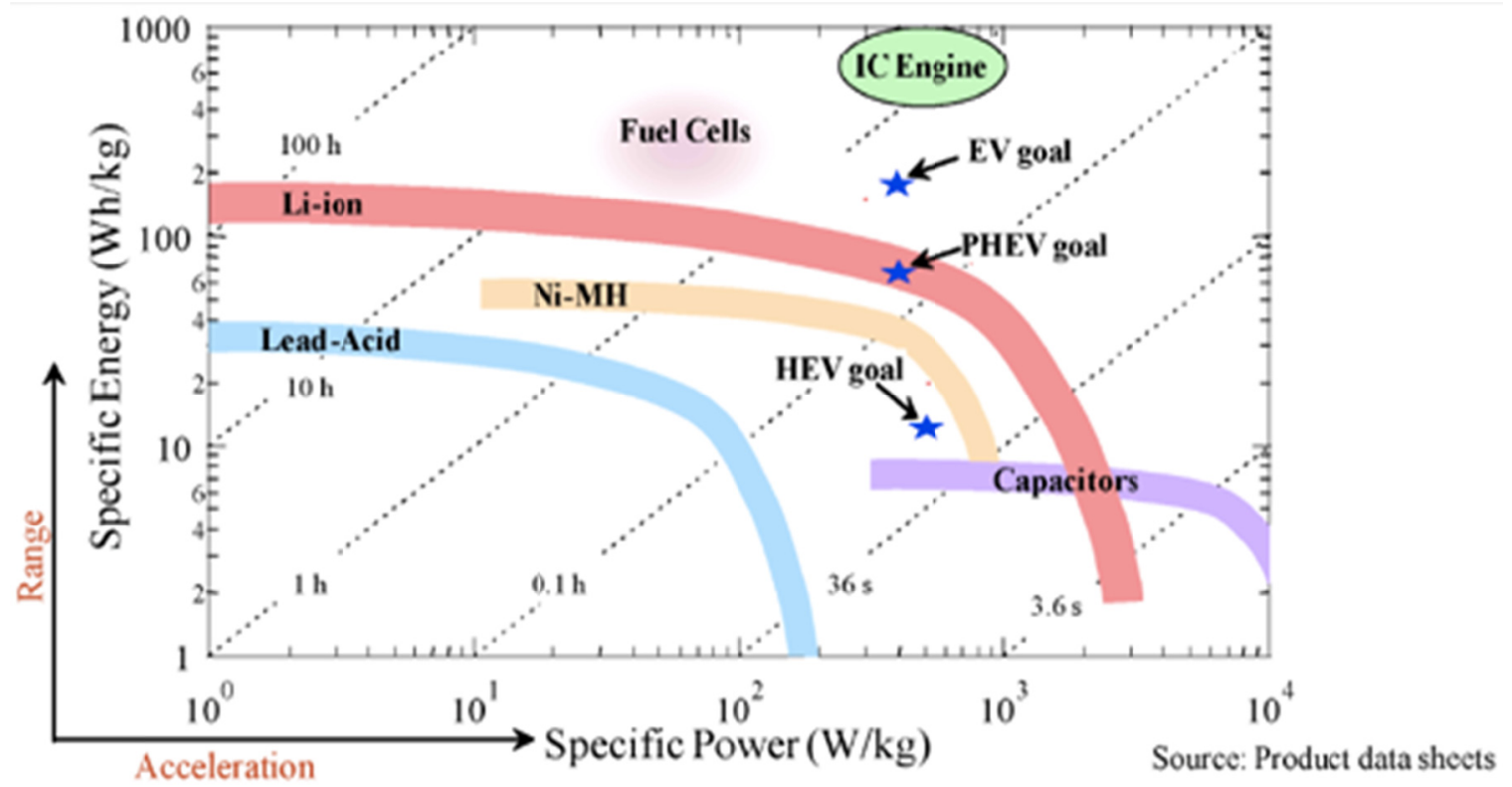

Figure 2.1 Ragone plot of specific power versus specific energy for various batteries. Adapted from Ref. [6].

\subsection{Historical Background}

M.S. Whittingham et al. published the first report on lithium batteries in 1976. This first proposed lithium batteries reported had a titanium (II) sulfide cathode and lithium metal anode [7]. Lithium is the lightest metal that delivers the high theoretical specific capacity of $3860 \mathrm{mAh} \mathrm{g}^{-1}$. It also has the lowest electrochemical reduction potential of $-3.045 \mathrm{~V}$ [8]. However, the formation of lithium dendrite on the surface of a lithium metal electrode during charge/discharge cycles results in safety issues and poor cycle life [8]. John Goodenough et al. proposed with lithium cobalt oxide as the anode material and lithium as cathode [9]. This finding paved the way for using lithium cobalt oxide as cathode material instead of lithium, which made lithium ion batteries possible. In 1977, Samar Basu demonstrated the electrochemical intercalation of lithium in graphite. Based on these findings, Bell laboratories proposed a graphite-based anode [10]. Rachid Yazami et al. in 
1980 demonstrated using solid electrolyte that lithium undergoes reversible intercalation with graphite, which would allow these batteries to be rechargeable [11]. In 1985, Akira Yoshino developed a LIB with carbon as the electrode and lithium cobalt oxide as cathode. In 1990, Sony Company commercialized non-aqueous LIBs, introducing a "rocking chair" concept, which utilizes the intercalation phenomenon where $\mathrm{Li}^{+}$insertion/deinsertion into active materials occurred [12]. In 1996, Goodenough et al. proposed lithium iron phosphate and other phospo-olivines as the cathode material [13]. Since then, LIBs have evolved incorporating new material chemistry, nanotechnology, polymer electrolytes with improved stability and higher energy density. Currently, there are more than 25 major competitors in the market, which focus on LIBs for EVs, HEVs and portable electronics.

\subsection{General working principle of a lithium-ion battery}

A typical "rocking-chair" LIB consists of a cathode and an anode, a porous polypropylene membrane separator acting as electrical insulation and an electrolyte of $\mathrm{LiPF}_{6}$ dissolved in a mixture of organic solvent devoid of moisture [4]. In a commercial LIB, $\mathrm{LiCoO}_{2}$ and graphite are used as cathode and anode materials, respectively. As it is depicted in Figure 1, the electrochemical potential difference between the anode and cathode drives $\mathrm{Li}^{+}$to move from $\mathrm{LiCoO}_{2}$ and simultaneously intercalate into graphite anode during charge process, On the other hand, $\mathrm{Li}^{+}$reverse the direction of movement while discharging, leaving the anode, and intercalate into the crystal structure of cathode $[5,12]$. The whole electrochemical insertion/extraction process is a solid-state redox reaction involving electrochemical charge-transfer, coupled with $\mathrm{Li}^{+}$insertion/extraction into/from the structure of cathode or anode. During the whole charge/discharge process, only $\mathrm{Li}^{+}$repeatedly moves between the cathode and the anode. 


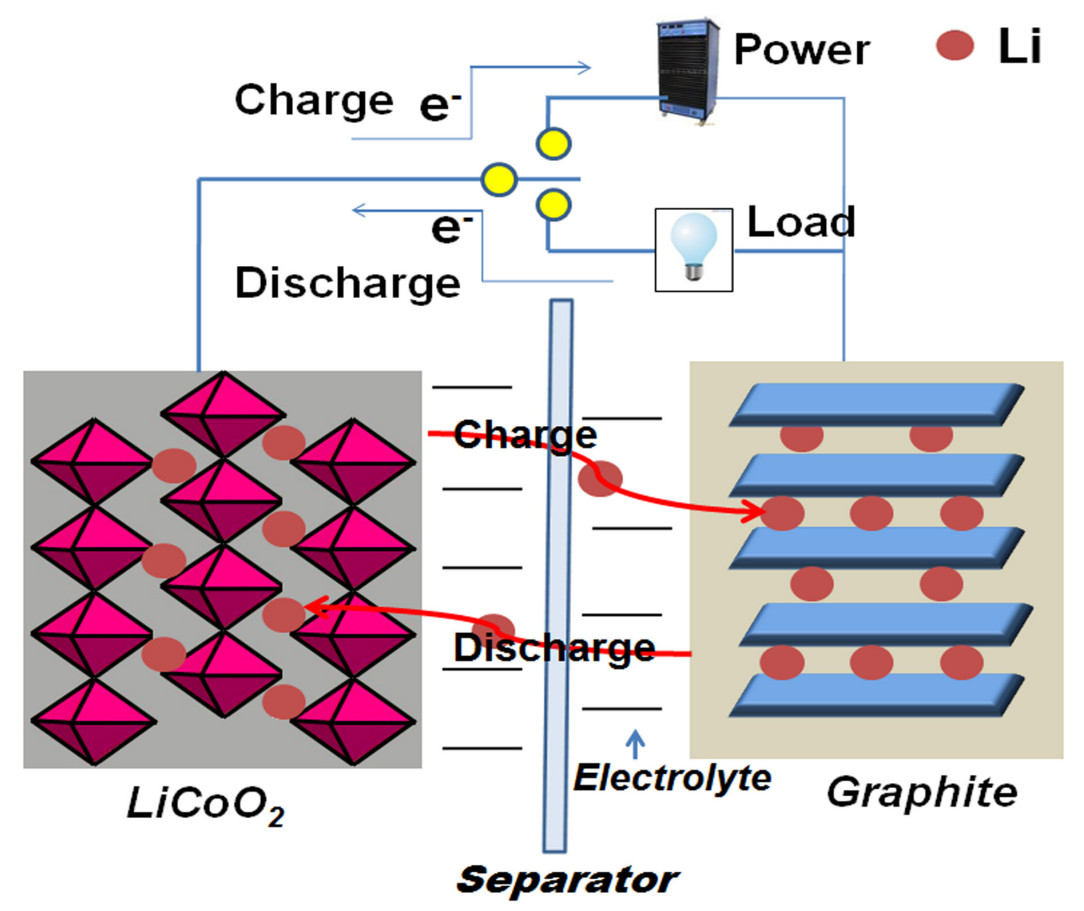

Figure 2.2 Representation of charge storage mechanisms in a lithium-ion battery. Adapted from Ref. [24].

The design of high performance electrode materials is critical for creating high performance lithium ion batteries. For example, the total capacity of lithium ion batteries is expressed as follows [14]:

$$
\text { TotalCapacity }=\frac{1}{\frac{1}{C_{A}}+\frac{1}{C_{C}}+\frac{1}{Q_{M}}}
$$

where $C_{\mathrm{A}}$ and $C_{\mathrm{C}}$ are the theoretical specific capacities of the cathode and anode materials, respectively, and $1 / Q_{\mathrm{M}}$ is the specific mass of other cell components (electrolyte, separator, current collectors, case, etc.) in $\mathrm{g} \mathrm{mAh}^{-1}$. Metallic lithium as anode material has high specific capacity and energy density. Lithium can be electroplated onto the anode during the 
charge process, leading to the growth of dendrites due to the non-uniform current density on the surface of lithium anode. These growing dendrites contact the cathode electrode resulting in internal short, which causes the combustion of the lithium. This poses severe safety problems [8]. Commercial graphite anode has a limited theoretical capacity of 372 $\mathrm{mAh} \mathrm{g}^{-1}$ to form $\mathrm{LiC}_{6}$ intercalation compound. Provided that the specific capacities of anode materials are increased up to $600 \mathrm{mAh} \mathrm{g}^{-1}$, the total battery capacity can be distinctly enhanced [13]. Because of this, attention has recently been turned toward obtaining anode materials that provide higher discharge capacity for carbon replacement, such as Sn $[14,15]$, $\mathrm{SnO}_{2}[16,17]$, transition metal oxides (such as: $\mathrm{Fe}_{2} \mathrm{O}_{3}[18,19]$, $\mathrm{CoO}[20,21], \mathrm{CuO}[22,23]$ ), etc.

\subsection{Electrode Materials for Anodes}

Graphite, used widely in commercialized LIBs, has limited theoretical capacity of $372 \mathrm{mAhg}^{-1}$ to form $\mathrm{LiC}_{6}$ intercalation compound. In addition to the graphite and various natural and synthesized carbon-based anode materials, nano carbon materials like carbon nanotubes and graphene have far greater potential to make contributions to increase the specific capacities of anodes for LIBs. Furthermore, there are many other novel anodes, such as high-capacity Si-based materials and Sn-based materials, some of which have been commercialized at small scale, although challenges still exist to improve their cycle life and other performance aspects. Anode materials, in general, are categorized into three groups according to their electrochemical mechanism with $\mathrm{Li}^{+}$during cycling:

1) Intercalation/de-intercalation anodes. Example: Carbon based anodes such as graphite, CNTs, hard carbon, etc [25]. In this type of anodes, lithium is stored between the graphitic layers. The reaction mechanism is as shown below: 


$$
\mathrm{Li}^{+}+\mathrm{e}^{-}+6 \mathrm{C} \stackrel{\mathrm{d}}{\rightleftarrows} \mathrm{LiC}_{6}
$$

2) Alloying/de-alloying anodes. Example: $\mathrm{M}=\mathrm{Si}$, $\mathrm{Sn}$, etc [26]. During the $\mathrm{Li}^{+}$storage process, different amounts of $\mathrm{Li}^{+}$could insert/de-insert into $\mathrm{M}$ and form various $\mathrm{Li}_{\mathrm{x}} \mathrm{M}$ $(\mathrm{x} \leq 4.4)$ alloys.

$$
\mathrm{M}+\mathrm{xLi}^{+}+\mathrm{xe}^{-\stackrel{\mathrm{d}}{\rightleftarrows}} \mathrm{Li}_{\mathrm{x}} \mathrm{M}
$$

3) Conversion reaction anodes. Example: Transition-metal oxides $\left(\mathrm{M}_{\mathrm{x}} \mathrm{O}_{\mathrm{y}}\right)$, such as $\mathrm{Fe}_{2} \mathrm{O}_{3}, \mathrm{CuO}, \mathrm{NiO}, \mathrm{Co}_{3} \mathrm{O}_{4}$, etc [27]. The reaction mechanism is different from classical lithium intercalation/de-intercalation in graphite or alloying/dealloying reactions of metallic or semi metallic anodes with lithium.

$$
2 \mathrm{M}_{\mathrm{x}} \mathrm{O}_{\mathrm{y}}+2 \mathrm{yLi}^{+}+2 \mathrm{ye}^{-\stackrel{\mathrm{d}}{\rightleftarrows}} 2 \mathrm{xM}+\mathrm{yLi}_{2} \mathrm{O} \quad(\mathrm{M}=\mathrm{Co}, \mathrm{Ni}, \mathrm{Fe}, \text { etc. })
$$

In the following section, the anode materials only relevant to this dissertation are discussed.

\subsubsection{Intercalation/De-intercalation Anodes: Carbon Based Anodes}

Carbon has attracted a lot of attention since the introduction of the rechargeable lithium battery by Sony [28]. The use of carbon instead of metallic lithium has decreased the energy density but improved the safety and cycle life of the battery. Carbon is abundant in nature, easy to synthesize and is inert, which makes it the favorable candidate. Carbon is characterized by the strong covalent bonds with low ionicity giving rise to large bandwidths. This, together with the ability to weakly bind lithium, gives rise to large reversible capacities at a high chemical potential of lithium [29]. The electrochemical potential of carbon intercalating with lithium is near to that of lithium. Carbon has several allotropes such as graphite, diamond and nanotubes with different structural modifications. These 
allotropes have different physical and electrochemical properties. The reactions of these materials with lithium depend on the structure, grain-size, morphology and crystallinity of the materials [30].

Graphite with a theoretical capacity of $372 \mathrm{mAhg}^{-1}$ is currently used as the commercial anode for LIBs. Among the allotropes of carbon, graphite is particularly interesting owing to its high electronic (in-plane) conductivity, attributed to the delocalized $\pi$-bonds [31]. The graphite is made of two-dimensional sheets of $\mathrm{sp}^{2}$ hybridized carbon atoms in hexagonal rings stacked usually in an $\mathrm{ABAB}$ pattern. The structure of graphite is marred by high density stacking faults and defects. The perfectly stacked regions are called crystallites, which are separate from the disordered carbon regions with no interplanar ordering. Lithium undergoes a "stage-wise" intercalation mechanism with graphite in which the lithium fully intercalates first into one interplanar layer before filling the neighboring layers [32]. The staging phenomenon is characterized by different potential steps in the discharge and charge curve [33]. The horizontal plateaus in the potential profile show the existence of two $\mathrm{Li}_{\mathrm{x}} \mathrm{C}_{6}$ phases in equilibrium and the vertical region represents single phase. If two phases are in equilibrium, then the chemical potential of lithium at that stage is equal. According to the equation $\mathrm{E}=\mu_{\mathrm{Li}} / \mathrm{F}$ where $\mu_{\mathrm{Li}}$ is the chemical potential of lithium and $\mathrm{F}$ is Faraday's constant, the electrode potential will be constant for a phase transition from one stage to another. The specific capacity of graphite is not sufficient for power high energy density applications such as EVs and HEVs. In order to improve the capacity of graphite anodes, several surface treatment methods [34] have been proposed and. Graphite is also mixed with nanoparticles of tin [35, 36, 37], tin oxide [37, 38], silicon [39] etc. Although the 
graphite nanocomposites showed promising results, the capacity is still lower compared to other types of anodes.

\subsubsection{CNT anodes}

Carbon nanotubes (CNT) are regarded as an excellent choice for LIB anode material due to their high conductivity, high strength, nanosize and graphitic layers for $\mathrm{Li}^{+}$ accommodation [34]. Both single walled and multiwalled CNT (MWCNT) have been exploited for this purpose. CNT are concentric cylinders of rolled graphitic sheets. $\mathrm{Li}^{+}$can intercalate into every second hexagon of the external surface of the rolled sheets [40]. Typically the reported specific capacities of CNT are higher than the theoretical value observed for $\mathrm{LiC}_{6}$. $\mathrm{CNT}$ as an active lithium-ion storage material can be assembled into freestanding electrodes (without any binder or current collector) or as a physical support for ultra-high capacity anode materials like silicon or germanium [41]. The measured reversible lithium-ion capacities for CNT-based anodes can exceed $1000 \mathrm{mAhg}^{-1}$ depending on experimental factors, which is a 3 times improvement over conventional graphite anodes. Some studies show that the lithium intake of up to $1400 \mathrm{mAhg}^{-1}$ for CNT in the $1^{\text {st }}$ cycle [42]. It is generally believed that the $\mathrm{CNT}$ react with $\mathrm{Li}^{+}$in the same way as graphite accompanied by surface storage mechanism and storage in defect sites [43]. In case of single walled CNT, it has been observed that there are no obvious intercalation or deintercalation plateaus in the voltage-profile indicating the absence of the staging mechanism found in traditional graphitic anodes [44]. However, reports have shown the presence of this mechanism in multiwalled CNT. There is no conclusive theory for the intercalation of Li into CNTs, though some speculate inter-tube spacings (not the inner core) in carbon nanotubes to provide the most accessible sites for Li storage [45]. The surface adsorption of 
these inter-tube spacings also plays an important role in the storage of lithium. The specific surface area and graphitization of the CNT affect its electrode performance. Graphitization, in particular, results in high irreversibility [46]. For example, slightly graphitized CNT show a capacity of $640 \mathrm{mAhg}^{-1}$ compared to $282 \mathrm{mAhg}^{-1}$ for fully graphitized CNT. Both forms exhibit voltage hysteresis of about $1 \mathrm{~V}$ due to a longer diffusion distance for deintercalating lithium. The large irreversible capacity, however, makes them unsuitable for commercial purposes. CNT are also used alongside other materials as composites. For example, CNT filled with metals such as $\mathrm{Sn}[47,48], \mathrm{Sn}_{2} \mathrm{Sb}[49,50], \mathrm{AgFeSn}$ [51], etc. showed highly reversible capacities. CNT composites with $\mathrm{Si}[52,53], \mathrm{SnO}_{2}$ [54], $\mathrm{V}_{2} \mathrm{O}_{5}$ [55], etc are also reported to perform well due to their synergistic effect. Free standing CNT, which act as both the active material and current collector without any binder, are reported to show a capacity of $300 \mathrm{mAhg}^{-1}$ which opens up the possibility for developing high temperature, lightweight and flexible batteries [56]. The incorporation of CNT as a conductive additive at a lower weight loading than conventional carbons, such as carbon black and graphite, presents a more effective strategy to establish an electrical percolation network. Lower weight loading of additive will allow an increase in the active material loading, which in turn allows an increase in the equivalent capacity. Because of these advantages, CNT have been used as an additive in both anode and cathode materials. A comparison of carbon black additive and multiwalled CNT additive in graphite anodes was carried out by X.L. Li et al. [57]. The comparison showed that the discharge capacity of graphite/CNT was $366 \mathrm{mAhg}^{-1}$ whereas it was $347 \mathrm{mAhg}^{-1}$ in the case of graphite/carbon black. The cycle stability in 50 cycles was improved from $94.5 \%$ in carbon black additives to $97.8 \%$ with the addition of CNT. Metallic CNT show ballistic transport that is the mean free path for electrons is on the 
order of microns unless scattered by defects. This property is useful to improving the rate capability performance [56]. Safety of the electrodes can be improved by the effective heat dissipation using CNT. CNT also improve the strength and flexibility of the electrode material and also prevent the particle separation in active material due to cycling [57]. Summary of the CNT composites found in literature is given below in table 1.1

Table 1.1 Summary of some of the CNT composites found in literature.

\begin{tabular}{|c|c|c|c|}
\hline Active Material & Current density & $\begin{array}{l}\text { Discharge capacity } \\
\qquad\left(\mathrm{mAhg}^{-1}\right)\end{array}$ & $\begin{array}{c}\text { Number of } \\
\text { cycles }\end{array}$ \\
\hline $\begin{array}{c}\mathrm{MWCNT} / \mathrm{CuO}(100-200 \mathrm{~nm}) \\
{[58]}\end{array}$ & $60 \mathrm{mAg}^{-1}$ & 627 & 50 \\
\hline $\begin{array}{c}\mathrm{Si} \text { (thin film)/CNT (6:1 mass } \\
\text { ratio) }[52]\end{array}$ & $360 \mathrm{mAg}^{-1}$ & 1711 & 50 \\
\hline $\mathrm{CNT} / \mathrm{Si}$ [53] & $100 \mathrm{mAg}^{-1}$ & 1000 & 100 \\
\hline $\begin{array}{c}\mathrm{CNTs} @ \mathrm{SnO}_{2}-\mathrm{Au}(10-15 \mathrm{~nm}) \\
\text { nanocables } \\
\mathrm{CNT} @ \mathrm{SnO}_{2} \text { nanocables [54] }\end{array}$ & $180 \mathrm{mAg}^{-1}$ & $\begin{array}{l}626 \\
464\end{array}$ & 40 \\
\hline CNT/Carbon layer [59] & $0.2 \mathrm{mAcm}^{-2}$ & 572 & 100 \\
\hline $\begin{array}{c}\mathrm{CNT} / 36 \mathrm{wt} \% \mathrm{Sb}(20 \mathrm{~nm}) \\
\mathrm{CNT} / 56 \mathrm{wt} \% \mathrm{SnSb}_{0.5}(100- \\
200 \mathrm{~nm} \text { in } \mathrm{CNT} \text { web; } 10-30 \mathrm{~nm} \text { on } \\
\text { the CNT walls) [47] }\end{array}$ & $50 \mathrm{mAg}^{-1}$ & 287 & 30 \\
\hline Graphite/CNT [57] & $0.1 \mathrm{C}$ & 366 & 50 \\
\hline
\end{tabular}




\begin{tabular}{|c|c|c|c|}
\hline $\begin{array}{c}\text { CNT-56 wt\% } \% \mathrm{Sn}_{2} \mathrm{Sb}(100-200 \mathrm{~nm} \\
\text { in CNT web; 10-30nm on the } \\
\text { CNT walls) [50] }\end{array}$ & $40 \mathrm{mAg}^{-1}$ & 372 & 80 \\
\hline $\mathrm{Ag}_{36.4} \mathrm{Fe}_{15.6} \mathrm{Sn}_{48} / \mathrm{CNTs}[51]$ & $0.2 \mathrm{mAcm}^{-2}$ & 420 & 300 \\
\hline $\mathrm{V}_{2} \mathrm{O}_{5} / 17 \mathrm{wt} \% \mathrm{SWNTs}[55]$ & $560 \mathrm{mAg}^{-1}$ & 418 & 20 \\
\hline $\begin{array}{c}\mathrm{MWCNT} / 4.69 \mathrm{wt} \% \mathrm{Sn} \\
\mathrm{MWCNT} / 6.33 \mathrm{wt} \% \mathrm{Sn}[48]\end{array}$ & $0.1 \mathrm{C}$ & 754 & 40 \\
\hline
\end{tabular}

\subsubsection{Graphene}

Recently, graphene, a 2 dimensional layer of $\mathrm{sp}^{2}$ hybridized carbon atoms which is also the integral part of graphite electrodes attracted a lot of attention as a potential anode for LIBs. This atomic layer of carbon was previously believed to be unstable compared to 1D nanowires and 0D fullerenes until it was unexpectedly observed by A. K. Geim et al. [60]. It has been proposed that lithium-ions can be adsorbed on both sides of the graphene sheet leading to two layers of lithium for each graphene sheet, with a theoretical capacity of $744 \mathrm{mAhg}^{-1}$ through the formation of $\mathrm{Li}_{2} \mathrm{C}_{6}[61,62]$. On the other hand, nano-cavities between graphene nanosheets created by scrolling and crumpling could also contribute to the lithium storage. The interaction between lithium atoms and nanopores results in an appreciable voltage hysteresis during the charging process [63]. Therefore, the graphene nanosheet electrode exhibited lithium storage behavior that was typical of both soft graphitized carbon and hard carbon. The possible reason is that the larger surface area and 
curled morphology of graphene sheets, with fewer layers, can provide more lithium insertion active sites, such as edge-type sites, or nanopores [64]. Haihui Wang et al. reported graphene sheets with approximately four stacked individual monatomic graphene layers, that showed a high $1^{\text {st }}$ cycle capacity of $2035 \mathrm{mAhg}^{-1}$ at $100 \mathrm{mAg}^{-1}$ [86] and $848 \mathrm{mAhg}^{-1}$ after 40 cycles. In comparison, 10-20 layers stackings of the monatomic graphene sheets exhibited a capacity of $540 \mathrm{mAhg}^{-1}$ at $50 \mathrm{mAg}^{-1}$ and $290 \mathrm{mAhg}^{-1}$ after 20 cycles [65]. Another report in which graphene nanosheet electrodes cycled between $0.05-3.0 \mathrm{~V}$ at $1 \mathrm{C}$ rate were found to have a capacity of $945 \mathrm{mAhg}^{-1}$ in $1^{\text {st }}$ cycle and $460 \mathrm{mAhg}^{-1}$ after 100 cycles. This high capacity of graphene can be attributed to lithium insertion cavities, lithium absorbtion on each side of carbon sheet, and lithium binding [66]. The reversible reaction of $\mathrm{Li}$ with the residual $\mathrm{H}$ in the graphene sheets and faradaic contribution allow for the large reversible capacity [66]. It is well known that the disordered carbons can yield higher capacity values than graphite [67-71], and the graphene can be considered as a very disordered carbon. Furthermore, it should be noted that the graphene sheets electrode exhibits a broad electrochemical window $(0.01-3.5 \mathrm{~V})$ as a function of lithium capacity and a large voltage hysteresis between discharge and charge voltage curves. This behaviour is unlike graphite and similar to the properties of disordered carbons.

\subsubsection{Summary}

Lithium storage for battery applications on the anode side has, for a long time, been dominated by carbon-based materials. Even though other solutions are currently being investigated at the moment, carbon may still play an important role in the future, as owing to its structural variability. The carbon materials offer a well-suited playground for optimizing micro and nanostructures not only in terms of capacity but also of rate performance. A sheer 
increase in surface area has to compete with increased irreversible capacity owing to electrolyte interaction. This dilemma may be solved using closed cavities that are accessible to Li but not the electrolyte. Another approach is performing the passivation layer on the anode material before use. The irreversible capacity may not be a serious problem because excess Li can be added when setting up the cell. One also has to be aware that the voltage range covered should not be too large (a steep curve ranging from 0.1 to $3 \mathrm{~V}$ during charging is not tolerable in cases where actual applications are concerned). Despite being an old materials area, research on carbon structures still offers surprises and reasons enough for more systematic experiments.

\subsubsection{Alloying/ dealloying anode: $\mathrm{SnO}_{2}$ anodes}

Tin oxides, $\mathrm{SnO}_{2}$ has received great attention as anode materials for LIBs since Fujifilm patented a tin based composite anode. Sony has commercialized an amorphous tin based composite anode in their Nexelion battery. $\mathrm{SnO}_{2}$ is an n-type, wideband-gap semiconductor under ambient conditions. During charge/discharge processes, $\mathrm{SnO}_{2}$ can be electrochemically reduced to $\mathrm{Sn}$ by $\mathrm{Li}^{+}$in the first cycle and subsequently forms various alloys $\left(\mathrm{Li}_{x} \mathrm{Sn}\right)$ with $\mathrm{Li}^{+}$as follows [72]:

$$
\begin{aligned}
& \mathrm{SnO}_{2}+4 \mathrm{Li}^{+}+4 \mathrm{e}^{-} \rightarrow 2 \mathrm{Li}_{2} \mathrm{O}+\mathrm{Sn} \\
& \mathrm{Sn}+\mathrm{xLi}^{+}+\mathrm{xe}^{-\stackrel{\mathrm{d}}{\rightleftarrows}} \mathrm{Li}_{\mathrm{x}} \mathrm{Sn}
\end{aligned}
$$

According to the reaction mechanism, during the first irreversible reaction, tin oxide reacts with lithium and forms tin and lithium oxide. Tin metal formed is dispersed in a $\mathrm{Li}_{2} \mathrm{O}$ matrix. This reaction is considered irreversible, though some recent reports indicate quasireversibility [72]. In the subsequent cycles, metallic tin reacts reversibly with lithium and 
forms lithium-tin alloy. Based on this mechanism, $\mathrm{SnO}_{2}$ anodes can deliver a high theoretical capacity of $782 \mathrm{mAhg}^{-1}$ at $\mathrm{x}=4.4$. This is a significant improvement over the theoretical capacity of $372 \mathrm{mAhg}^{-1}$ for graphite. Irreversible electrochemical reduction of oxide, however, results in some irreversible capacity. Most importantly, volume changes of as much as $259 \%$ occurred when $\mathrm{Li}^{+}$was alloyed and de-alloyed from $\mathrm{Sn}$-based materials. This drastic volume change led to structural instability of the electrode causing cracking and crumbling of the electrode [73] thereby reducing the cycle life of the battery. The metallic tin formed during cycling tends to aggregate resulting in loss of contact, hence poor cyclability. Different textures and microstructures of the material play an important role in their electrochemical behavior. For instance, using composites [74], alloys [75], nanosize [76], and/or nanostructures [77] can mitigate the issues associated with $\mathrm{SnO}_{2}$ anodes.

The morphology of the anodes can affect the electrochemical performance. It has been shown that porous morphology demonstrates improved performance over dense film or particles [78-82]. This is because the porous structures can alleviate the stress due to volume changes.

Cycle performance of $\mathrm{SnO}_{2}$ anodes with different morphologies were reported in various studies [78]. In the first cycle, compared with the two dense $\mathrm{SnO}_{2}$ films, the porous $\mathrm{SnO}_{2}$ film showed a higher initial capacity loss. This occurs because the large specific surface area of $3 \mathrm{D}$ porous $\mathrm{SnO}_{2}$ expenses more lithium and a more irreversible SEI layer is formed in this process [79]. The $3 \mathrm{D}$ porous $\mathrm{SnO}_{2}$ film displays the best capacity retention and the highest discharge capacity. The high porosity and large surface area of porous $\mathrm{SnO}_{2}$ are thought to contribute to $\mathrm{Li}^{+}$diffusion, leading to an improved rate capability [80]. Compared to nanowires, nanotubes or nanopowders of tin oxide, 3D reticular tin oxide thin film shows 
higher reversible specific capacity [81]. Considering the inclusion of additive and binder, the real capacities of the nanowires, nanotubes, or nanopowders of tin oxide are much lower than that of 3D reticular tin oxide, which does not have any additives. In another instance, Chen et al. used ESD method to create the $\mathrm{Li}_{2} \mathrm{O}-\mathrm{CuO}-\mathrm{SnO}_{2}$ composites as anodes of lithium ion batteries [82]. These composites consist of randomly arranged hollow porous spheres that consist of a multideck-cage structure. After 100 cycles, the reversible discharge capacity is $560.8,718.1$, and $823 \mathrm{mAh} \mathrm{g}^{-1}$ for the $\mathrm{SnO}_{2}, \mathrm{CuO}-\mathrm{SnO}_{2}$, and $\mathrm{Li}_{2} \mathrm{O}-\mathrm{SnO}_{2}$ electrodes. These correspond to $48 \%, 72 \%$, and $74 \%$ of their first discharge capacity, respectively. The outstanding high capacity, capacity retention, and rate capability of the $\mathrm{Li}_{2} \mathrm{O}-\mathrm{CuO}-\mathrm{SnO}_{2}$ are related with its special multideck-cage morphology and the ternary composition. The nanostructured particles shorten the transport lengths for both electrons and lithium ions, while the unique porous structure ensures a high electrode-electrolyte contact area and confers the ability to accommodate the volume change during charge/discharge processes.

Nanostructured electrodes are shown to improve the electrochemical behavior with high rate capabilities and cyclability due to their ability to buffer the volume change and shorten $\mathrm{Li}^{+}$diffusion path. The use of nanostructured $\mathrm{SnO}_{2}$ materials allows, as a result of the intimate nanoscale contact, not only an increase in the power density, but also an enhancement of $\mathrm{Li}^{+}$reversibility, and hence cycle life [83]. For example, Charles R. Martin et al. [84] compared a thin film (550 nm thick) and nanostructured nanofibrils $(110 \mathrm{~nm}$ diameter) electrodes of similar mass. The nanostructured electrode showed two times higher capacity at high discharge rates than the thin film electrodes. It also showed an exceptionally high capacity after 1400 cycles. $\mathrm{SnO}_{2}$ nanotubes synthesized using CNT as template showed 
a high first cycle discharge capacity of $1821 \mathrm{mAhg}^{-1}$, and decreased to $435 \mathrm{mAhg}^{-1}$ after 50 cycles [85]. High capacity was reasoned to be the effect of the limited mobility of the nanotubes themselves due to the tubular organization that helps to preserve the electrical pathway and large surface area contributing towards easy $\mathrm{Li}^{+}$diffusion.

Composites of $\mathrm{SnO}_{2}$ have been recently investigated due to their synergistic interactions. Either one, or both of the constituents reacts electrochemically with lithium. One of the constituents of the composite can act as a buffer matrix while the other reacts with lithium. This matrix can also prevent the aggregation of tin particles. Composites can improve conductivity, relieve stress, and improve electrochemical performance [86-91]. For example, in $\mathrm{SnO}_{2} / \mathrm{C}$ composites, the conductivity is enhanced by carbon [86]. Microwave assisted synthesis [87] or polyol assisted thermal decomposition [88] can be used to synthesize $\mathrm{SnO}_{2}-\mathrm{C}$ composites. Also, $\mathrm{SnO}_{2} / \mathrm{CNT}$ composites were prepared using supercritical fluids with $\mathrm{SnO}_{2}$ particles of 3-5 nm decorated on the CNT surface [89]. This composite anode still showed a capacity of $400 \mathrm{mAhg}^{-1}$ after 30 cycles. $\mathrm{SnO}_{2}$ nanoparticlesgraphite composites have also been explored with satisfying results. This composite exhibits a higher capacity than the graphite anode, but nevertheless smaller than that of the $\mathrm{SnO}_{2}$ anodes. For example, Jim Y. Lee et al. used Pechini process [90] to derive $\mathrm{SnO}_{2}$ and $\mathrm{SnO}_{2}$ graphite composites with capacities of $280 \mathrm{mAh} \mathrm{g}^{-1}$ and $600 \mathrm{mAh} \mathrm{g}^{-1}$ after 30 cycles. Some of $\mathrm{SnO}_{2}$ anodes reported in literature are summarized in the table 1.2. 
Table 1.2 Summary of some of the $\mathrm{SnO}_{2}$ based anodes with modified morphology, structure and composites.

\begin{tabular}{|c|c|c|c|c|}
\hline Materials & $\begin{array}{c}\text { Voltage } \\
\text { window } \\
\text { (V) }\end{array}$ & $\begin{array}{l}\text { Current } \\
\text { density or } \\
\text { C-rate }\end{array}$ & $\begin{array}{c}\text { Initial } \\
\text { Capacity } \\
\left(\mathbf{m A h g ^ { - 1 }}\right)\end{array}$ & $\begin{array}{l}\text { Capacity } \\
\left(\mathrm{mAhg}^{-1}\right) \\
\text { (n cycles) }\end{array}$ \\
\hline $\mathrm{SnO}_{2}$-Reticular [82] & $0.05-1.5$ & $100 \mathrm{mAg}^{-1}$ & 720 & $300(50)$ \\
\hline $\begin{array}{c}\mathrm{SnO}_{2} \text {-Porous, Spherical, } \\
\text { multideck-cage [81] }\end{array}$ & $0.01-3$ & $0.5 \mathrm{C}$ & 1168 & $560.8(100)$ \\
\hline $\begin{array}{c}\mathrm{SnO}_{2}-3 \mathrm{D} \text { porous amorphous } \\
{[80]}\end{array}$ & $0.01-3$ & $0.5 \mathrm{C}$ & 1150 & $689(100)$ \\
\hline $\begin{array}{l}\mathrm{SnO}_{2} \text { nanoparticles } \\
(30-50 \mathrm{~nm})[87]\end{array}$ & $0.05-1.2$ & $33 \mu \mathrm{Acm}^{-2}$ & 812.7 & $250(50)$ \\
\hline $\begin{array}{l}\text { Ultrafine } \mathrm{SnO}_{2} \text { nanoparticles } \\
\qquad(5 \mathrm{~nm})[89]\end{array}$ & $0.01-1.50$ & $200 \mathrm{mAg}^{-1}$ & 1438 & $400(100)$ \\
\hline $\begin{array}{c}\mathrm{SnO}_{2} \text { nanoparticles } \\
(5,11,20 \text { and } 39 \mathrm{~nm})[83]\end{array}$ & $0.05-1.0$ & $50 \mathrm{mAg}^{-1}$ & $\begin{array}{c}734.7,2089, \\
1779 \text { and } \\
1458\end{array}$ & $\begin{array}{c}131,452,367 \\
\text { and } \\
293(30)\end{array}$ \\
\hline $\begin{array}{c}\mathrm{SnO}_{2} \text { Nanorods }(15 \mathrm{~nm}) \\
{[80]}\end{array}$ & $\begin{array}{l}0.005-1.0 \\
0.005-2.0\end{array}$ & $0.1 \mathrm{mAmg}^{-1}$ & $\begin{array}{l}\sim 700 \\
\sim 1100\end{array}$ & $\begin{array}{l}\sim 700(60) \\
\sim 400(60)\end{array}$ \\
\hline $\begin{array}{l}\text { (i) Pure } \mathrm{SnO}_{2} \text { nanowires, (30- } \\
\qquad 100 \mathrm{~nm}) \\
\text { (ii) } \mathrm{Sn} \text { nanocluster (15nm)- } \\
\text { covered } \mathrm{SnO}_{2} \text { nanowires, } \\
\text { (iii) } \mathrm{Sn} \text { nanoclusters } \\
\text { distributed in between the } \\
\mathrm{SnO}_{2} \text { nanowire networks [96] }\end{array}$ & 0 to 2.2 & $100 \mathrm{mAg}^{-1}$ & $\begin{array}{l}\text { (i) } 2400 \text {, } \\
\text { (ii) } 2013 \text {, } \\
\text { (iii) } 2800 \text {. }\end{array}$ & $\begin{array}{l}\text { (i) } 166(40) \text {, } \\
\text { (ii) } 845(40) \text {, } \\
\text { (iii) } 490(40) \text {. }\end{array}$ \\
\hline
\end{tabular}




\begin{tabular}{|c|c|c|c|c|}
\hline $\begin{array}{c}\text { Nanofibrils (110nm) } \\
{[85]}\end{array}$ & $0.2-0.9$ & $2.32 \mathrm{mAcm}^{-2}$ & 500 & $600(1400)$ \\
\hline $\mathrm{SnO}_{2}$ nanotubes (20-30nm) & $0.005-3$ & $0.2 \mathrm{C}$ & 1821 & $435(50)$ \\
{$[95]$} & & & & \\
\hline $\mathrm{SnO}_{2} / \mathrm{CNT}$ & $0.1-2$ & $0.1 \mathrm{C}$ & 1460 & $404(20)$ \\
$\left(\mathrm{SnO}_{2}: 4.9 \mathrm{~nm}\right)$ & & & & \\
{$[81]$} & $0.005-2$ & $0.2 \mathrm{mAcm}^{-2}$ & $\sim 1150$ & $\sim 400(30)$ \\
\hline $\mathrm{SnO}_{2} / \mathrm{CNT}$ & & & & \\
$\left(\mathrm{SnO}_{2}: 3-5 \mathrm{~nm}\right)[90]$ & & & & \\
\hline $\mathrm{SnO}_{2} / \mathrm{graphite}$ & $0.005-2$ & $0.4 \mathrm{mAcm}^{-2}$ & & \\
\hline$\left(\mathrm{SnO}_{2}: 10 \mathrm{~nm}\right)[92]$ & & & & \\
\hline
\end{tabular}

Tin oxide and its composites have been widely studied as anode materials since the early 1990's. Though tin oxide has some disadvantages, such as the large irreversible capacity loss and volume expansion, it is still considered to be a promising anode material to replace graphite for high power applications. It is reported that the disadvantages of $\mathrm{SnO}_{2}$ anodes can be alleviated by fabricating nanomaterials and designing nanostructures,. Thus, composites of $\mathrm{SnO}_{2}$ with nanocarbon materials are of particular interest, owing to their improved electrochemical performance.

\subsection{Experimental Technique - Electrostatic spray deposition}

A wide variety of porous or hollow structures including hollow spheres, mesoporous structures, and porous nanobelts have been prepared using sol-gel method [78], thermal evaporation [79], and template-assisted synthesis (such as: AAO template and 
supramolecular templating). Nevertheless, template-assisted synthesis has its own disadvantages. For example, it is easy to destroy the porous or hollow structures during the hard-template (e.g. silica template) removal process. For soft template (e.g. hydrothermal synthesis) methods, it is difficult to prevent the aggregation of final products. Furthermore, most of the samples synthesized by these methods are in powder form. To prepare a laminated electrode, all of these porous or hollow powders must be mixed with a conductive agent (carbon black) and binder (polyvinylidene fluoride, PVDF), which will easily destruct the hollow and porous structures.

Electrostatic spray deposition (ESD), initially developed by Schoonman and coworkers at Delft University of Technology, is a unique preparation method for depositing various films [92]. Because of its simple and low-cost setup, non-vacuum, low temperature deposition condition, and good control of the film composition and morphology, ESD technique is superior to other film formation methods such as sputtering, CVD, and sol-gel. Due its many advantages, ESD has already been employed to create anode films with different morphologies including dense, fractal-like porous or sponge-like threedimensional cross-linked porous structure [93]. Particularly, the 3D sponge-like films with their high porosity and a narrow pore size distribution are mechanically strong and are beneficial for withstanding the large volume changes of anode materials during charge/discharge process. It is also expected that $\mathrm{Li}^{+}$transport properties of 3D sponge-like porous anode films is faster than in the films of other morphologies probably due to their high surface area [94]. ESD also makes possible the preparation of an anode film without the use of extra binder and conductive materials, improving the energy density of lithium 
ion batteries. Clearly, ESD-derived anode films are favorable for the application in lithiumion batteries.

Figure 3 schematically shows the ESD experimental set-up. It consists of a nozzle connected with a syringe that supplies the precursor solution, a substrate at high temperature, and a DC high voltage power supply. The surface of the conducing substrate is controlled at a certain temperature where evaporation and chemical reactions occur simultaneously to form the deposited film. During the films deposition, the following processes takes place, in general [95]: (i) spray formation: When a DC high voltage is applied to the metallic nozzle, an electrostatic field is immediately set up across the nozzle and the grounded substrate. As soon as the precursor solution reaches the tip of the nozzle, it is atomized into charged droplets by the electrohydrodynamic force. (ii) droplet transport, evaporation, disruption: under the columbic force, droplets move towards the heated substrate causing the solvent to evaporate. Evaporation of the solvent results in shrinkage of the droplet. The total charge on the surface of droplet does not change, so the shrinkage of droplet causes an increase in its charge density. A charged droplet may be disrupted into a few smaller droplets after reaching a maximum attainable charge density. (iii) preferential landing: the induced charge distribution on the surface of the grounded substrate generally is not uniform. Therefore, the electric field on the local curvature of the surface is stronger than at other places. When a charged droplet approaches the surface, it will be more attracte towards these curved areas. (iv) discharge, droplet spreading: When a charged droplet contacts with the surface of the substrate, or the earlier formed layer, it starts to discharge by transferring the charge to the grounded substrate, either immediately, or through the layer to the substrate. 


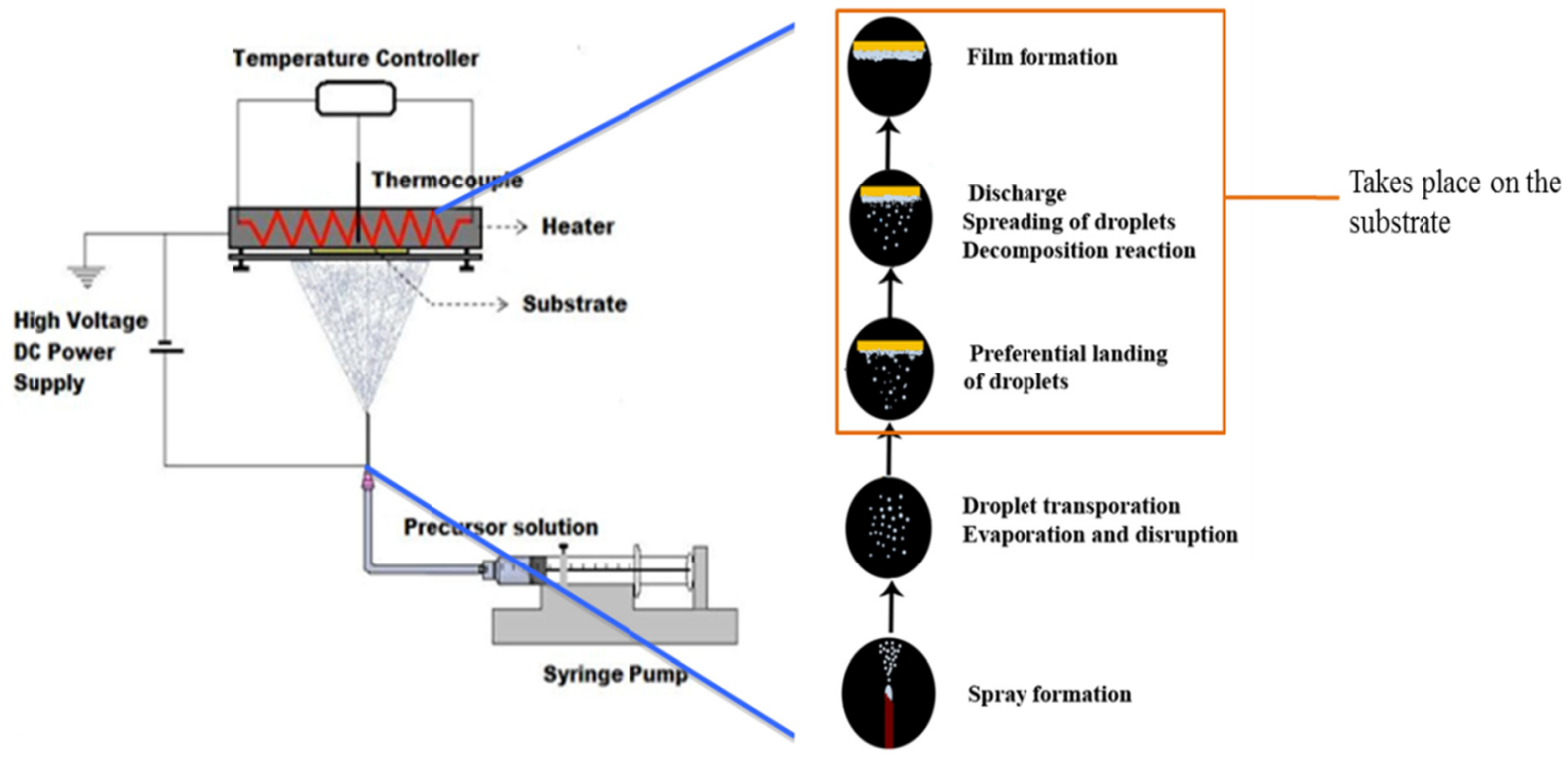

Figure 2.3. Schematic of the ESD experimental set-up showing the processes involved in ESD: (i) spray formation; (ii) droplet transport, evaporation, disruption; (iii) preferential landing; (iv) discharge, droplet spreading; (v) film formation by decomposition and drying of the precursor salt.

The relative value of interfacial tensions between the substrate and ambient gas, between the substrate and the drop liquid, and between the drop liquid and ambient gas determine the spreading rate of droplets:

$$
\mathrm{S}=\gamma_{\mathrm{sv}}-\gamma_{\mathrm{sl}}-\gamma_{\mathrm{lv}}
$$

If $\mathrm{S}<0$, only partial wetting occurs with equilibrium reached at a finite contact area. If $\mathrm{S} \geq$ 0 , the drop spreads until it completely covers the surface. The value of $\mathrm{S}$ is intimately related to the spreading rate. Therefore, the choice of substrate will affect the spreading rate of the liquid droplet, and may ultimately affect the morphology of the layer. (v) decomposition and drying of the precursor salt: the decomposition reaction (either partial or 
complete) of the solute may have occurred before the droplets reached the substrate, which is expected if the surrounding temperature is high enough and dried droplets have been formed. Rearrangement of these dry particles on the substrate by surface-by-surface diffusion is not expected at moderate deposition temperatures less than $500{ }^{\circ} \mathrm{C}$. In this case, a grain-like structure is expected to form instead of a very dense morphology. In this technique, experimental parameters such as high voltage, the distance between nozzle and substrate, the flow rate and viscosity of precursor solution, and substrate temperature, have some influence on the morphology of film. Solution chemistry including the precipitation process and the pyrolysis, or reaction of the solutes is also important parameters at low deposition temperatures or when using a high boiling point solvent. We can modify these parameters to tailor the morphology of deposited films. For example, Gao et al. investigated the influence deposition temperature, substrate materials, and solvent composition had on the morphology of $\mathrm{La}_{0.7} \mathrm{Ca}_{0.3} \mathrm{CrO}_{3-\delta}$ [95]. They prepared the $\mathrm{La}_{0.7} \mathrm{Ca}_{0.3} \mathrm{CrO}_{3-\delta}$ films with porous reticulated models, cage-like particles, and interconnected nanowire structures. They found that when the substrate temperature increased, the porosity of $\mathrm{La}_{0.7} \mathrm{Ca}_{0.3} \mathrm{CrO}_{3-\delta}$ film remarkably decreased; the pore and pore-wall sizes both became smaller. When changing the substrate material from nickel, aluminum, and alumina substrates to a copper substrate, the microstructure of $\mathrm{La}_{0.7} \mathrm{Ca}_{0.3} \mathrm{CrO}_{3-8}$ film was converted from a porous reticulated model to a cage-like particle model. They proposed it was due to the bigger contact angle on the copper substrate than that of the other substrates. Moreover, changing the solvent composition, may significantly change the layer morphology from a porous reticulated model to an interconnect nanowire structure. 
This ESD technique introduces the opportunity to precisely control the morphology of the anode materials in lithium ion batteries. Controlling these morphologies plays an enormous role in improving the cycle performance of anode materials. Especially, the three dimensional sponge-like anode materials with a high porosity and a narrow pore size distribution are mechanically strong, and beneficial for buffering the large volume change of the anode materials during charge/discharge process. On the other hand, $\mathrm{Li}^{+}$transport properties of 3D sponge-like porous anode materials are faster than those of other morphologies, probably due to their high surface area. ESD also makes possible the preparation of an anode material without using binder or a conductive agent, which are normally used to enhance the energy density of lithium ion batteries. Because of these advantages, ESD-derived anode materials are extremely favorable for the application in lithium-ion batteries.

\subsection{References}

[1] C. C. Chan, Proc. IEEE. 90, 247(2002).

[2] H. K. Liu, G. X. Wang, Z. P. Guo, J. Z. Wang, and K. Konstantinov, J. Nanosci. Nanotechnol. 6, 1 (2006).

[3] Y. Nishi, J. Power Sources, 100, 101 (2001).

[4] M. Winter and R. J. Brodd, Chem. Rev., 104, 4245 (2004).

[5] J. Chen and F. Cheng, Acc.Chem. Res., 42, 713 (2009).

[6] V.Srinivasan, Almaden conference, 2009.

[7] M.S. Whittingham, Science,192, 1126 (1976).

[8] F. Orsini, A. Du Pasquier, B. Beaudoin, J. M. Tarascon, M. Trentin, N. Langenhuizen, E. De Beer, and P. Notten, J. Power Sources, 76, 19(1998). 
[9] R. Yazami, and Ph. Touzain, J. Power Sources, 9, 365(1983).

[10] S. Basu, US patent 4304825, 1981

[11] Sony Corporation, US4959281,1990.

[12] C. Burda, X. B. Chen, R. Narayanan, and M. A. El-Sayed, Chem. Rev. 105, 1025(2005).

[13] U.Kasavajjula, C.S.Wang, and A.J. Appleby, J. of Power Sources, 163, 1003 (2007).

[14] Y. Idota, T. Kubota, A. Matsufuji, Y. Maekawa, and T. Miyasaka, Science, 276, 1395 (1997).

[15] G. Derrien, J. Hassoun, S. Panero, and B. Scrosati, Adv. Mater., 19, 2336 (2007).

[16] H. Bryngelsson, J. Eskhult, and L. Nyholm, Electrochim. Acta, 53, 7226 (2008).

[17] J. Hassoun, G. Derrien, S. Panero, and B. Scrosati, J. of Power Sources, 83, 339 (2008).

[18] M.V. Reddy, Y. Ting, C.H.Sow, Z.X Shen, C.T. Lim, G.V.S Rao, and B.V.R. Chowdari, Adv. Fucnt.Mater., 17, 2792 (2007).

[19] B.T. Hang, I. Watanabe, T. Doi, S. Okada, and J.I Yamaki, J. of Power Sources, 161, 1281(2006).

[20] F. Li, Q.Q. Zou, and Y.Y Xia, J. of Power Sources, 177, 546 (2008).

[21] W.L. Yao, J. Yang, J.L.Wang, and Y. Nuli, J. of Electrochem. Soc., 155, A903 (2008).

[22] J. Morales, L. Sanchez, F. Martin, J.R. Ramos-Barrado and M. Sanchez, Electrochim. Acta, 49, 4589 (2004).

[23] S.Q.Wang, J.Y. Zhang, C.H. Chen, Scripta Mater. 57, 337(2007).

[24] S. H. Ng, J. Z. Wang, D. Wexler, K. Konstantinov, Z. P. Guo, and H. K. Liu, Angew. Chem. Int. Ed., 45, 6896 (2006).

[25] D. Guerard and A. Herold, Carbon 13, 337 (1975).

[26] M. Zanini, S. Basu, and J. E. Fischer, Carbon, 16, 211 (1978).

[27] T. Zheng, J. S. Xue, and J. R. Dahn, Chem. Mater, 8, 389 (1996).

[28] J. Li, C. Wu, and L. Guan, J. Phys. Chem., C 113, 18431 (2009). 
[29] Z. H.Yang and H. Q. Wu, Solid State Ionics, 14, 173 (2001).

[30] Q. Wang, L. Liu, L. Chen, and X. Huang, J. Electrochem Soc. 151, A1333 (2004).

[31] J. Y. Eom, J. W. Park, H. S. Kwon, and S. Rajendran, J. Electrochem Soc. 153, A1678 (2006).

[32] H.M. Hsoeh, N.H.Tai, C.Y.Lee, J.M.Chen, and F.T. Wang, Rev. Adv. Mater. Sci. 5, 67 (2003).

[33] H. Azuma, H. Imoto, S. Yamada, and K. Sekai, J. Power Sources 81, 1 (1999).

[34] Z. W. Zhao, Z. P. Guo, P. Yao, and H. K. Liu, J. Mater. Sci. Technol. 24, 657 (2008).

[35] M. Broussely, P. Biensan, and B. Simon, Electrochim. Acta 45, 3 (1999).

[36] Y. Wang, J. Y. Lee, and T. C. Deivaraj, J. Electrochem. Soc. 151, A1804 (2004).

[37] Y. Wang, J. Y. Lee, and B.H. Chen, J. Electrochem. Soc. 151, A563 (2004).

[38] Y. Wang, J. Y. Lee, and B.H. Chen, Electrochem. Solid St. 6, A19 (2003).

[39] W. Wang and P. N. Kumta, J. Power Sources 172, 650 (2007).

[40] M. Winter, J. O. Besenhard, M. E. Spahr, and P. Novak, Adv. Mater. 10, 725 (1998).

[41] M. Yoshio, S. Kugino, and N. Dimov, J. Power Sources 153, 375 (2006).

[42] M. Yoshio, T. Tsumura, and N. Dimov, J. Power Sources 163, 215 (2006).

[43] X. Wu, Z. Wang, L. Chen, and X. Huang, Electrochem. Comm. 5, 935 (2003).

[44] H. Li, X. J. Huang, L. Q. Chen, G. W. Zhou, Z. Zhang, D. P. Yu, Y. J. Mo, and N. Pei, Solid State Ionics 135, 181 (2000).

[45] J. L. Gómez Cámer, J. Morales, L. Sánchez, P. Ruch, S. H. Ng, R. Kötz, and P. Novák, Electrochim. Acta 54, 6713 (2009).

[46] S. H. Ng, J. Z. Wang, D. Wexler, K. Konstantinov, Z. P. Guo, and H. K. Liu, Angew. Chem. Int. Ed. 45, 6896 (2006).

[47] R. D. Cakan, M. M. Titirici, M. Antonietti, G. L. Cui, J. Maier, and Y. S. Hu, Chem. Commun. 32, 3759 (2008).

[48] A. Magasinski, P. Dixon, B. Hertzberg, A. Kvit, J. Ayala, and G. Yushin, Nat. Mater. 9, $353(2010)$.

[49] L. O. Laurence, T. Monique, Z. David, and B. Claude, Chem. Mater. 20, 1212 (2008). 
[50] H. Dong, R.X. Feng, X.P. Ai, Y.L. Cao, and H.X. Yang, Electrochim. Acta 49, 5217 (2004).

[51] H. Y. Lee, Y. L. Kim, M. K. Hong, and S. M. Lee, J. Power Sources 141, 159 (2005).

[52] H. Y. Lee and S. M. Lee, J. Power Sources 112, 649 (2002).

[53] G. X. Wang, L. Sun, D. H. Bradhurst, S. Zhong, S. X. Dou, and H. K. Liu, J. Power Sources 88, 278 (2000).

[54] H. Azuma, H. Imoto, S. Yamada, and K. Sekai, J. Power Sources 81, 1 (1999).

[55] Y. S. Hu, P. Adelhelm, B. M. Smarsly, S. Hore, M. Antonietti, and J. Maier, Adv. Func. Mater. 17, 3851 (2007).

[56] T. Kasuh, A. Mabuchi, K. Tokumitsu, and H. Fujimoto, J. Power Sources 68, 99 (1997).

[57] W. X. Chen, J. Y. Lee, and Z. Liu, Carbon 41, 959 (2003).

[58] W. X. Chen, J. Y. Lee, and Z. Liu, Electrochem. Comm. 4, 260 (2002).

[59] J. Yin, M. Wad, Y. Kitano, S. Tanase, O. Kajita, and T. Sakaia, J. Electrochem. Soc. 152, A1341 (2005).

[60] L. F. Cui, L. Hu, J. W. Choi, and Y. Cui, ACS Nano 4, 3671 (2010).

[61] W. Wang, and P. N. Kumta, ACS Nano 4, 2233 (2010).

[62] G. Chen, Z. Wang, and D. Xia, Chem. Mater. 20, 6951 (2008).

[63] J.Y. Xiang, J.P. Tu, J. Zhang, J. Zhong, D. Zhang, and J.P. Cheng, Electrochem.Comm. 12, 1103 (2010).

[64] J. Chen, A.I. Minett, Y. Liu, C. Lynam, P. Sherrell, C. Wang, and G. G. Wallace, Adv. Mater. 20, 566 (2008).

[65] D. Larcher, S. Beattie, M. Morcrette, K. Edström, J. C. Jumas, and J. M. Tarascon, J. Mater. Chem. 17, 3759 (2007).

[66] U. Kasavajjula, C. S. Wang, and A. J. Appleby, J. Power Sources 163, 1003 (2007).

[67] J. W. Kim, J. H. Ryu, K.T. Lee, and S. M. Oh, J. Power Sources 147, 227 (2005).

[68] J. Graetz, C. C. Ahn, R. Yazami, and B. Fultz, Electrochem. Solid.St. 6, A194 (2003).

[69] B. Gao, S. Sinha, L. Fleming, and O. Zhou, Adv. Mater. 13, 816 (2001). 
[70] H. Li, X. Huang, L.Chen, G. Zhou, Z. Zhang, D. Yu, Y. J. Mo, and N. Pei, Solid State Ionics 135, 181 (2000).

[71] H.L. Zhang, Y. Zhang, X. G. Zhang, F. Li, C. Liu, J. Tan, and H. M. Cheng, Carbon 44, 2778 (2006).

[72] M. Winter and J. O. Besenhard, Electrochim. Acta 45, 31 (1999).

[73] Y. Idota, T. Kubota, A. Matsufuji, Y. Maekawa, and T.Miyasaka, Science 276, 1395 (1997).

[74] I. Rom, M. Wachtler, I. Papst, M. Schmied, J.O. Besenhard, F. Hofer, and M. Winter, Solid State Ionics 143, 329 (2001).

[75] S. Yang, P. Y. Zavalij, and M. S. Whittingham, Electrochem. Comm.5, 587 (2003).

[76] A. Jaworek and A.T. Sobczyk, J. Electrostat. 66, 197 (2008).

[77] J. H. Ahn, G. X. Wang, J. Yao, H. K. Liu, and S. X. Dou, J. Power Sources 119, 45 (2003).

[78] Y. Idota, M. Mishima, M. Miyaki, T. Kubota, and T. Misayaka, Eur. Pat. Appl. 651450 A1 950503.

[79] Y. Yu, L. Gu, A.Dhanabalan, C.H. Chen, and C. Wang, Electrochim. Acta 54, 7227 (2009).

[80] H. J. Ahn, H. C. Choi, K. W. Park, S. B. Kim, and Y. E. Sung, J. Phys. Chem. B 108, 9815 (2004).

[81] Y.Yu, C.H.Chen and Y.Shi. Adv. Mater. 19, 993 (2007).

[82] R. D. Cakan, Y.S. Hu, M. Antonietti, J. Maier, and M.M. Titirici, Chem. Mater. 20, 1227 (2008).

[83] L. Yuan, Z.P. Guo, K. Konstantinov, J.Z. Wang, and H.K. Liu, Electrochim. Acta 51, $3680(2006)$.

[84] D. Deng and J. Y. Lee, Chem. Mater. 20, 1841 (2008).

[85] F.J.P. Alonso, I. M. Cabrera, M. L. Granados, F. Kapteijn, and J.L.G Fierro, J. Catal. 239, 340 (2006).

[86] H.J. Choi, J. Moon, H.B. Shim, K.S. Han, E.G. Lee, and K.D. Jung, J. Am. Ceram. Soc. 89,343 (2006).

[87] S.H. Ng, D.I. dos Santos, S.Y. Chew, D. Wexler, J. Wang, S.X. Dou, and H.K. Liu, 
Electrochem. Comm. 9, 915 (2007).

[88] G. An, N. Na, X. Zhang, Z. Miao, S. Miao, K. Ding, and Z. Liu, Nanotechnology 18, 435707 (2007).

[89] L. Gao, H.Z. Wang, J.S. Hong, H. Miyamoto, K. Miyamoto, Y. Nishikawa, and S.D.D.L. Torre, Nanostruct. Mater. 11, 43 (1999).

[90] N. Li and C.R. Martin, J. Electrochem. Soc. 148, A164 (2001).

[91] L.P. Zhou, J. Xu, X.Q. Li, and F. Wang, Mater. Chem. Phys. 97, 137(2006).

[92] A.A. Zomeren, E.M. Kelder, J.C.M. Marijnissen, and J. Schoonman, J. Aerosol Sci., 25,1229 (1994).

[93] J.L. Shui, Y. Yu, and C.H. Chen, Applied Surface Science, 253, 2379 (2006).

[94] C.H. Chen, E.M. Kelder, and J. Schoonman, J. Mater. Sci. Lett. 16, 1967 (1997).

[95] Y.Z.Jiang, Y. Yu, W.P. Sun, C.H. Chen, G.Y. Meng, and J.F. Gao, J. Electrochem. Soc., 154, E107 (2007). 


\section{POROUS TIN OXIDE/CNT COMPOSITE ANODES: INFLUENCE OF} COMPOSITION AND DEPOSITION TEMPERATURE ON THE ELECTROCHEMICAL PERFORMANCE

\subsection{Introduction}

Hybrid electric vehicles and portable electronics are two important applications of lithium ion batteries (LIBs) research. Improving the energy capacities of both anode (the focus of this study) and cathode materials is crucial to the overall performance of LIBs [1]. Graphite, one of the allotropes of carbon, with a theoretical capacity of $372 \mathrm{mAhg}^{-1}$, is widely used as the anode material in commercial lithium ion rechargeable batteries [2]. However, the discharge capacity of graphite is limited due to its low lithium storage capability. Recently, some elements (such as $\mathrm{Sn}, \mathrm{Si}, \mathrm{Ge}$ ) [3-5], metal oxides (such as $\mathrm{SnO}_{2}, \mathrm{CoO}, \mathrm{Fe}_{3} \mathrm{O}_{4}$ ) [6-8], or compounds that alloy with lithium (such as $\mathrm{SnSb}, \mathrm{NiSi}, \mathrm{CuSn}$ ) [9-11] have been demonstrated to yield higher capacities than graphite. Among these, tin has gained much attention because of its theoretical specific capacity reaching as high as $781 \mathrm{mAhg}^{-1}[3,12]$. In 1997, Fuji Photo Film Celltec. Co. (Japan) used amorphous tin-based composite as a negative electrode in STALION battery, which prompted a leap in the interest in tin based anode materials [13]. Pure tin anodes have considerable challenges, such as the high internal stress that arises from the large volume change and aggregation of metallic tin particles during cycling. This results in the loss of electrical contact between the anode and current collector, which causes poor conductivity and cyclability of the tin anodes $[1,3]$. Using tin oxide instead of metallic tin as the anode can mitigate these issues [14]. It is widely accepted that tin oxide undergoes a two-step reaction mechanism with lithium as follows $[2,3,6,14]$ :

$$
\mathrm{SnO}_{2}+4 \mathrm{Li}^{+}+4 \mathrm{e}^{-} \rightarrow \mathrm{Sn}+2 \mathrm{Li}_{2} \mathrm{O}
$$




$$
\mathrm{Sn}+\mathrm{x} \mathrm{Li}^{+}+\mathrm{x} \mathrm{e}^{-} \stackrel{\mathrm{d}}{\rightleftarrows} \mathrm{Li}_{\mathrm{x}} \mathrm{Sn} \quad(\mathrm{x} \leq 4.4)
$$

$\mathrm{SnO}_{2}$ reacts with $\mathrm{Li}$ resulting in the formation of lithium oxide during the first step, which as a buffer matrix prevents the aggregation of tin nanoparticles formed in the subsequent reversible lithium-tin alloying reaction. Stress-related problems can also be solved by using various morphologies of tin oxide such as porous [15-18], core-shell [19], nanowires [20], etc.

Improvements in cyclability and conductivity have been achieved using tin based composite anodes (e.g. tin oxide/ carbon) $[13,21-23]$ where one of the constituent materials mainly acts as a buffer while the other reacts with lithium. Carbon nanotubes (CNT), with high conductivity and low mass density, were also considered for use as the negative electrode material of LIBs [24]. Tin oxide/ CNT composites were synthesized using various methods such as sol-gel technique [25], spray pyrolysis [26], homogeneous precipitation [27], supercritical fluids [28], diffusion methods [29], etc. For example, An et al. [28] reported $\mathrm{SnO}_{2} / \mathrm{CNT}$ nanocomposites, fabricated via the supercritical fluids method, had a discharge capacity of $400 \mathrm{mAhg}^{-1}$ after 30 cycles. Diffusion method was employed by $\mathrm{Fu}$. et al. [29] to prepare $\mathrm{SnO}_{2}$ inside CNT, which showed $27.7 \%$ retention of the initial capacity after 20 cycles. However, these results reported so far indicated high irreversible capacity, low cycle life and complicated materials synthesis procedures. In addition, when fabricating these materials as the anode, conductive additives and binders were mixed that may alter their morphology as well as decrease the effective loading of the active materials.

Here, we used Electrostatic Spray Deposition (ESD) [31-33] method to prepare porous $\mathrm{SnO}_{2} / \mathrm{CNT}$ composite anodes on porous nickel foam substrates. This technique 
provides a simple and versatile way to generate multi-component metal oxide thin films with various morphologies, including dense [15, 31], porous, reticular [15, 30], cage-like [16], etc. Adjusting the experimental parameters such as flow rate, voltage, current, substrate temperature, precursor solution, etc can control the morphologies of the samples. The anodes prepared using ESD can be subjected to electrochemical tests without any further modification or addition of the binder and conductive materials. In this work, we have studied the effects of CNT content and deposition temperature on the morphologies and electrochemical performance of the $\mathrm{SnO}_{2} / \mathrm{CNTs}$ composite anodes. Substrate nickel foam acts as a current collector facilitating the percolation of the electrolyte. CNT in the composite act as the buffer matrix for the volume change and participate in the lithium-ion insertion \& desertion. Also, CNT can improve the conductivity of the composite.

\subsection{Experimental Details}

Experimental set-up of ESD used in this work was described in the Figure 2.3. [15-16, 29].

A precursor solution was prepared by dissolving stoichiometric proportions of $8 \mathrm{mM}$ tin (IV) acetate (Sigma Aldrich) and dispersing $\mathrm{x}$ wt.\% (where $\mathrm{x}=10,20,30,40$ ) of short COOH-functionalized CNT (Cheap Tubes Inc.) in the solvent mixture of 1,2 propanediol and ethanol (4:1 volume ratio). The samples were referred to as $\mathrm{SnO}_{2} / \mathrm{x}$ CNT where $\mathrm{x}$ is the weight percentage of CNT content in the composites. The solution was homogenized by using a high power ultrasonic dispenser (Sonics VC750) for 10 minutes at $60 \%$ of the maximum amplitude. The resultant solution was pumped through a needle at a flow rate of 5 $\mathrm{ml} / \mathrm{h}$. Nickel foam disks with $\Phi 14 \mathrm{~mm}$ were used as the substrate. Samples were deposited at different substrate temperatures of 200,250 and $300{ }^{\circ} \mathrm{C}$ for $1 \mathrm{~h}$. The distance of $4 \sim 5 \mathrm{~cm}$ 
and voltage of $5 \sim 6 \mathrm{kV}$ was maintained between the needle and the substrate. The reference samples of pure $\mathrm{SnO}_{2}$ and CNTs were prepared in the same manner as above $\mathrm{SnO}_{2} / \mathrm{CNT}$.

The morphologies of the as-deposited films were investigated using Scanning electron microscopy (JOEL 6335 FE-SEM) and a sub-eV-sub-angstrom-microscope (SESAM, Carl Zeiss, Oberkochen, Germany). X-ray diffraction (XRD) studies were carried out using Rigaku-MiniFlex $\left(\mathrm{Cu} \mathrm{K} \mathrm{K}_{\alpha}\right.$ radiation at $\left.30 \mathrm{kV}\right)$. Electrochemical test cells (2032 coin cells) were assembled in argon filled glove box (VAC Nexus I), in which the oxygen concentration and moisture level were maintained below $1 \mathrm{ppm}$. The as-deposited anodes were used as the working electrode and a lithium foil as the counter electrode and reference electrode. Celgard 2400 micro porous polypropylene was used as a separator. The electrolyte was 1M lithium bis(perfluoroethylsulfonyl)imide/EC:DMC (1:1 volume ratio) solution. Electrochemical characterization was performed using Bio-logic versatile multichannel potentiostat (VMP3).

\subsection{Results and Discussions}

Figure 3.1a shows the typical XRD pattern of $\mathrm{SnO}_{2} / 10 \mathrm{CNT}$ film prepared at $200{ }^{\circ} \mathrm{C}$. The peaks at $2 \theta=26.6,33.9,38.0$, and $65.5^{\circ}$ can be assigned to the (110), (101), (200), and (301) planes of $\mathrm{SnO}_{2}$ (JCPDS card No. 41-1445), respectively. Broad and less intense peaks of $\mathrm{SnO}_{2}$ imply that the oxide exists in an amorphous state or nano-sized particles. Intense peaks at $2 \theta=44.8,52.2$, and $76.9^{\circ}$ are identified from substrate Ni foam (JCPDS 04-0850). The diffraction peaks of CNT appear at $2 \theta=26.3,43.6$ and $55.2^{\circ}$, which correspond to (002), (101), and (004) planes (JCPDS card No. 65-6212), respectively. In order to verify the XRD results, the same sample was characterized by Raman spectroscopy. Raman spectra of $\mathrm{SnO}_{2} / 10 \mathrm{CNT}$ exhibit two strong peaks centered at 1580 and $1349 \mathrm{~cm}^{-1}$ (Figure $3.1 \mathrm{~b}$ ), 
corresponding to the characteristic $\mathrm{E}_{2 \mathrm{~g}}$ and D modes of CNT, respectively [34]. Due to the amorphous nature of tin oxide, the weak and broad peaks at 465, 520, and $586 \mathrm{~cm}^{-1}$, which appear in the wave number range below $1000 \mathrm{~cm}^{-1}$, can be assigned to the $\mathrm{E}_{2 \mathrm{~g}}, \mathrm{~S} 1$ and $\mathrm{S} 2$ mode of Sn (IV)-O bond vibration [35-37]. S1 and S2 are disorder-activated modes, which increase with the increase in the degree of disorder (reducing crystal symmetry). There are no peaks of Ni foam in the Raman spectra because metals are not Raman active [38].
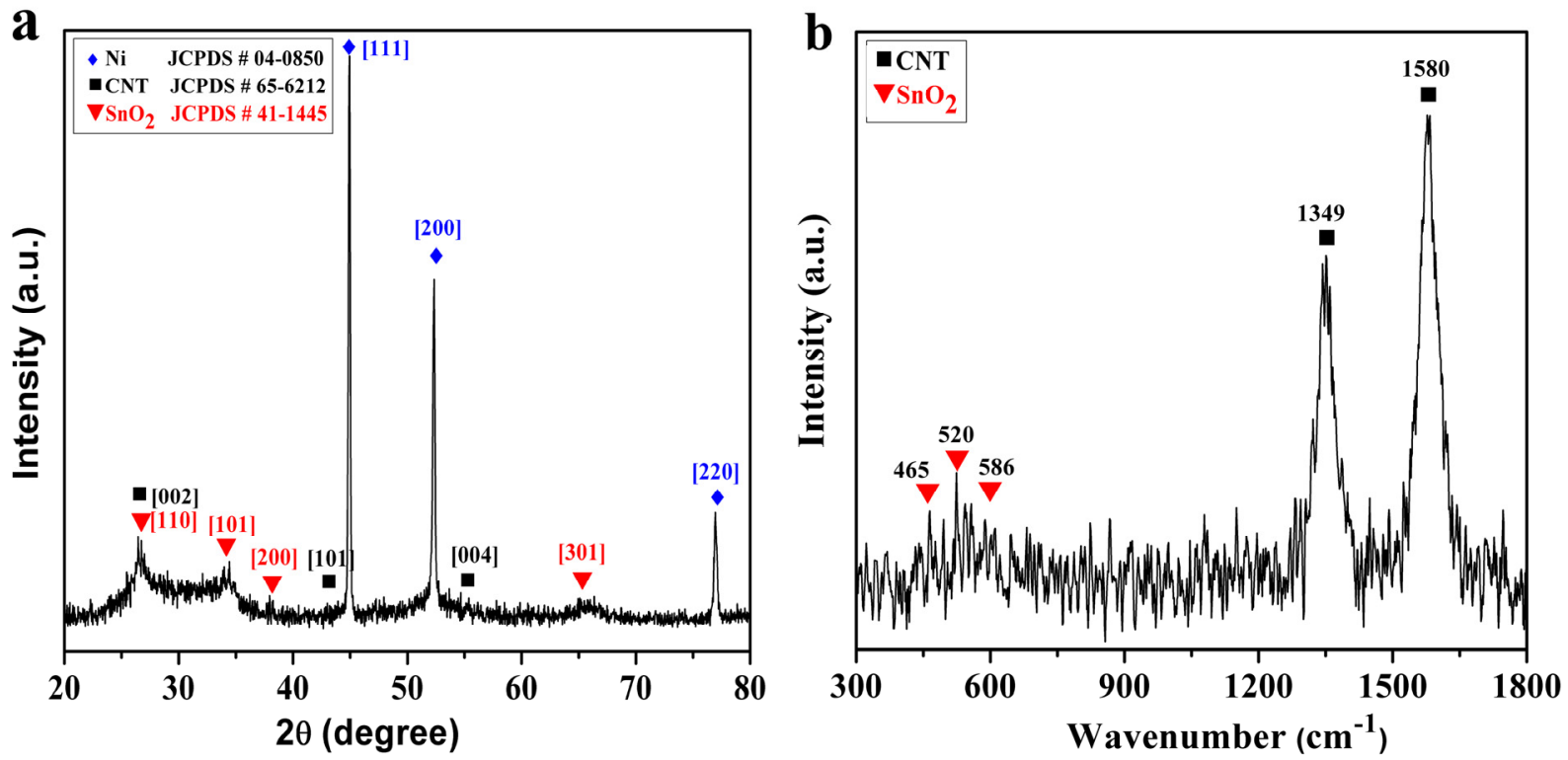

Figure 3.1 (a) X-ray Diffraction pattern, (b) Raman Spectroscopy of as-deposited $\mathrm{SnO}_{2} / 10 \mathrm{CNT}$ on Ni substrate at $200{ }^{\circ} \mathrm{C}$.

As shown in Figure 3.2, SEM images of the as-prepared samples containing $20 \%$ CNT prepared at 200, 250 and $300{ }^{\circ} \mathrm{C}$ exhibit hierarchical porous thin films on the surface of porous $\mathrm{Ni}$ foam substrates (Figures 3.2a, b and c). The deposition temperature has a pronounced effect on the morphologies of the samples. At $200{ }^{\circ} \mathrm{C}$, the morphology shows numerous holes on the thin layer of $\mathrm{SnO}_{2} / \mathrm{CNT}$ film. At 250 and $300{ }^{\circ} \mathrm{C}$, annular rings with 
different diameters are observed. The diameter of the outer rings typically ranges from 10 to $20 \mu \mathrm{m}$ at $250{ }^{\circ} \mathrm{C}$, and around $40 \mu \mathrm{m}$ at $300{ }^{\circ} \mathrm{C}$. Smaller pores, up to few microns in diameter, are observed inside the bigger rings and/or on the walls. The samples with different percentages of CNT have a similar morphology at $250{ }^{\circ} \mathrm{C}$, which shows reticular 3D porous structure (Figure 3.2b, d, e and f).

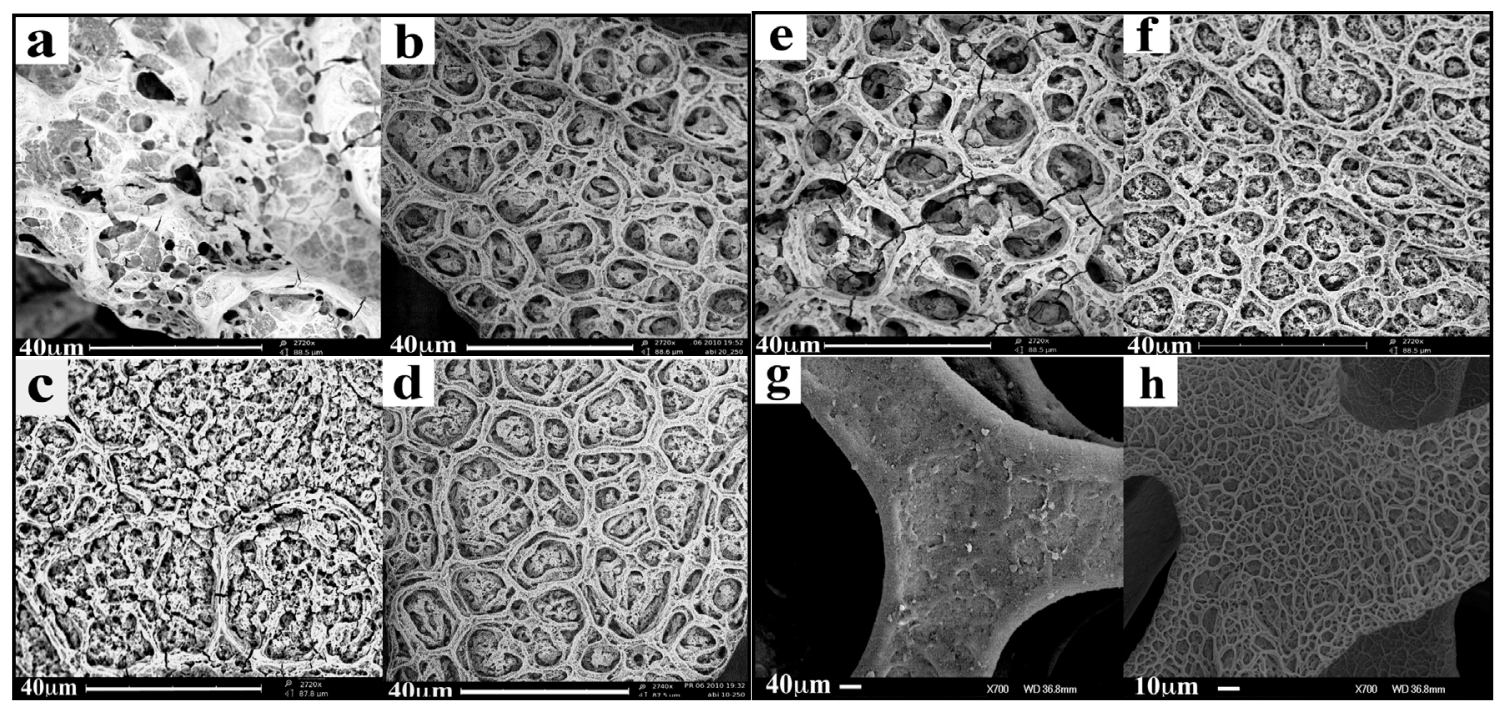

Figure 3.2 SEM images of the as-deposited $\mathrm{SnO}_{2} / 20 \mathrm{CNT}$ samples at (a) $200{ }^{\circ} \mathrm{C}$, (b) $250{ }^{\circ} \mathrm{C}$, (c) 300 ${ }^{\circ} \mathrm{C}$, (d) $\mathrm{SnO}_{2} / 10 \mathrm{CNT}$ samples deposited at $250{ }^{\circ} \mathrm{C}$, (e) $\mathrm{SnO}_{2} / 30 \mathrm{CNT}$ samples deposited at $250{ }^{\circ} \mathrm{C}$, (f) $\mathrm{SnO}_{2} / 40 \mathrm{CNT}$ samples deposited at $250{ }^{\circ} \mathrm{C}$, (g) Pure CNT deposited at $250{ }^{\circ} \mathrm{C}$, and (h) pure $\mathrm{SnO}_{2}$ deposited at $250{ }^{\circ} \mathrm{C}$.

The mechanism for the formation of porous structures can be described as follows [30-32]: As the droplet reaches the tip of the needle, it is charged by the applied electrostatic field. The charged droplet is atomized by the electro-hydrodynamic forces and reaches the grounded substrate by electrostatic force. Since the substrate temperature was always maintained higher than the boiling point of the solvent, there was a temperature gradient 
between the flying droplets and the substrate. Hence, the solvent of the droplets would be partially evaporated on their way to the heated substrate. The degree of the evaporation determines the morphologies of the as-prepared samples. At $200{ }^{\circ} \mathrm{C}$, the solvents were evaporated from the substrate relatively slower than that of $250{ }^{\circ} \mathrm{C}$. This results in a rather dense morphology with holes. Whereas at $300{ }^{\circ} \mathrm{C}$, more solvent was evaporated on the way to the substrate that reduced the thickness of pore walls and porosity. At $250{ }^{\circ} \mathrm{C}$, the sample shows a reticular porous structure due to the moderate evaporation of the solvent. CNT in the composite anodes are seldom seen on the surface in SEM images, since most of them were coated with $\mathrm{SnO}_{2}$. Pure CNT anodes (Figure 2g) showed a very different morphology with matted structures, in contrast to pure $\mathrm{SnO}_{2}$ (Figure 2h) and its composites.

Figure 3.3a shows the distribution of $\mathrm{SnO}_{2}$ on a CNT surface by zero-loss filtered elastic bright field image from TEM. For better visualization, corresponding elemental mapping image is shown in Figure 3.3b. Elemental mapping of carbon (blue) and tin oxide (yellow) was obtained using the characteristic energy losses of the tin $\mathrm{N}$ ionization edge close to $32 \mathrm{ev}$ and carbon $\sigma+\pi$ plasmon close to $24 \mathrm{eV}$. The contrast in this mapping is roughly proportional to $Z^{1.7}$, where $Z$ is the atomic number. Since $\mathrm{SnO}_{2}$ is much heavier than $\mathrm{CNT}$, the regions rich in $\mathrm{SnO}_{2}$ concentration show significant contrast. Although few of the larger $\mathrm{SnO}_{2}$ particles are observed in the TEM image to be detached from the surface of CNTs, most of $\mathrm{SnO}_{2}$ nanoparticles between $4 \sim 10 \mathrm{~nm}$, are distributed along the walls of CNT. This implies that the CNT wall can also anchor $\mathrm{SnO}_{2}$ nanoparticles with narrow distribution of particle size, in addition to microscale $\mathrm{SnO}_{2}$ structures observed from SEM images. Moreover, these CNTs have open ends (shown in Figure 3.3c), which is beneficial during lithium insertion/ desertion because they provide a larger channel space [25]. 


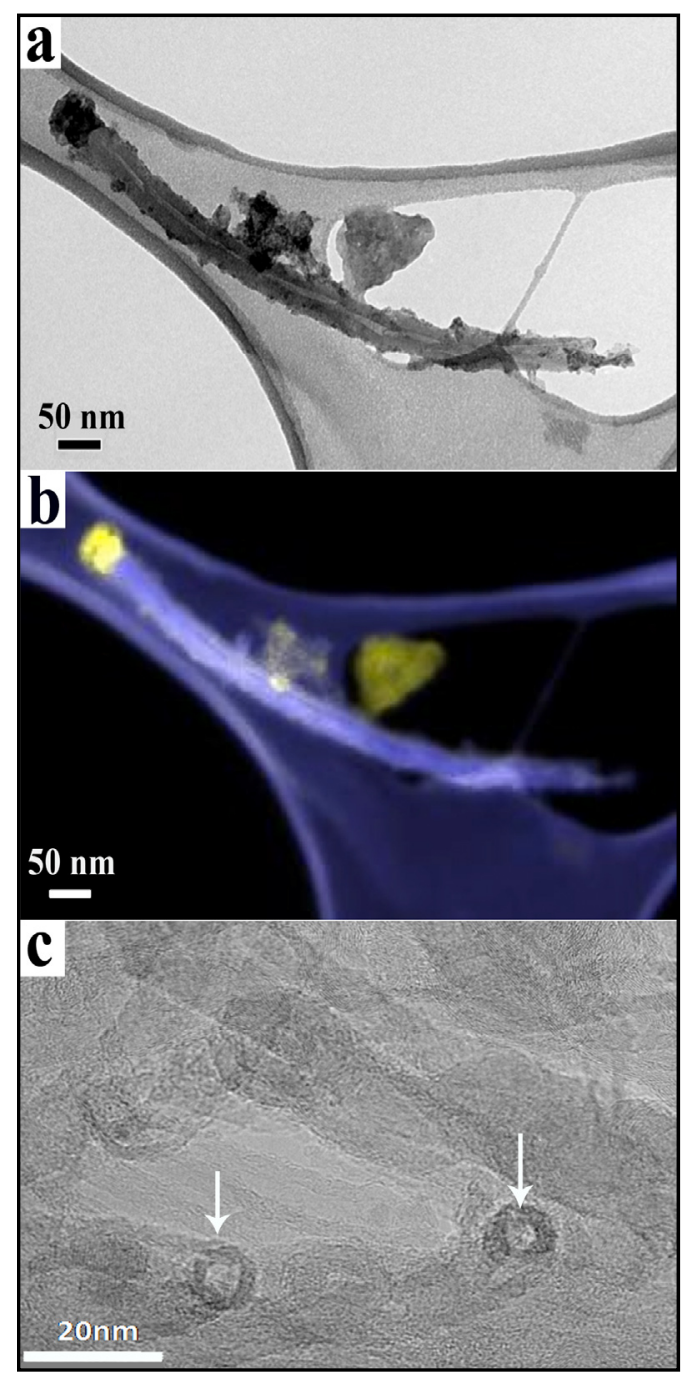

Figure 3.3 (a) Typical TEM image, and (b) elemental mapping of $\mathrm{SnO}_{2} / 30 \mathrm{CNT}$ sample deposited at $250^{\circ} \mathrm{C}$. (c) HRTEM of CNT with arrows indicating open ends.

Charge - discharge profiles of the as-deposited pure CNT, pure tin oxide, and $\mathrm{SnO}_{2} / 30 \mathrm{CNT}$ are shown in Figures $3.4 \mathrm{a}$, b and c. Pure CNT voltage profile reveals the SEI formation between 1.25 0.6 V (shown in Figure 3.4a). The voltage decreases during the discharge process and the lithium insertion/ extraction into the pseudo-graphitic layers of CNT can be found from 0.5 to $0.01 \mathrm{~V}$ [33]. Lithium de-intercalation occurs between 0.3 and 
$1.3 \mathrm{~V}$. The first cycle discharge capacity of pure CNT is $781 \mathrm{mAhg}^{-1}$, whereas it decreased to $256 \mathrm{mAhg}^{-1}$ in the second cycle (Figure $3.4 \mathrm{a}$ ), corresponding to $33 \%$ capacity retention. For pure tin oxide, during discharge, there are two plateaus at $\sim 1.5-0.9 \mathrm{~V}$ and $\sim 0.9-0.4 \mathrm{~V}$, which are related to the reduction of $\mathrm{SnO}_{2}$ to $\mathrm{Sn}{ }^{[39]}$ and $\mathrm{SEI}$ formation [40], respectively. Lithium alloying with Sn takes place at a voltage below $0.5 \mathrm{~V}$ [41] (Figure 3.4b). Plateau at $0.5 \mathrm{~V}$ to $0.7 \mathrm{~V}$ during charge cycle can be related to the reversible reaction of $\mathrm{Li}_{\mathrm{x}} \mathrm{Sn}$ to $\mathrm{Sn}$. Discharge capacity of pure $\mathrm{SnO}_{2}$ in the first and second cycles are 1180 and $473 \mathrm{mAhg}^{-1}$, respectively. This means $40 \%$ of the initial capacity is retained for pure tin oxide (Figure 3.4b). From $\mathrm{SnO}_{2} / \mathrm{CNT}$ profile shown in Figure 3.4c, the plateau $\sim 1.2-0.7 \mathrm{~V}$ indicates SEI formation, and the other one at $0.7 \sim 0.4 \mathrm{~V}$ corresponds to the reduction of tin oxide by lithium and alloying of tin-lithium. The plateau below $0.20 \mathrm{~V}$ indicates the lithium insertion into CNT [42]. During charge, a plateau is observed at above $0.4 \mathrm{~V}$ corresponding to the dealloying of lithium. For the $\mathrm{SnO}_{2} / \mathrm{CNT}$ composite, the initial discharge capacity was 1650 $\mathrm{mAhg}^{-1}$ and second cycle capacity was $787 \mathrm{mAhg}^{-1}$ (Figure 3.4c). Among the voltage profiles of the three samples, $\mathrm{SnO}_{2} / \mathrm{CNT}$ showed a higher capacity retention of $48 \%$ in the second cycle. 


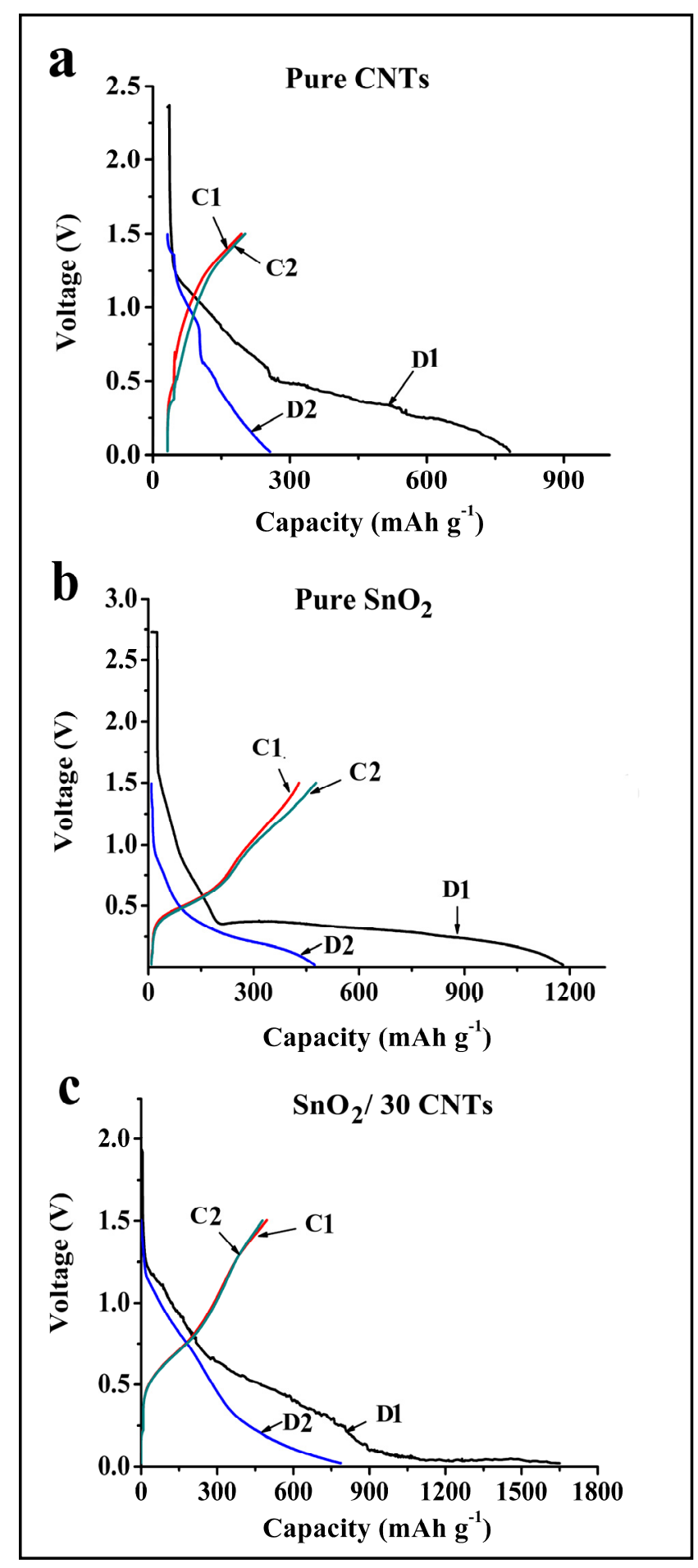

Figure 3.4 First and second cycle charge-discharge profiles of (a) pure $\mathrm{CNT}$ at $250{ }^{\circ} \mathrm{C}$, (b) pure $\mathrm{SnO}_{2}$ at $250{ }^{\circ} \mathrm{C}$, and (c) $\mathrm{SnO}_{2} / 30 \mathrm{CNT}$ at $250{ }^{\circ} \mathrm{C} . \mathrm{D} 1, \mathrm{D} 2$ are the first and second discharge cycles, respectively. $\mathrm{C} 1, \mathrm{C} 2$ are the first and second charge cycles, respectively. 
Figure 3.5a shows the influence of deposition temperature on the performance of the samples. Compared to the samples deposited at 200 and $300{ }^{\circ} \mathrm{C}$, the samples prepared at $250^{\circ} \mathrm{C}$ show the highest capacity. At the end of 50 cycles, samples with 30 wt. $\%$ CNT content showed reversible capacities of 371,473 , and $310 \mathrm{mAhg}^{-1}$ for 200,250 and $300{ }^{\circ} \mathrm{C}$ deposition temperatures, respectively. This can be related to capacity retentions of 31 , 30 ,and 34 wt. \% of the first discharge capacity, respectively. As we know, the deposition temperatures of the samples affect the morphologies of the composite anodes (shown in Figure 3.2). The samples deposited at $250{ }^{\circ} \mathrm{C}$ with the reticular structure showed a high capacity because the reticular structure facilitates easy percolation of the electrolyte into the sample and shortens the lithium diffusion path. The porous structure also acts as a buffer zone to alleviate the stress from volume changes during charge-discharge process.

The influence of CNT content on the performance of the composite anodes is shown in Figure 3.5b. Pure CNT show a capacity of $800 \mathrm{mAhg}^{-1}$ during the first cycle, which greatly reduces to $210 \mathrm{mAhg}^{-1}$ after 50 cycles. Pure $\mathrm{SnO}_{2}$ exhibited a first cycle capacity of $1180 \mathrm{mAhg}^{-1}$, but dropped to less than $300 \mathrm{mAhg}^{-1}$ after 50 cycles due to its poor conductivity. Compared to the pure $\mathrm{SnO}_{2}$, the capacities of $\mathrm{SnO}_{2} / \mathrm{CNT}$ composites increased greatly due to the improved conductivity by the addition of CNT. Moreover, the electrochemical performance is affected by the percentage of CNT content in the composite. When CNT content is 10 wt. \%, the capacity is increased slightly, probably due to little improvement of conductivity of the composites. With the increase of CNT content $(\geq 20 \mathrm{wt}$. \%), samples showed an expected increase in capacity and improved cyclability. 


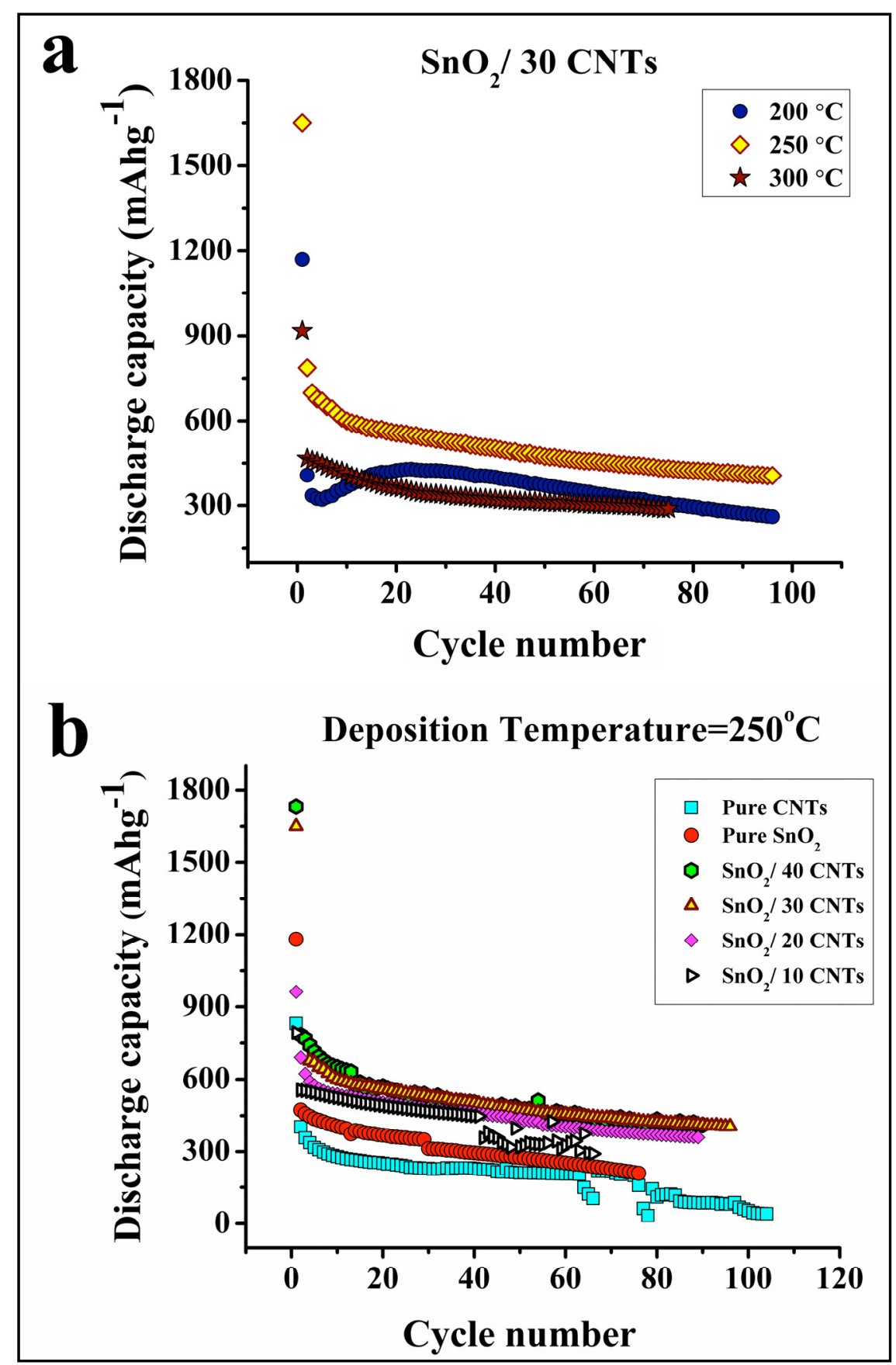

Figure 3.5 Variations in the discharge capacity versus cycle number for (a) different deposition temperatures of $\mathrm{SnO}_{2} / 30 \mathrm{CNT}$ composites, (b) different compositions of $\mathrm{CNT}$ in $\mathrm{SnO}_{2} / \mathrm{CNT}$ composites deposited at $250{ }^{\circ} \mathrm{C}$. The samples were tested at a current density of $0.1 \mathrm{~mA} / \mathrm{cm}^{2}$ between $0.02-1.5 \mathrm{~V}$. 
First cycle discharge capacities of the samples increase with increasing CNT content (shown in Figure 3.5b). Similar trend is observed for the irreversible capacity loss. However, when the CNT content increase to $40 \mathrm{wt} . \%$, the capacity of the composites does not further increase, and is closer to that of $\mathrm{SnO}_{2} / 30 \mathrm{CNT}$. This decrease in capacity with further increase in CNT ratio (from 30 to $40 \mathrm{wt}$ \%) may be due to the relatively decreasing contribution of $\mathrm{SnO}_{2}$ in the composite. After 50 cycles, samples deposited at $250{ }^{\circ} \mathrm{C}$ showed reversible capacities of $319,437,473$, and $473 \mathrm{mAhg}^{-1}$ for $10,20,30$, and 40 wt. $\%$ of CNT, respectively. This corresponds to capacity retentions of $40,45,30$, and 28 wt. $\%$ of the first discharge capacity respectively. These results indicate that the addition of CNT improves the conductivity and cyclability of the anode, as well as contributing to an improved capacity.

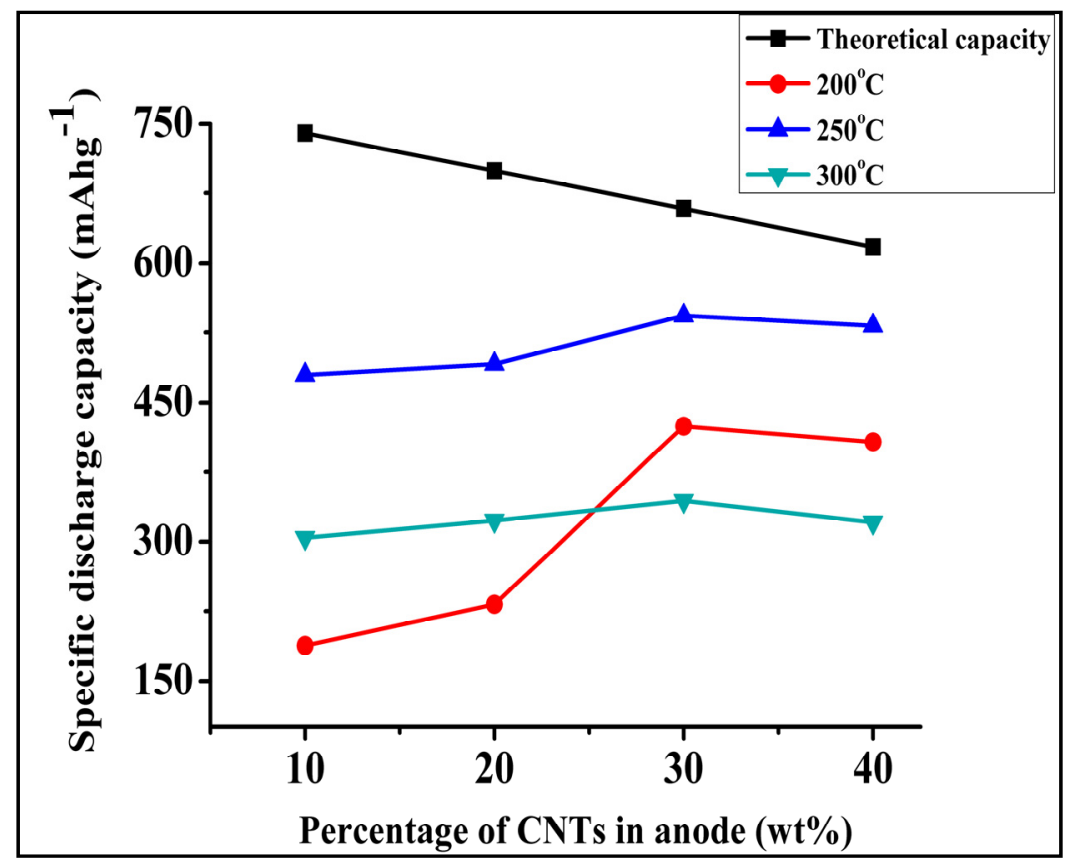

Figure 3.6 Comparison of theoretical and practical discharge capacity for different weight percent of CNT in the composite anodes deposited at 200,250 and $300{ }^{\circ} \mathrm{C}$ after 25 cycles. 
The comprehensive comparison of discharge capacity of the samples with various CNT contents and deposition temperatures at 25th cycle is shown in Figure 3.6. The effect of addition of CNT on the capacity of the samples does not follow the same trend as the calculated theoretical specific capacity of the composites, which is calculated from the theoretical capacity of $\mathrm{SnO}_{2}$ and CNT taking account of the different weight percentages. It is expected that the theoretical capacities of the composites decrease with an increase in CNT content because of lower theoretical capacity of CNT. On the other hand, capacities obtained from experiments gradually increases with increase in CNT content resulting in the capacities of samples with 30 and $40 \%$ CNT being higher than the samples with 10 and 20 $\%$ CNT. This is due to the increasing conductivity of the composite and contribution of CNT towards the capacity. Also, the discharge capacity of the sample with 30 wt. \% CNT is comparatively higher than the rest irrespective of deposition temperature. At the deposition temperature of $250^{\circ} \mathrm{C}$, all samples showed higher capacities than other samples deposited at 200 and $300{ }^{\circ} \mathrm{C}$.

\subsection{Conclusion}

Porous composite thin film electrodes containing tin-oxide and CNT were fabricated using the ESD method. Deposition temperatures and the percentage of CNT were found to affect the performance of the anode. Reticular structure formed at $250{ }^{\circ} \mathrm{C}$ showed good performance. The capacity and cyclability of the anode increased with increasing CNT content (in the range below $40 \mathrm{wt}$ \%). Discharge capacities from all the composite samples after 50 cycles were higher than the typical graphite anode. $30 \mathrm{wt}$ \% CNT content and 250 ${ }^{\circ} \mathrm{C}$ deposition temperature were found to show better performance from this study. 


\subsection{References}

[1] J.M. Tarascon and M. Armand, Nature, 414, 359 (2001).

[2] I.A. Courtney and J.R. Dahn, J. Electrochem. Soc., 144, 2943 (1997).

[3] M. Winter and J. O. Besenhard, Electrochim. Acta, 45, 31 (1999).

[4] S.Bourderau, T. Brousse, and D.M. Schleich, J. Power Sources, 81-82, 233(1999).

[5] C.K. Chan, X.F. Zhang, and Y. Cui, Nano Lett., 8, 307 (2008).

[6] Y. Idota, T.Kubota, A. Matsufuji, Y. Maekawa, and T.Miyasaka, Science, 276, 1395 (1997).

[7] G.X.Wang, Y.Chen, K.Konstantinov, M.Lindsay, H.K. Liu, and S.X.Dou, J. Power Sou rces, 109, 142 (2002).

[8] P.L. Taberna, S. Mitra, P. Poizot, P. Simon, and J.M. Tarascon, Nat. mater. 5, 567 (2006).

[9] I.Rom, M. Wachtler, I. Papst, M. Schmied, J.O. Besenhard, F.Hofer, and M.Winter, Solid State Ionics, 143, 329 (2001).

[10] G.X. Wang, L. Sun, D.H. Bradhurst, S.Zhong, S.X. Dou, and H.K.Liu, J Alloy Compd., 306, 249 (2000).

[11] H.C. Shin and M. Liu., Adv. Funct. Mater., 15, 582 (2005).

[12] S. Yang, P. Y. Zavalij, and M. S. Whittingham, Electrochem. Comm, 5, 587 (2003).

[13] Y. Idota, M. Mishima, M. Miyaki, T. Kubota, and T. Misayaka, Eur. Pat. Appl. 651450 A1 950503.

[14] J. H. Ahn, G. X. Wang, J. Yao, H. K. Liu, and S. X. Dou, J. Power Sources119, 45 (2003).

[15] Y.Yu, L.Gu, A.Dhanabalan, C.H. Chen, and C.Wang, Electrochim. Acta, 54, 7227 (2009).

[16] Y. Yu, C.H. Chen, and Y. Shit, Adv. Mater., 19, 993 (2007).

[17] R. D. Cakan, Y.S. Hu, M. Antonietti, J. Maier, and M.M. Titirici, Chem. Mater., 20, 1227 (2008).

[18] L. Yuan, Z.P. Guo, K. Konstantinov, J.Z. Wang, and H.K. Liu. Electrochim. Acta 51, $3680(2006)$. 
[19] D. Deng and J. Y. Lee. Chem. Mater., 20, 1841 (2008).

[20] Y. Wang, I. Ramos, and J. J. S.Avil'es, Nanotechnology 18, 295601 (2007).

[21] H.C. Shin and M. Liu, Adv. Funct. Mater. 15, 582 (2005).

[22] I. Grigoriants, A. Soffer, G. Salitra, and D. Aurbach, J. Power Sources 146, 185 (2005).

[23] J. Read, D. Foster, J. Wolfenstine, and W. Behl, J. Power Sources 96, 277 (2001).

[24] P. M. Ajayan and O. Z. Zhou, Top. Appl. Phys. 80, 391 (2001).

[25] J. Chen and G. Lu,Nanotechnology 17, 2891(2006).

[26] M.H. Chen, Z.C. Huang, G.T. Wu, G.M. Zhu, J.K. You, and Z.G. Lin: Mater. Res. Bull. 38, 831 (2003).

[27] J. Xie and V.K. Varadan, Mater. Chem. Phys, 91, 274 (2005).

[28] G. An, N. Na, X. Zhang, Z. Miao, S. Miao, K. Ding, and Z. Liu, Nanotechnology, 18, 435707 (2007).

[29] Y. Fu, R. Ma, Y. Shu, Z. Cao, and X. Ma, Mater. Lett., 63, 1946 (2009)

[30] J.L. Shui, Y. Yu, and C.H. Chen, Appl. Surf. Sci., 253, 2379 (2006).

[31] S.C.G. Leeuwenburgh, J.G.C. Wolke, J. Schoonman, and J.A. Jansen, Thin Solid Films 472, 105 (2005).

[32] A. Jaworek and A.T. Sobczyk, J. Electrostat. 66, 197 (2008).

[33] L. K. Zhi, X. Y.Hui, W. X. Lin, and L. G. Hua, J. Wuhan Univ. Technol.19, 21 (2004).

[34] P.C. Eklund, J.M. Holden, and R.A. Jishi, Carbon, 33, 959(1995).

[35] J. Pal and P. Chauhana, Mater. Charact. 60, 1512 (2009).

[36] J.X. Zhou, M.S. Zhang, J.M. Hong, and Z. Yin, Solid State Commun.,138,24 (2006).

[37] J.X. Wang, D.F. Liu, H.J. Yuan, L.J. Ci, Z.P. Zhou, and Y. Gao Solid State Commun., 130,89 (2004).

[38] W. Chen, X. Pan, and X. Bao, J. Am. Chem. Soc.129, 7421 (2007).

[39] J.Y.Kim, I.E. King, P.N. Kumta, and G.E. Blomgren, J. Electrochem. Soc, 147, 4411(2000). 
[40] H. Li, X. J. Huang, and L.Q. Chen, Electrochem. Solid-State Lett., 1, 241 (1998).

[41] I. A. Courtney and J. R. Dahn, J. Electrochem. Soc. 144, 2045 (1997).

[42] Z. Wang, G. Chen, and D. Xia, J. Power Sources, 184, 432(2008). 


\section{INVESTIGATION OF ELECTROCHEMICAL IMPEDANCE SPECTROSCOPY OF TIN OXIDE/CARBON NANOTUBE COMPOSITE ANODES FOR LI-ION} BATTERIES

\subsection{Introduction}

Recently, amorphous tin oxide based anodes for rechargeable lithium batteries have drawn great attention due to their high specific capacity and energy density compared to commercial graphite anode [1]. A two-step reaction mechanism of tin oxides with lithium was proposed and confirmed by considering the results of in-situ x-ray diffraction (XRD), Raman, and high-resolution transmission electron microscope (HRTEM) [2].

$$
\begin{aligned}
& \mathrm{SnO}_{2}+4 \mathrm{Li}+4 \mathrm{e}^{-} \longrightarrow 2 \mathrm{Li}_{2} \mathrm{O}+\mathrm{Sn} \\
& \mathrm{Sn}+\mathrm{xLi}^{+}+\mathrm{xe}^{-} \underset{\mathrm{c}}{\stackrel{\mathrm{d}}{\rightleftarrows}} \mathrm{Li}_{\mathrm{x}} \mathrm{Sn}
\end{aligned}
$$

Lithium first reacts irreversibly with oxide to produce amorphous $\mathrm{Li}_{2} \mathrm{O}$ and $\mathrm{Sn}$, then $\mathrm{Sn}$ alloys with $\mathrm{Li}$ and forms different $\mathrm{Li}-\mathrm{Sn}$ alloys dispersed in a matrix of $\mathrm{Li}_{2} \mathrm{O}$. The first reaction step is known as a replacement reaction, the second step as an alloying/de-alloying reaction. During the early charge-discharge cycles, a surface film (passivation layer) was formed on the surface of the anodes by electrolyte decomposition reaction [3-5]. The formation of surface film usually consumes lithium and contributes to the large irreversible capacity, but, it also helps to maintain the stability of the anode and improve cycle life [5]. Since the charge transfer processes corresponding to lithium alloying/de-alloying in the subsequent cycles occur through the film-covered electrodes, the film characteristics play a significant role in the rate capability and overall performance of the cell. Intensive research 
has been focused on the complex interfacial reactions between electrolyte and electrode that includes the formation and growth of the surface film, the resistance of charge transfer, and the capacitance of double layer [6-10]. Currently, X-ray photoelectron spectroscopy (XPS) [11], scanning electron microscopy (SEM), transmission electron microscopy (TEM) [12], cyclic voltammetry (CV) [13-15], Fourier transform infrared microscopy (FTIR) [16], and electrochemical impedance spectroscopy (EIS) [17,18] are commonly used for investigating the morphology, composition $\&$ growth of surface film, resistance, aging effect $\&$ stability of the anode material, kinetics of lithium ion diffusion and the order in which the reactions proceed. For example, from FTIR analysis, it was found that the composition of pthe assivation layer on the $\mathrm{SnO}_{2}$ anode varied with discharge potential and stabilized gradually with cycling [19]. Using in-situ AFM studies, I.T. Lucas et al. reported that the initial surface layer formation were observed at $2.5 \mathrm{~V}$ vs. $\mathrm{Li} / \mathrm{Li}^{+}$, but this was followed by a gradual change in film morphology at potentials between 2.5 to $0.7 \mathrm{~V}$ and the layer tended to undergo continuous reformation during the following cycles [20]. Dahn et al. studied the nano-SnO particles before and after discharge using HRTEM. After discharge, it was noted that a perfect shell structure with $30-40 \mathrm{~A}$ was formed which prevented electron tunneling and protected the electrolyte from further reduction [21]. In this study, (EIS) technique was used. EIS is a non-destructive technique and a powerful tool for the study of electrochemical systems unlike XPS, SEM, and TEM, which are destructive techniques and are not easy to adopt for sealed cells. EIS has a high time resolution (up to $10^{-5} \mathrm{~s}$ ) that can be used for the study of the electrochemical processes. The cell impedance is measured in the form of real and imaginary components and phase angle, which are used to examine and qualitatively determine several processes such as the electronic/ionic conduction in the electrode and 
electrolytes, interfacial charging either at the surface films or the double-layer, charge transfer processes and the mass transfer effects, if any. The analysis of impedance data requires the development of sufficiently precise mathematical models. The model describing the electrochemical system has to satisfy the physicochemical equations for the reaction rate, for the accumulation of species (charged and neutral), and for the geometry of the system. Electrochemical impedance spectroscopy of various anodes materials such as $\mathrm{SnO}_{2}$ anodes $[4,9]$ and carbon nanotubes $[22,23]$ were studied before. For instance, in $\mathrm{SnO}_{2}-\mathrm{C}$ composite, it was observed that the impedance of the surface film decreased as the content of tin-oxide was increased, which resulted in a higher capacity [24]. Yun et al. carried out the impedance measurements of tin oxide thin film electrodes and suggested that the alloying reaction between lithium and metallic tin involved a decreasing trend in the chargetransfer resistance down to a certain critical state of charge $(<0.2 \mathrm{~V})$, beyond which the resistance increased again $(<0.1 \mathrm{~V})[25]$. Studies of CNT show that the diffusion of lithiumions into the opened CNT is faster than into closed CNT [26]. The open tubes have larger double layer capacitance values than closed tubes. Reason being, the hollow of the tubes take part in the formation of the electrical double layer. Diffusion coefficients for the open CNT were larger than those for the closed CNT [23]. So far, to the best of our knowledge, there is no report available for the impedance study of $\mathrm{SnO}_{2} / \mathrm{CNT}$ composite anodes. Previously, we fabricated and studied the electrochemical performance of $\mathrm{SnO}_{2} / \mathrm{CNT}$ composite anodes [27]. We demonstrated that the addition of CNT to pure tin oxide improved the cyclability and the efficiency of the anode materials due to the synergistic effect of $\mathrm{SnO}_{2}$ and $\mathrm{CNT}$. Among the various compositions used, we found that composites with $30 \%$ and $40 \%$ CNT contents demonstrated better electrochemical performance. 
However, the underlying mechanism of contribution of CNT to the stability of the anodes was not investigated in our previous study. In this work, we investigated the changes in the resistances of $\mathrm{SnO}_{2} / \mathrm{CNT}$ anodes at different depths of charge/discharge upon cycling. This will help us to understand the effect of the formation of surface film on the stability of the anodes with respect to CNT content in the composite.

\subsection{Experimental method}

Tin oxide/CNT composite electrodes were synthesized using electrostatic spray deposition technique (ESD) on a nickel foam substrate [11]. Tin (IV) acetate (Alfa aesar) was dissolved in 1, 2 propane diol and ethanol ( $3: 1 \mathrm{v} / \mathrm{v})$ using an ultrasonicator. $\mathrm{X} w \mathrm{t} \%$ of $\mathrm{CNT}(\mathrm{x}=10,20$, 30, 40) was then added and dispersed using the high power sonicator for about 7 minutes. This solution was used as a precursor to deposit tin oxide/CNT composite electrodes using electrostatic spray deposition technique (ESD) on a nickel foam substrate at $250{ }^{\circ} \mathrm{C}$ [27]. Control samples of pure tin oxide and pure CNT were deposited using a similar procedure without adding CNT and tin oxide, respectively. The battery test cells (2032 coin cells) were assembled using as-prepared tin oxide/CNT as the working electrode and lithium as the reference and counter electrode. $1.1 \mathrm{M}$ lithium bis(perfluoroethylsulfonyl) imide/EC:DMC:DEC (1:1:1 w/w) was used as the electrolyte. All the cells were assembled in an argon-filled glove box (Nexus I, Vac atm) with less than 1 ppm of oxygen and moisture. Electrochemical impedance spectroscopy investigation and charge-discharge cycling were carried out using a biologic versatile multichannel potentiostat. Cycling tests were performed at $0.100 \mathrm{~mA}$ between $0.02-1.5 \mathrm{~V}$. Electrochemical impedance of the cell was carried out over a frequency range of $100 \mathrm{kHz}$ to $1 \mathrm{mHz}$ with an initial delay of $30 \mathrm{sec}$. A sinusoidal perturbation with peak-to-peak amplitude of $10 \mathrm{mV}$ was applied. Impedance was 
measured at the open circuit potential and also at $1.3 \mathrm{~V}, 0.6 \mathrm{~V}, 0.3 \mathrm{~V}$ and $0.02 \mathrm{~V}$. The cell was given a rest time of 10 minutes at each voltage. Measurement of each spectrum takes about $\sim 22$ min without the rest time. Three spectra measurements were taken at each voltage. Three samples were tested for a particular CNT content and also for control samples. Equivalent circuits were fitted using Z-fit software with a $\chi^{2}$ value of $10^{-4}$. After 50 cycles the sealed cell was disassembled inside the glove box. The anode was washed with dimethyl carbonate (DMC) thoroughly and then dried. Morphologies of the as-prepared samples before and after cycling were studied using JEOL JSM-6330F field emission scanning electron microscope (FESEM).

\subsection{Results and Discussion}

The plateaus in the voltage profiles indicate the electrochemical reaction that takes place in the cell as evident from the charge-discharge profiles of pure tin oxide, pure CNTs and tin oxide/ $30 \%$ CNTs composite in the $1^{\text {st }}, 2^{\text {nd }}$ and $20^{\text {th }}$ cycles shown in Figure 4.1. From these curves, it is clear that there is a large irreversible capacity loss during the first two cycles but the loss in capacity is less between the $2^{\text {nd }}$ and $20^{\text {th }}$ cycles. For pure tin oxide, surface film layer formation occurs above $1.0 \mathrm{~V}$ and reduction of $\mathrm{SnO}_{2}$ to $\mathrm{Sn}$, as well as lithium alloying with Sn takes place at voltage below 1.0V in the first cycle [28] (Figure 4.1a). 

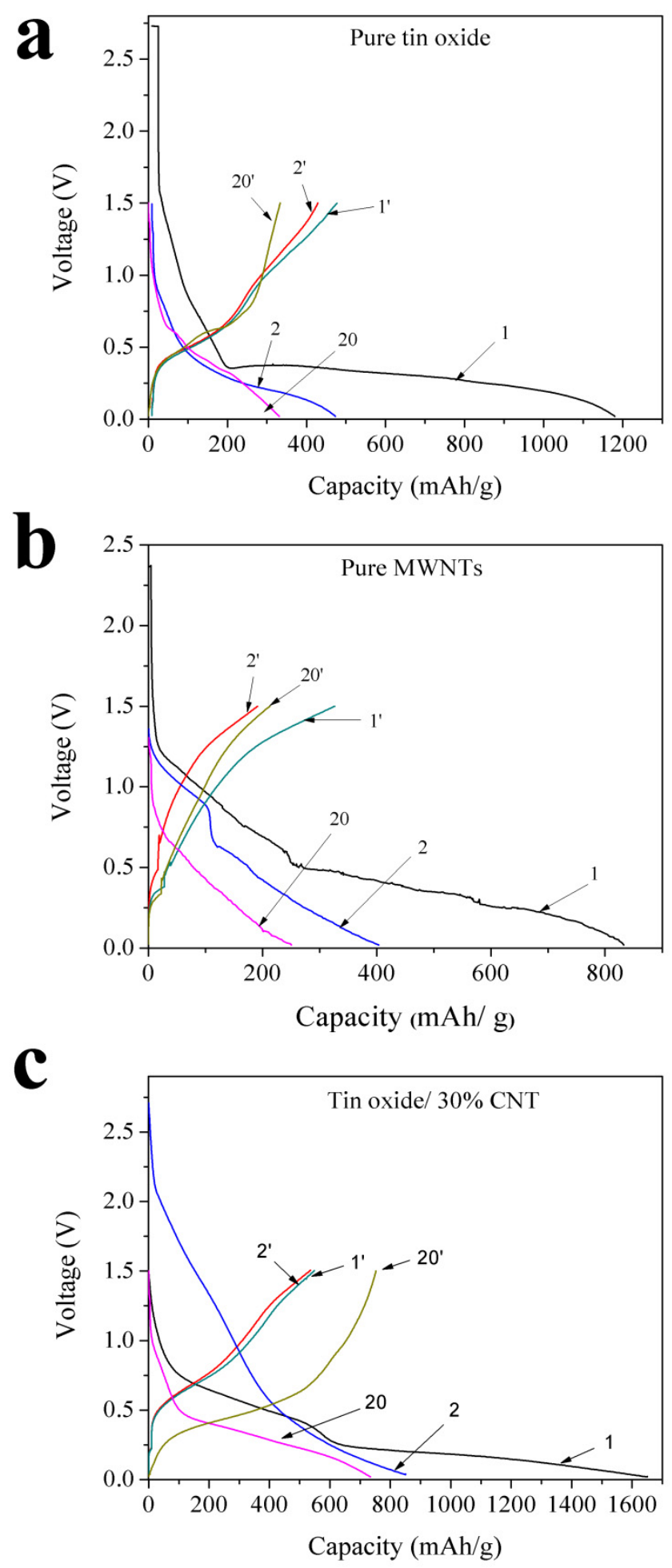

Figure 4.1 Charge-discharge profiles of a) Pure tin oxide, b) pure CNT, and c) tin oxide/30\% CNT. 
The plateau above $1.0 \mathrm{~V}$ was reduced significantly during second cycle and could not be distinguished after 20 cycles. The voltage profile of pure CNT during the first cycle reveals the surface layer formation between $1.25 \sim 0.6 \mathrm{~V}$ (shown in Figure 4.1b). The voltage decreases during the discharge process and the lithium insertion into the pseudo-graphitic layers of CNT can be found from 0.5 to $0.02 \mathrm{~V}$ during the first cycle. [22]. The discharge plateau for tin oxide/ 30\% CNT composite at first cycle (Figure 4.1c) indicates the surface film formation at $\sim 1.2-0.7 \mathrm{~V}$, and $0.7 \sim 0.4 \mathrm{~V}$ corresponds to the reduction of tin oxide by lithium and the alloying of tin-lithium [29]. The plateau below $0.20 \mathrm{~V}$ indicates the lithium insertion into CNT [26]. Plateau corresponding to the lithium alloying can be seen after 20 cycles whereas the plateau at $\sim 1.2-0.7 \mathrm{~V}$ is not prominent after the first cycle indicating the surface film formation occurs predominantly during first cycle.

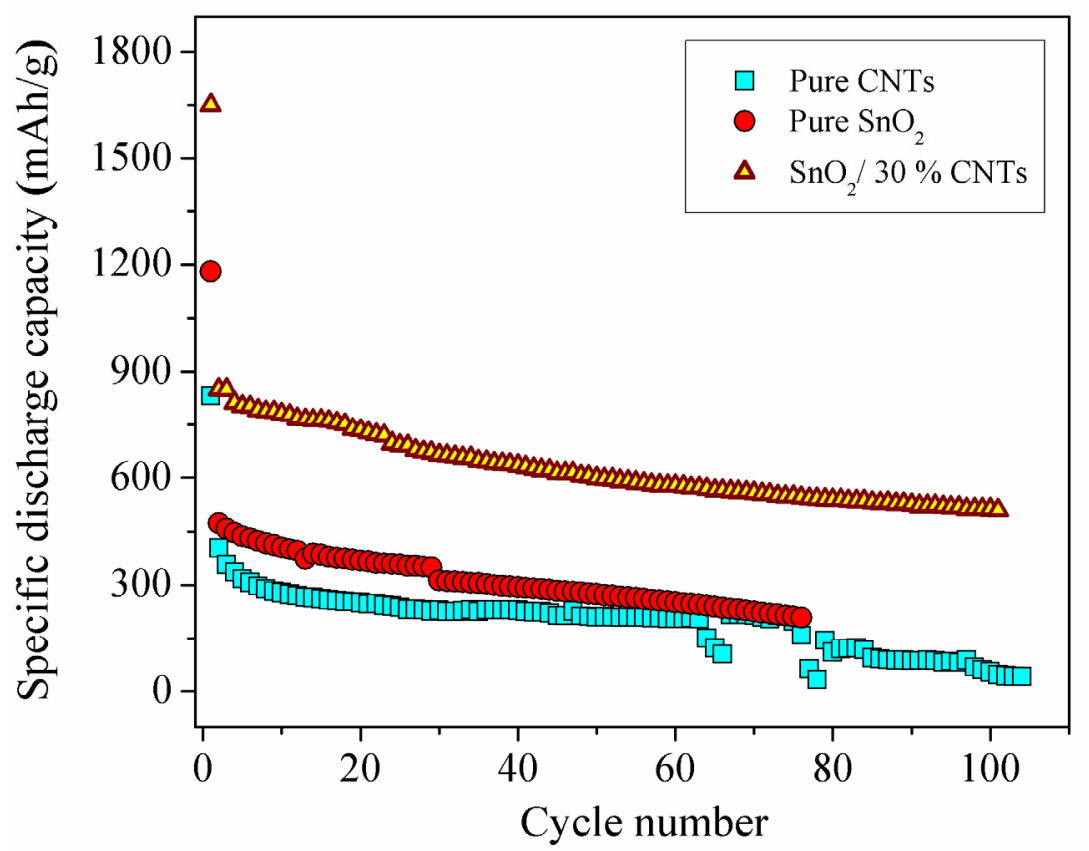

Figure 4.2 Cycle performances of pure tin oxide, pure CNT, and tin oxide $/ 30 \% \mathrm{CNT}$. 
The capacity, capacity retention, and cycle performance can be studied from the galvanostatic potential cycling. Figure 4.2 compares the difference in cycling performance for pure CNT, pure tin oxide and tin oxide/ $30 \% \mathrm{CNT}$. Clearly, the cycle performance of the tin oxide/ CNT composite is better compared to pure CNT and pure tin oxide. The composite anode shows a stable capacity with capacity retention of $86 \%$ after 20 cycles (compared to second cycle capacity) whereas it is $62 \%$ and $77 \%$ for pure CNT and pure tin oxide, respectively. It is well accepted that during charge/discharge process, the large volume change of $\mathrm{SnO}_{2}$ anode results in poor cycling performance [4]. Figure 4.3 shows the SEM images of the tin oxide $/ 30 \%$ CNTs composite before and after cycling. The morphology of the samples showed annular rings with different diameters. The diameter of the outer rings typically ranges from several microns to $30 \mu \mathrm{m}$ and smaller pores up to few microns in diameter are observed inside these bigger rings and on their walls. After 50 cycles, the samples retained this morphology with no flaking, or peeling of the anode material except for the presence of few cracks. The similar morphologies before and after cycles indicate that our composites can buffer the large volume change very effectively, which is promising for creating a stable $\mathrm{SnO}_{2}$ based anode.
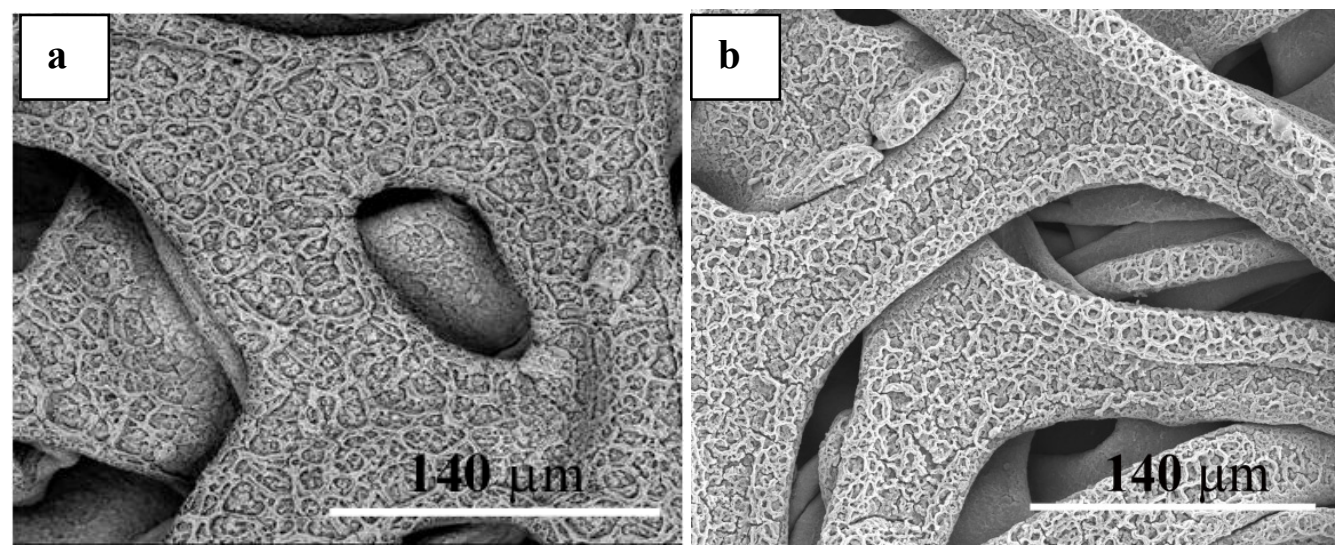

Figure 4.3 SEM images of Tin oxide/30\% CNT a) before cycling and, b) after cycling for 50 cycles. 
In this research, the impedance measurements were carried out at $1.3,0.6,0.3$, and $0.02 \mathrm{~V}$ to study the resistance of the film at different discharge depths upon cycling. The voltages were selected based on the voltage plateaus in the charge-discharge profiles (Figure 4.1). The resultant impedance spectra at these voltages can reveal the intrinsic property of the corresponding reactions at those voltages. Impedance is also tested at the same voltages mentioned above for different cycles to study the stability of the surface film formed on the anode. During lithiation and delithiation cycling, however, contributions of the lithium electrode to the EIS are believed to be invariant due to the instant stripping and plating of lithium [30], hence the surface of lithium remains constantly fresh. Since we can ignore the contribution of lithium to the EIS spectra, any change in the EIS during the cycling process could be considered as the contribution of the anode [30]. In Figure 4.4, the experimental data (indicated by dots) and simulated data (indicated by line) for tin oxide/ 30\% CNT composite is shown for different voltages and at different cycles. The impedance spectra observed consists of a semicircle at the high frequency end. Information regarding solution, surface film resistances can be obtained from the semicircle at the high frequency end. The depressed nature of the semicircle can be attributed to the merging of the two different semicircles. One is due to the surface film and the other, is from the charge-transfer process. At the low frequency end, there is an arc, which is similar to an arc instead of a straight-line. Previous studies suggested that this could be due to the phase transformation and Warburg impedance [18]. The experimental data was fitted using an equivalent circuit as shown in the insets in figure 4.4. $R_{s}, R_{1}$ are solution and surface resistances, respectively. $R_{2}$ is the resistance due to phase transformation. $\mathrm{Q}_{1}$ and $\mathrm{Q}_{2}$ are the capacitance of surface film and phase formation. $\mathrm{W}$ is Warburg impedance due to diffusion. At open circuit voltage, the 
anode behaves like a blocking electrode. During the first cycle in figure $4.4 \mathrm{a}$, the diameter of the semi-circle increases slightly as the anode is discharged until $0.3 \mathrm{~V}$ and then decreases slightly at $0.02 \mathrm{~V}$. The increase in the diameter of the semi-circle till $0.3 \mathrm{~V}$ can be ascribed to the change in Li-Sn phase [25]. The variation in the diameter of the semicircle can be clearly noticed during the second cycle in figure $4 \mathrm{~b}$. This could be attributed to the change in resistance of the anode during the lithiation due to the formation of more Li-Sn alloys and lithium intercalation into CNT. The volume changes during this alloy formation can also affect the electrical properties of the anode. The clear separation of the two semicircles at $0.6 \mathrm{~V}$ after 20 cycles of cycling in figure $4.4 \mathrm{c}$ indicates the formation of two different phase regions. However, this disappears at $0.3 \mathrm{~V}$ with more lithiation. $\mathrm{R}_{\mathrm{s}}$ values are in the range of $\sim 4-8$ ohms, $R_{2}$ varies between $\sim 30-250$ ohms and $R_{3}$ in the order of $10^{3}$ ohms. The values of $\mathrm{Q}_{1}$ and $\mathrm{Q}_{2}$ are in $\mathrm{mF}$ and $\mu \mathrm{F}$. The relation between $\sigma$ and $\mathrm{W}$ is given by $\mathrm{W}=\frac{\sqrt{2} \sigma}{\sqrt{i 2 \pi} \sqrt{f}}$, where $\sigma$ is the warburg coefficient and $f$ is the frequency. The $R_{1}$ values increased during discharge from $1.3 \mathrm{~V}$ to $0.3 \mathrm{~V}$ because of the formation of different phases of Li-Sn alloys. 

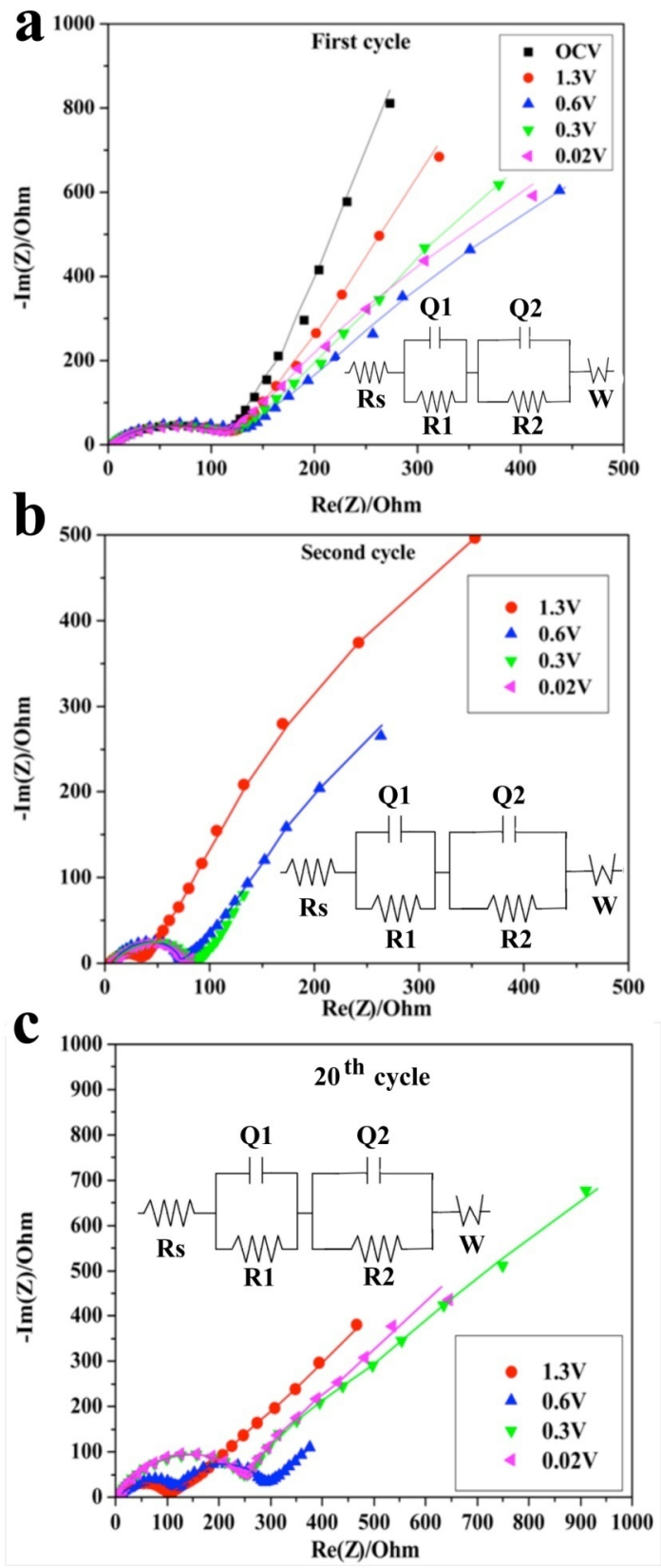

Figure 4.4 EIS data and simulation results for tin oxide/30\% CNT at different voltages during a) $1^{\text {st }}$ cycle, b) $2^{\text {nd }}$ cycle and c) $20^{\text {th }}$ cycle. Lines indicate the simulation data and dots indicate the EIS experimental data. Inset: Equivalent circuit used to fit impedance data. Rs, R1 are solution resistance and surface resistance, respectively. R2 is the resistance due to phase transformation. Q1 and Q2 are the capacitance of surface film and phase formation. $\mathrm{W}$ is Warburg impedance due to diffusion. 
In figure $4.5 \mathrm{a}$, changes in the resistance of the surface layers formed on composites with different CNT content at different cycles are shown. The surface resistance is proportional to the redox reactions at the surface. It is clear that the surface film resistances $\mathrm{R}_{1}$ of the composite anodes with different CNT contents are lower than the pure $\mathrm{SnO}_{2}$ and pure CNT. $\mathrm{R}_{1}$ decreases initially, but increases with cycling. This may be due to the increase in the charge-transfer resistance across the surface film, possibly caused by the thickening of the surface film [31]. A thicker surface layer usually helps to increase the stability of the anode, but also increases the resistance. The change in the resistance $R_{1}$ upon cycling is relatively lower for the composite anodes and pure CNT anodes than the pure $\mathrm{SnO}_{2}$. This is due to the addition of CNT. As the CNT content in the composites is increased, change in $\mathrm{R}_{1}$ upon cycling decreases. Hence, the composites with $30 \%$ and $40 \% \mathrm{CNT}$ contents are more stable during cycling. The underlying processes for $\mathrm{R}_{2}$ and $\mathrm{Q}_{2}$ need to be studied carefully at low frequencies [10]. The $\mathrm{R}_{2}$ value obtained through fitting is very high, and therefore, was not considered in this study. Figure $4.5 \mathrm{~b}$ shows the change in the capacitance of surface film. $\mathrm{Q}_{1}$, in general, is proportional to the surface area and permittivity of the electrode material and inversely proportional to the thickness of the electrical double layer. The surface film capacitance of the composites with $30 \%$ and $40 \%$ CNT is very low compared to the rest of the anodes in this study. The reason for this is unclear. The values for $\mathrm{Q}_{1}$ are similar to the values reported for $\mathrm{SnO}$ anodes [32] From our previous study, composites with $30 \%$ and $40 \%$ CNT showed higher capacity and a more stable cycling performance [11]. This indicates that the composites with 30-40\% CNT content can perform particularly well. 

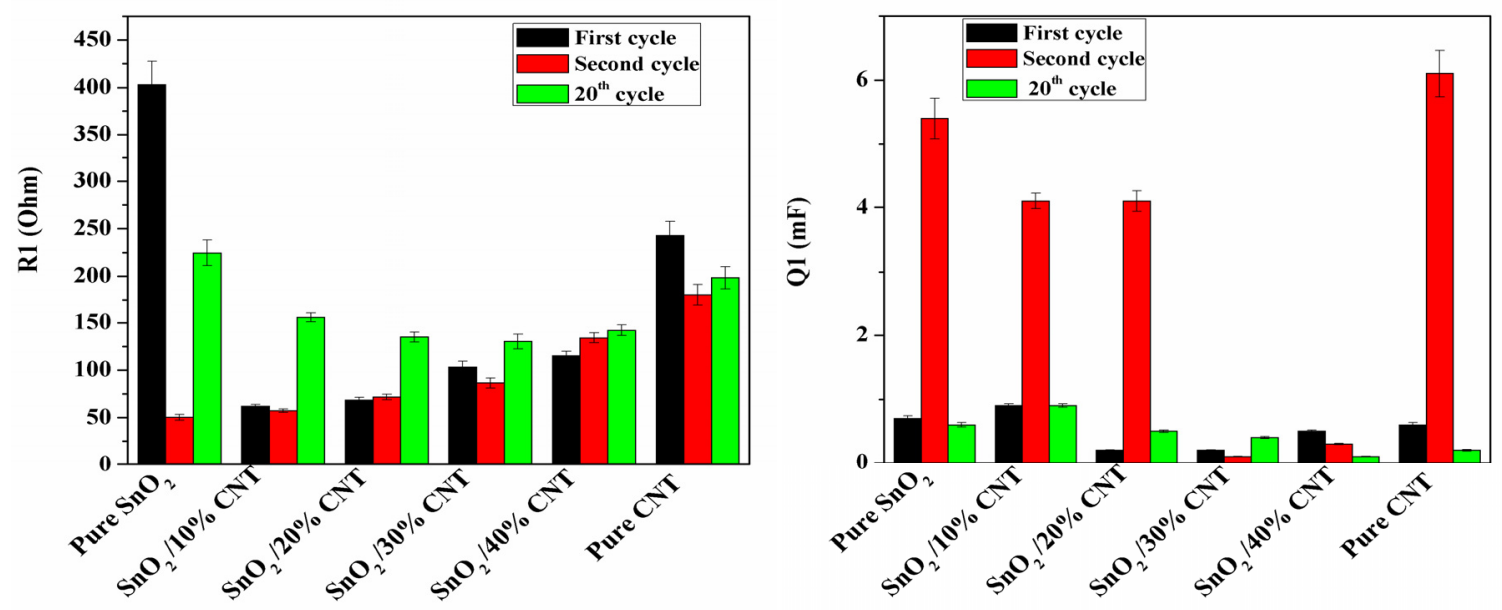

Figure 4.5 a) Change in R1 with \%CNT in the composite and cycling. b) Change in Q1 with \%CNT in the composite and cycling.

\subsection{Conclusion}

EIS investigations were carried out to study the surface film resistance of $\mathrm{SnO}_{2} / \mathrm{CNT}$ composite anodes. The high frequency semicircle corresponds to the surface film resistance and the capacitance while the low frequency end corresponds to the phase transformation and diffusion. Equivalent circuits were proposed and the values of the components were obtained. It is clear that the change in surface film resistance on the composite during cycling was lower than that of the pure $\mathrm{SnO}_{2}$. This can be attributed to the addition of CNT. The higher the CNT content in the composite, the lower the change in surface film resistance at certain voltage upon cycling. The surface resistance increased with the depth of discharge and decreased slightly at the fully lithiated state. Further studies on the low frequency large diameter part semicircle are needed to understand the evolution of the phase transformation resistance. 


\subsection{References}

[1] Y. Idota, T. Kubota, A. Matsufuji, Y. Maekawa, and T. Miyasaka, Science, 276, 1395 (1997).

[2] I.A. Courtney and J.R. Dahn, J. Electrochem. Soc. 144, 2045 (1997).

[3] H. Li, X. J. Huang, and L.Q. Chen, Electrochem. Solid-state Lett., 1, 241(1998)

[4] H.Li, X.J. Huang, and L. Q. Chen, J. Power Source, 81-82,340 (1999).

[5] S.S. Zhang, K. Xu, and T.R. Jow, Electrochim. Acta 51, 1636 (2006).

[6] T. Brousse, R. Retoux, U. Herterich, and D.M. Schleich, J. Electrochem. Soc., 145, 1(1998).

[7] H. Zheng, K. Jiang, T. Abe, and Z. Ogumi, Carbon, 44(2), 203(2006).

[8] A. C. Bose, D. Kalpana, P. Thangadurai, and S. Ramasamya, J. Power Sources, 107, 138(2002).

[9] D. Aurbach, A.Nimberger, B. Markovsky, E. Levi, E. Sominski, and A. Gedanken, Chem. Mater., 14, 4155 (2002).

[10] M. Mohamedi, Seo-Jae Lee, D. Takahashi, M. Nishizawa, T. Itoh, and I. Uchida, Electrochim. Acta , 46 (8), 1161 (2002).

[11] S. Leroy, H. Martinez, R. Dedryve're, D. Lemordant, and D. Gonbeau, Appl. Surf. Sci., 253, 4895 (2002).

[12] A. Naji, J. Ghanbaja, P. Willmann, and D. Billaud, J. Power Sources, 207, 81 (1999).

[13] Y.N. Li, J. Yang, and Z. Jiang, J. Phys. Chem. Solids, 67, 882 (2001).

[14] L. Fransson, T. Eriksson, K. Edstrom, T. Gustafsson, and J.O. Thomas, J. Power Sources, 101, 1. (2001)

[15] H. Lee, S. Choi, S. Choi, H.J. Kim,Y. Choi, S.Yoon, and J.J. Cho, Electrochem.Commun., 9, 801 (2007).

[16] J.Li, H.Li, Z.Wang, L.Chen, and X.Huang, J.Power sources 107, 1(2002).

[17] H. Schranzhofer, J. Bugajski, H.J. Santner, C. Korepp, K.C. Moller, J.O. Besenhard, M. Winter, and W. Sitte, J. Power Sources, 153, 391 (2006).

[18] M. Stromme, J. Isidorsson, G. A. Niklasson, and C. G. Granqvist, J. Appl. Phys., 80 (1), 233 (1996). 
[19] H. Feng, Z. Yunhong, Z. Hui, and L. Xiangzhong, J.Wuhan University of TechnologyMater. Sci. Ed. (2008)

[20] I. T. Lucas, E.Pollak, and R. Kostecki, Electrochem. Commun., 11, 2157(2009).

[21] C Branci, N Benjelloun, J Sarradin, and M Ribes, Solid State Ionics , 135(1-4), 169 (2000)

[22] K.Z. Lin, Y .H. Xui, and X .L. Wang, J. Wuhan University of Technology-Mater. Sci.Ed., 19,21 (2006).

[23] N.A. Kaskhedikar and J. Maier, Adv. Mater., 21, 2664 (2000).

[24] J.Y. Kim, I.E. King, P.N. Kumta, and G.E. Blomgren, J. Electrochem. Soc. 147, 4411 (2000).

[25] S. C. Nam, Y. H. Kim,W. I. Cho, B. W. Cho, H. S. Chun, and K. S. Yun, Electrochem and Solid-State Letters , 2 ,9 (1999).

[26] D. Sheng Su and R. Schlçgl, ChemSusChem, 3, 136,(2010).

[27] A. Dhanabalan, Y. Yu, X.Li, W.Chen, K. Bechtold, L. Gu, and C. Wang, J. Mater. res., 25, 1554 (2010).

[28] Y.Yu, L.Gu, A.Dhanabalan, C.H. Chen, and C.Wang, Electrochim. Acta 54,7227 (2009).

[29] Z. Wang, G. Chen, and D. Xia, J. Power Sources, 184, 432 (2008).

[30] N. Munichandraiah, L.G. Scanlon, and R.A. Marsh, J. Power Sources, 72, 203 (1998).

[31] P.B.Balbuena and Y.Wang, Imperial College press, (2004)

[32] H. Li, X. Huang, and L. Chen, J.Power Sources 81-82. 340 (1999). 


\section{FABRICATION AND CHARACTERIZATION OF TIN OXIDE/GRAPHENE COMPOSITE ANODES}

\subsection{Introduction}

To meet the high energy density requirements for modern communication and transportation systems, many research attempts have been made to improve the performance of LIBs using new electrode materials and/or novel nano structures [1-4]. Due to their high theoretical specific capacity, amorphous tin oxides have been reported as a good candidate for rechargeable LIB anodes $[1,5]$. It was proposed that tin oxide reacts with lithium and forms Sn and lithium oxide in the first step of the reaction $[6,7]$. Lithium oxide formed during this reaction acts as a buffer matrix during the formation of Li-Sn alloys in the second step of the reaction. Lithium is consumed in the first step, which is in general an irreversible reaction and hence results in the loss of lithium. There is also the disadvantage of large volume expansion and aggregation of the particles during cycling which results in the pulverization of the electrodes and loss of electrical contact. Different methods have been proposed to improve the performance of the tin oxide anodes such as the use of nanomaterials $[8,9]$, alloys $[10,11]$, composites $[12,13]$, etc. Composites with nanomaterials have been found to improve the performance of the electrodes [14, 15]. For example, addition of graphene may help improve the conductivity and hence result in better performance. Graphene has a high surface area, which increase the electrode/electrolyte contact area and thereby improving the charge-transfer kinetics. Graphene may buffer the volume change during cycling by acting as an inactive matrix when Sn alloys with Li. Graphene has been investigated as an anode material for LIBs and exhibited large reversible specific capacity [16-20]. There are some reports of tin oxide/graphene composites in the literature [21-25]. Various methods have 
been used to fabricate these composites- self-assembly [21], in-situ chemical synthesis [22], hydrolysis [23], reduction [24] etc. Guoxiu Wang et al. reported a capacity of $520 \mathrm{mAh} / \mathrm{g}$ after 100 cycles tested in the range of $0.01-3.0 \mathrm{~V}$ for $\mathrm{SnO}_{2} / 40 \%$ graphene composite prepared by in-situ chemical synthesis [22]. Ilhan A.Aksay et al. fabricated $\mathrm{SnO}_{2} / 40 \%$ graphene composite using ternary self-assembly method. They reported a capacity of 625 $\mathrm{mAh} / \mathrm{g}$ after 100 cycles when tested between $0.02-1.5 \mathrm{~V}$ [21]. For $\mathrm{SnO}_{2} / 34 \%$ graphene and $\mathrm{SnO}_{2} / 36 \%$ graphene prepared via chemical method and hydrolysis respectively, the capacities obtained were $634 \& 513 \mathrm{mAh} / \mathrm{g}$ after 50 and 10 cycles, respectively. The voltage windows used to test were $0.001-3.0 \mathrm{~V}$ and $0.05-3.0 \mathrm{~V}$ for $\mathrm{SnO}_{2} / 34 \%$ graphene and $\mathrm{SnO}_{2} / 36 \%$ graphene, respectively $[23,25]$. The difference in the electrochemical performance for similar composition of the composites reported separately could be attributed to many factors such as synthesis method, voltage window, morphologies, etc. For instance, electrostatic spray deposition technique [ESD] was successfully employed to fabricate anodes with better electrochemical performance. Using this method, the fabrication of the electrodes is simplified by directly depositing the composite on the current collector. Samples can be tested without the addition of a binder unlike a conventional electrode fabrication technique. Morphology of the samples can be controlled by controlling the experimental parameters such as deposition temperature, precursor solution, flow rate, voltage, etc. In this work, we investigated tin oxide/graphene composites deposited using electrostatic spray deposition technique (ESD). Addition of graphene is expected to improve the performance of the tin oxide anodes by synergetic effect. Two different sets of composite samples, as-deposited $\left(195^{\circ} \mathrm{C}\right)$ and post-heat treated $\left(280{ }^{\circ} \mathrm{C}\right)$ were studied as 
well as control samples of pure tin oxide as-deposited $\left(195^{\circ} \mathrm{C}\right)$ and post-heat treated $(280$ $\left.{ }^{\circ} \mathrm{C}\right)$. The samples were characterized and the electrochemical performances were analyzed.

\subsection{Experimental method}

$0.106 \mathrm{M}$ sodium hydroxide was added slowly to $0.054 \mathrm{M} \mathrm{SnCl}_{4}$. The resulting sol solution was then heated at $120^{\circ} \mathrm{C}$ for $12 \mathrm{hrs}$ until all the solution was evaporated, leaving a white tin oxide powder. This tin oxide powder was used in the preparation of precursor solution. Precursor solution for tin oxide/graphene composite was prepared by mixing tin oxide and $30 \mathrm{wt} \%$ graphene with ethylene glycol \& ethanol and deposited on a nickel foam substrate using electrostatic spray deposition technique at a temperature of $195{ }^{\circ} \mathrm{C}$. Some of the samples deposited were post-heat treated at a temperature of $280{ }^{\circ} \mathrm{C}$ in an inert atmosphere (nitrogen). The morphologies of the as-deposited films were investigated using Scanning electron microscopy (JOEL 6335 FE-SEM). X-ray diffraction (XRD) studies were carried out using D5000 diffracktometer. Electrochemical test cells were assembled in an argon atmosphere using tin oxide/graphene thin film samples as anode and lithium as counter and reference electrode in an electrolyte of 1.1M FC-130 dissolved in ethylene carbonate, dimethyl carbonate and diethyl carbonate (EC: DMC: DEC, 1:1:1 w/w). Electrochemical tests were carried out between $3.00-0.02 \mathrm{~V}$ at $0.2 \mathrm{C}$ rate.

\subsection{Results and discussions}

The morphology of the as-deposited films of pure tin oxide, graphene and tinoxide/graphene composites were investigated using SEM (Figure 5.1). Pure tin oxide samples showed a porous structure whereas as-deposited graphene showed a dense film like morphology. Tin oxide/graphene composites did not exhibit a 3D porous morphology as 
expected, instead the pores are significantly lesser and smaller. There is no change in the morphology when the samples were post heat treated to $280{ }^{\circ} \mathrm{C}$ (not shown).

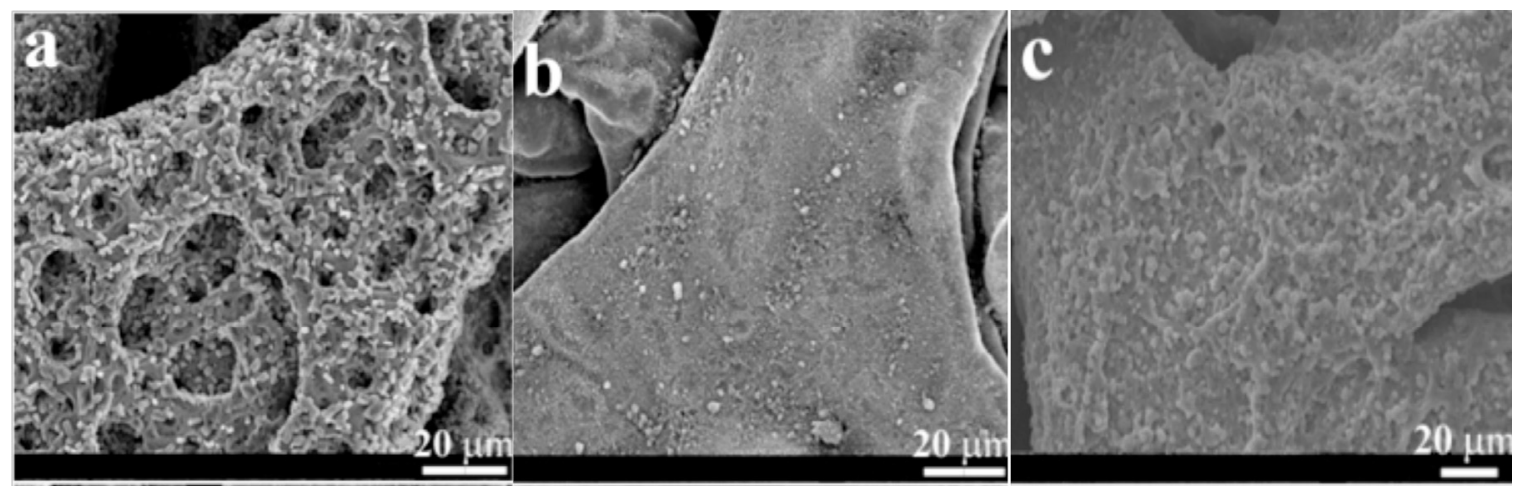

Figure 5.1 SEM images of a) pure tin oxide, b) pure graphene, and c) Tin oxide/graphene deposited at $195{ }^{\circ} \mathrm{C}$ by ESD method.

Figure 5.2 shows the X-ray diffraction pattern of the as-deposited and post-heat treated samples. All the samples for XRD were deposited on a glass substrate to avoid the interference from substrate $\mathrm{Ni}$ foam. The peaks at $2 \theta=26,34,52^{\circ}$ were assigned to the (110), (101) and (211) planes of $\mathrm{SnO}_{2}$ (JCPDS card No. 41-1445), respectively in both pure tin oxide and tin oxide samples. Graphene peaks (002) at $\sim 27^{\circ}$ are overlapped with tin oxide peaks in the composite samples. The residual $\mathrm{NaCl}$ peaks from the tin oxide powder (used in precursor solution) were found in the pattern (JCPDS card no: 05-0628) for as-deposited pure tin oxide and the composite samples. But these disappeared in the post-heat treated samples. There is no shift in the peak positions though the intensity of the peaks slightly increased after post-heat treatment. 
Figure 5.2 X-Ray diffraction patterns of a) pure tin oxide, and b) tin oxide/graphene 
The charge-discharge profile (Figure 5.3) was obtained using cyclic chargedischarge at a constant current density of $0.2 \mathrm{C}$ between $0.01-3.0 \mathrm{~V}$. It clearly indicates three voltage plateaus corresponding to the decomposition reaction $(\sim 1.25 \mathrm{~V})$, lithium alloy formation with tin $(\sim 0.5 \mathrm{~V})$ and carbon $(\sim 0.1 \mathrm{~V})$ during discharge. During charge, the lithium de-alloying occurs around $\sim 0.75 \mathrm{~V}$ and lithium de-intercalates from the layers in the graphene above $\sim 0.3 \mathrm{~V}$. There is no difference in the voltage plateaus for the as-deposited composites and post-treat heated samples. The first cycle discharge capacity of tin oxide/graphene @ $195{ }^{\circ} \mathrm{C}$ was $1360 \mathrm{mAh} / \mathrm{g}$ and charge capacity was $940 \mathrm{mAh} / \mathrm{g}$ with a columbic efficiency of $69 \%$. During second cycle, the charge capacity was $915 \mathrm{mAh} / \mathrm{g}$ but the discharge capacity reduced to $964 \mathrm{mAh} / \mathrm{g}$. This results in an increased columbic efficiency of $95 \%$. The irreversible capacity loss was around $396 \mathrm{mAh} / \mathrm{g}$. Similarly for tin oxide/graphene @ $280{ }^{\circ} \mathrm{C}$, first and second cycle discharge capacities were 1423 and 1110 $\mathrm{mAh} / \mathrm{g}$. Charge capacities were $1124 \mathrm{mAh} / \mathrm{g}$ and $1065 \mathrm{mAh} / \mathrm{g}$ in the first and second cycles. Irreversible loss of capacity between the first and second cycle was $313 \mathrm{mAh} / \mathrm{g}$. Corresponding columbic efficiencies were $79 \%$ and $96 \%$. The increase in the columbic efficiency suggests that the $\mathrm{Li}+$ ions that were trapped or undergo side reactions reduced considerably after the first cycle. 

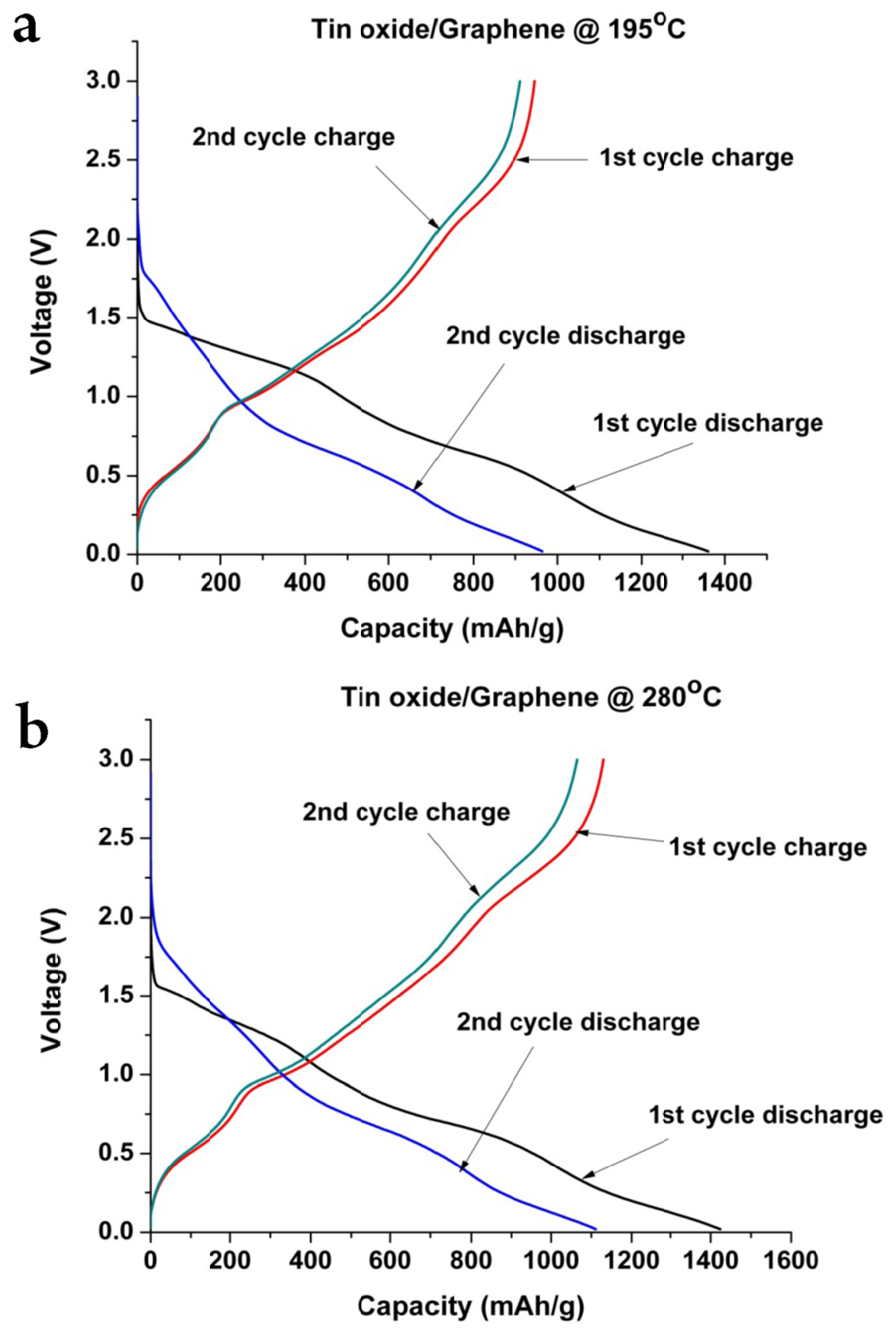

Figure 5.3 Charge-discharge characteristics of tin oxide/graphene composite at a) $195{ }^{\circ} \mathrm{C}$, b) $280{ }^{\circ} \mathrm{C}$

Figure 5.3 shows the electrochemical performance of the composites. The capacity and cycle performance of the electrodes were evaluated by galvanostatic discharge-charge 
measurements at a discharge rate of $0.2 \mathrm{C}$ (Figure 5.3a). Both the composite electrodes showed a gradual decrease in the capacity. In the case of pure tin oxide anodes @ $195^{\circ} \mathrm{C}$ and @ $280^{\circ} \mathrm{C}$, initial capacities were around 780 and $750 \mathrm{mAh} / \mathrm{g}$, respectively. Irreversible capacity loss was $200 \mathrm{mAh} / \mathrm{g}$ for tin oxide @ 280 $\mathrm{C}$ and $310 \mathrm{mAh} / \mathrm{g}$ for tin oxide anodes @ $195^{\circ} \mathrm{C}$. At the 10th cycle, tin oxide/graphene @ $195^{\circ} \mathrm{C}$ showed $774 \mathrm{mAh} / \mathrm{g}$ whereas tin oxide/graphene @ $280{ }^{\circ} \mathrm{C}$ showed $975 \mathrm{mAh} / \mathrm{g}$. Stability vise, all of the electrodes lose their capacity gradually with cycling. After 70 cycles, tin oxide/graphene anodes @ $195^{\circ} \mathrm{C}$ and $280{ }^{\circ} \mathrm{C}$ had capacity retentions of 55 and $66 \%$, of the second cycle capacity, respectively. The capacity retentions are 33 and $42 \%$ for pure tin anodes $@ 195^{\circ} \mathrm{C}$ and $280{ }^{\circ} \mathrm{C}$, respectively, after 70 cycles. The composite $@ 195^{\circ} \mathrm{C}$ reaches fairly stable capacity whereas the capacity of composite @ $280^{\circ} \mathrm{C}$ drops towards the capacity of composite@ $195^{\circ} \mathrm{C}$. The effect of the addition of graphene to tin oxide can be seen clearly in figure 3. The capacity was increased atleast $2 \mathrm{X}$ times by the addition of graphene. This can be attributed to the synergetic effect of graphene, which improves the conductivity of tin oxide and provides a buffer matrix during cycling. The effect of $\mathrm{NaCl}$ impurities in the as-deposited samples on the performance was not studied. Studies show that $\mathrm{NaCl}$ dissolves in the electrolyte [2627]. The energy density of the anodes (Figure 5.3b) were calculated using the formula Energy density $(\mathrm{kWh} / \mathrm{Kg})=$ Capacity $(\mathrm{Ah} / \mathrm{kg}) *$ Nominal voltage $(\mathrm{V}) / 1000$. At the $70^{\text {th }}$ cycle, the energy density of the composites @ $195^{\circ} \mathrm{C}$ and $280^{\circ} \mathrm{C}$ are 1.24 and $1.76 \mathrm{kWh} / \mathrm{kg}$. Comparatively, commercially used graphite electrodes usually have energy densities in the range of $0.0372-0.0744 \mathrm{kWh} / \mathrm{kg}$ [28].

Figure 5.5 shows the rate capability of the composite anodes and normalized capacities with respect to capacity obtained at a $0.5 \mathrm{C}$ low discharge rate. The samples were 
tested at $0.5,1,2,4,6,8$, and $10 \mathrm{C}$ rates. The rate capability of tin oxide/graphene @ $280{ }^{\circ} \mathrm{C}$ was better than the composite $@ 195{ }^{\circ} \mathrm{C}$. The degeneration rate of specific discharge capacities with increasing current density was lower for composites @ $280{ }^{\circ} \mathrm{C}$. However, both the composites lose their capacity with increased rate of discharge. At a 10C rate of discharge, capacity obtained was only $30 \%$ of the capacity obtained at $0.5 \mathrm{C}$ rate for tin oxide/graphene@280 ${ }^{\circ} \mathrm{C}$ whereas it is only 10\% for tin oxide/graphene@ $195{ }^{\circ} \mathrm{C}$. From figures 5.4 and 5.5, the electrochemical performance of the anodes can thus be summarized as: tin oxide/graphene @ $280{ }^{\circ} \mathrm{C}>$ tin oxide/graphene @ $195^{\circ} \mathrm{C}>$ tin oxide. 

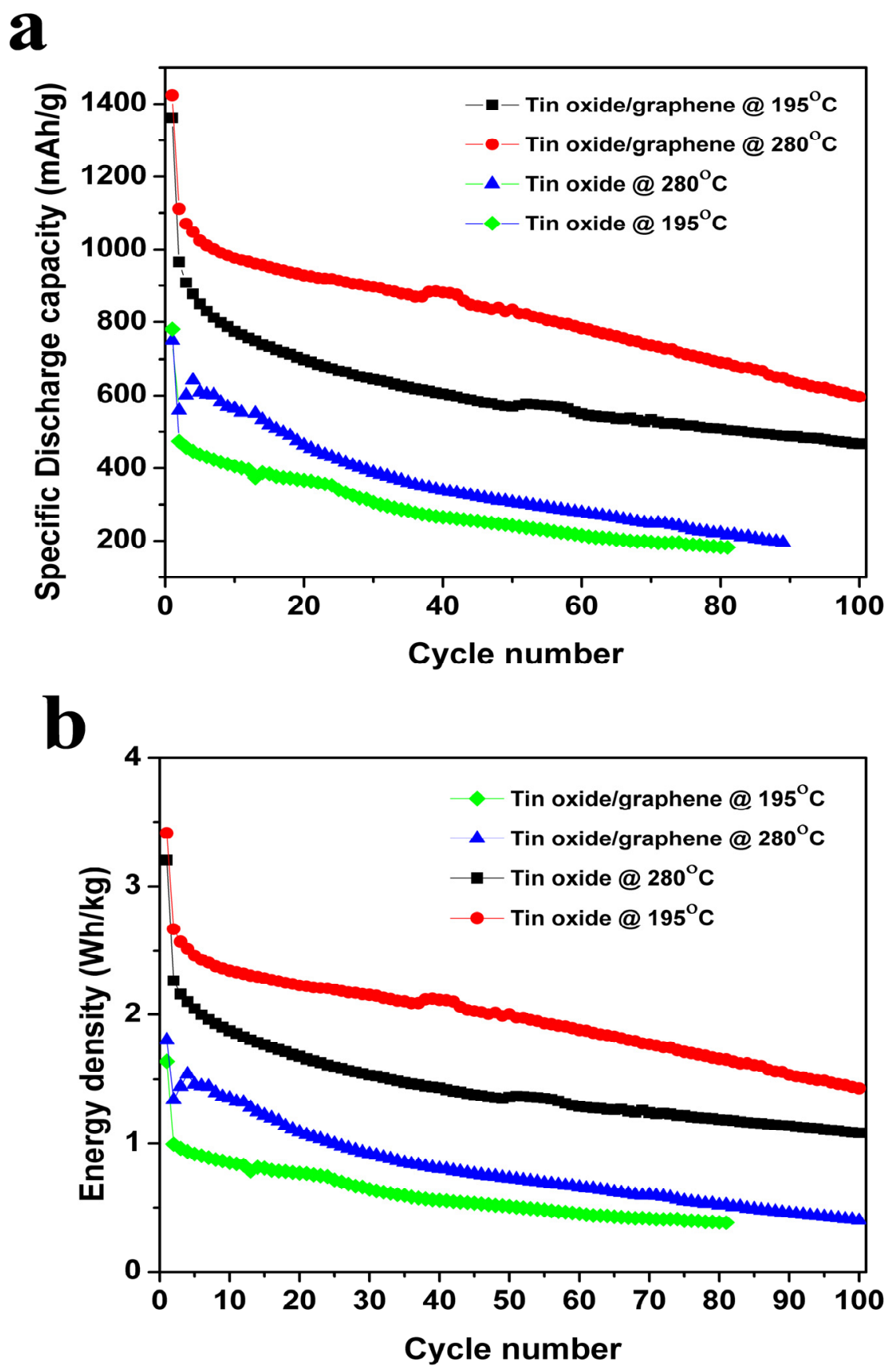

Figure 5.4 Comparison of a) cycle performance, and b) energy density of tin oxide /graphene composites and tin oxide. 

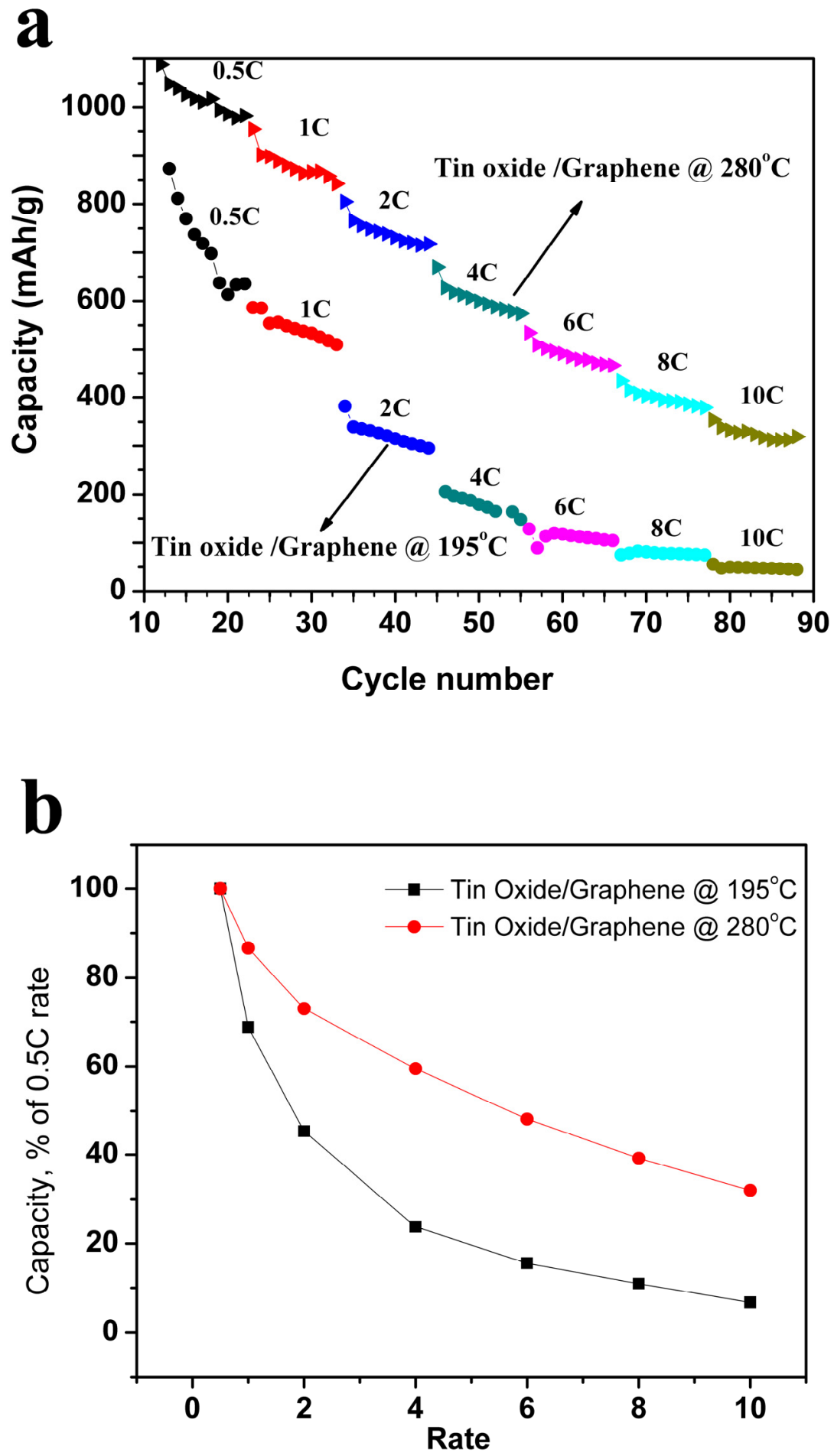

Figure 5.5 a) Rate capability of tin oxide /graphene composites, b) Normalized capacity versus rate of discharge of tin oxide /graphene composites. 


\subsection{Conclusions}

Tin oxide /graphene composites were fabricated using ESD and their electrochemical performance was studied. The composites showed better performance than the pure tin oxide anodes synthesized under the same experimental condition. The specific capacity and energy density of tin oxide/graphene@280 ${ }^{\circ} \mathrm{C}$ was higher than tin oxide/graphene@195 ${ }^{\circ} \mathrm{C}$. After 70 cycles, the capacities of tin oxide/graphene anodes @ $195^{\circ} \mathrm{C}$ and $280{ }^{\circ} \mathrm{C}$ were 534 and $737 \mathrm{mAh} / \mathrm{g}$, respectively. The energy densities of the composites even after 70 cycles were much higher than the commercial graphite anodes.

\subsection{References}

[1] Y. Idota, T. Kubota, A. Matsufuji, Y. Maekawa, and T. Miyasaka, Science, 276, 1395 (1997).

[2] J.Maier, Nat. Mater. 4, 805 (2005).

[3] X. W. Lou, Y. Wang, C. Yuan, and J. Y. Lee, L. A. Archer, Advanced. Mater., 18, 2325. (2006).

[4] C.K.Chan, X.F. Zhang, and Y. Cui, Nano Lett, 8, 307 (2008).

[5] T. Brousse, R. Retoux, U. Herterich, and D.M. Schleich, J. Electrochem. Soc., 145, 1 (1998).

[6] I.A. Courtney and J.R. Dahn,, J. Electrochem. Soc, 144, 2045 (1997).

[7] Y. Wang, H. C. Zeng, and J. Y. Lee, Adv. Materials, 18, 645 (2006).

[8] M. Li, Q. Lu, Y. Nuli, and X. Qian, Electrochem. Solid-State Lett., 10, K33(2007).

[9] Y.Yu, C.H. Chen, and Y. Shi, Adv. Mater., 19, 993 (2007)

[10] K. T. Lee, Y. S. Jung, and S. M. Oh, J. Am. Chem. Soc., 125, 5652 (2003).

[11] F.S. Ke, L. Huang, H. B. Wei, J.S. Cai, X.Y. Fan, F.Z. Yang, and S.G. Sun, J. Power Sources, 170, 450 (2007).

[12] S. Machill, T. Shodai, Y. Sakurai, and J.I. Yamaki, J. Power Sources, 73, 216 (1998).

[13] S.M. Paek, E.J. Yoo, and I. Honma, Nano Lett., 9, 72 (2009). 
[14] G. Du, C. Zhong, P.Zhang, Z. Guo, Z. Chen, and H. Liu, Electrochim. Acta 55, 2582 (2010)

[15] Yinzhu Jiang, Yue Xu, Tianzhi Yuan, and Mi Yan, Materials Letters 91,16 (2013).

[16] J. Yao, X. Shen, B. Wang, H. Liu, and G. Wang, Electrochem. Commun., 11, 1849 (2009).

[17] E. Yoo, J. Kim, E. Hosono, H. Zhou, T. Kudo, and I. Honma, Nano Lett. 8, 2277(2008).

[18] D. Pan, S. Wang, B. Zhao, M. Wu, H. Zhang, Y. Wang, and Z. Jiao, Chem. Mater. 21, 3136(2009).

[19] P. Guo, H. Song, and X. Chen, Electrochem. Commun. 11, 1320 (2009).

[20] G. Wang, X. Shen, and J. Yao, J. Park, Carbon 47, 2049 (2009).

[21] D. Wang, R. Kou, D. Choi, Z. Yang, Z. Nie, J.Li, L. V. Saraf, D. Hu, J. Zhang, G. L. Graff, J. Liu, M. A. Pope, and I. A. Aksay, , ACS Nano , 4 ,1587 (2010).

[22] G. Wang, X. Shen, J. Yao, and J. Park, Carbon, 47, 2049 (2009)

[23] H. Kim, S-W. Kim, Y.-U.Park, H. Gwon, D.-H. Seo, Y. Kim, and K. Kang, Nano Res. 3,813 (2010).

[24] Z. Wang, H. Zhang, N. Li, Z. Shi, Z. Gu, and G. Cao, 748-756. In Nano Research,3, 748 (2010)

[25] Y. Li, X. Lv, J. Lu, and J. Li, J. Phys. Chem. C, 114, 21770 (2010).

[26] S. P. Ong, V. L. Chevrier, G. Hautier, A. Jain, C.Moore, S. Kim , X. Ma, and G.Ceder, Energy Environ. Sci., 3680, 4, (2011).

[27] S. S. Zhang, J. Power Sources 162, 1379, (2006).

[28] J.-M. Tarascon and M. Armand, Nature 414, 359 (2001). 


\section{FABRICATION OF TIN-CARBON COMPOSITE ANODE MATERIAL BY ELECTROSPINNING AND ELECTROSTATIC SPRAY DEPOSITION FOR LITHIUM RECHARGEABLE BATTERY}

\subsection{Introduction}

Increase in environmental regulations forces the companies to switch over to alternative energy resources. Rechargeable Li-ion batteries (LIBs) are potential candidates for running hybrid electric vehicles and portable electronics because of their high energy densities. Numerous research efforts are focused on developing novel materials for the components of these electrochemical storage devices [1-4]. Achieving high energy density, long cycle life, capacity retention, and eco-friendliness plays a major part in the focus of these studies. Electrode materials are the most important part of a LIB as these contain the active materials, which stores and provide energy. In this study, we focus on the fabrication and characterization of anode materials. Currently, carbon is used as an anode material in the commercial Li-ion battery. The theoretical capacity of carbon is $372 \mathrm{mAh} / \mathrm{g}$ [5-6]. Capacity of the anodes can be improved by using different metals, metal oxides, composites, and alloys. Metallic tin has been explored for use as a negative electrode for LIBs owing to its high theoretical capacity of $990 \mathrm{mAh} / \mathrm{g}$. Tin undergoes an alloying mechanism as compared to the intercalation mechanism in carbon electrodes.

However, tin anodes exhibit low cycle life. Several factors have been identified as the source of this poor cyclability in tin anodes: 1) Lithium atomic radius (2.05 $\AA)$ is far higher than that of $\mathrm{Sn}(1.72 \AA)^{[7]}$. When the maximum $4.4 \mathrm{Li}$ reacts with $\mathrm{Sn}$ to form $\mathrm{Li}_{4.4} \mathrm{Sn}$, the large atomic uptakes ( $440 \%$ increase in the number of atoms) can induce large volume change (359\%) ${ }^{[8]}$. Substantial volume change, due to the alloying and de-alloying 
mechanism during cycling, results in mechanical failure, pulverization, and loss of electrical contact between the current collectors and active materials. 2) Aggregation of tin nanoparticles occurs during cycling [9]. Various methods have been proposed to mitigate these problems. Problems of volume change and aggregation can be reduced by using intermetallic compounds or by providing a "buffer"- matrix with an active/inactive composite alloy or hollow/ porous structures $[10,11]$. For instance, nano-tin dispersed in a carbon matrix improved the cyclability of the tin anode $[12,13]$. Carbon-encapsulated hollow tin nanoparticles as anodes have been reported to show excellent performance [14, 15]. Pulverization of electrodes can be prevented by choosing smaller sized particles, optimized binder, and composite materials for the anode [16, 17]. In this report, we explore the fabrication of tin-carbon composite material using electrospinning and electrostatic spray deposition. Different morphologies of tin-carbon composite produced using these methods, such as the hollow fibers and porous films, were discussed. Because of their simple and low-cost setup, non-vacuum, low temperature deposition conditions, and good control of the composition and morphology, these techniques are superior to other methods such as sputtering, CVD and sol-gel. Hollow/Porous structures are expected to buffer the stress during volume change. Carbon can improve conductivity and also acts as a buffermatrix, resulting in an improvement of the performance of the electrode material.

\subsection{Experimental section}

The schematic of the experimental set-up of an electro spinning technique is shown in figure 1. The set-up for coaxial spinning consists of: (a) two stainless steel needles with an inner diameter of $0.5 \mathrm{~mm}$ and an outer diameter of $1.2 \mathrm{~mm}$ placed coaxially, (b) thin copper plate as the collector for nanofibers, (c) High voltage source and (d) two syringe pumps. The 
distance between the needle and the collector was $15 \mathrm{~cm}$. The outer and inner solutions can be fed at different flow rates. A high voltage of $20 \mathrm{kV}$ was supplied between the needles and the grounded substrate. The fiber formed by this method is either hollow or has a core-shell structure. The experimental set-up of the ESD technique (Spray-up mode) is almost identical to electro spinning set-up except for the heater and temperature controller. Here the substrate is usually heated at a high temperature to enable the solvent evaporation. The main difference between ESD and electro spinning is the viscosity of the precursor solution and the solvents used. For example, in order to obtain Sn-C composite by electro spinning, Polyacrylonitrile (PAN) powder was dissolved in N, N- dimethylformamide (DMF) at $80{ }^{\circ} \mathrm{C}$ with vigourous stirring to prepare a $10 \mathrm{wt} \%$ concentrated outer solution. The inner solution was a mixture of tributyltin and mineral oil in 1:1 weight ratio. The fibers collected on the copper substrate, were removed and soaked in n-octane for more than $12 \mathrm{~h}$ to extract the mineral oil. This resulted in hollow carbon nanofibers. These hollow fibers were then pyrolysed at $1000{ }^{\circ} \mathrm{C}$ in a mixture of $\mathrm{Ar}(95 \mathrm{vol} \%)$ and $\mathrm{H}_{2}(5 \mathrm{vol} \%)$ atmosphere for $5 \mathrm{~h}$ at a rate of $2{ }^{\circ} \mathrm{C} / \mathrm{min}$. From this process, Sn encapsulated carbon nanoparticles in hollow carbon nanofibers can be obtained. In case of electrostatic spray deposition technique, tin acetate was dissolved in butyl carbitol solvent. This was then refluxed with PVP at a temperature of $40^{\circ} \mathrm{C}$. The resulting precursor solution was sprayed at a temperature of $350{ }^{\circ} \mathrm{C}$. After deposition, the film was then heated in a mixture of $\mathrm{Ar}(95 \mathrm{vol} \%)$ and $\mathrm{H}_{2}(5 \mathrm{vol} \%)$ atmosphere for about $1 \mathrm{~h}$ at $500^{\circ} \mathrm{C}$ and for $1 \mathrm{~h}$ at $900{ }^{\circ} \mathrm{C}$ at the heating rate of $2{ }^{\circ} \mathrm{C} / \mathrm{min}$. X-ray diffraction (SIEMENS D-5000) was used to determine the composition and crystal structures of the annealed Sn-C nanofibers. Surface morphology was investigated using a JEOL 6300F field-emission scanning electron microscope operated at $15 \mathrm{keV}$. High- 
resolution transmission electron microscopy (HRTEM) was performed using a JEOL 4000EX transmission electron microscope operated at $400 \mathrm{keV}$.

Electrochemical experiments were performed with the $\mathrm{Sn}-\mathrm{C}$ composite as the working electrode and lithium foil as both the counter and reference electrodes. For fibers prepared using electrospinning technique, a working electrode was prepared as a mixture of electrospun Sn-C composite, carbon black and poly (vinyl difluoride) (PVDF) at a weight ratio of 70:15:15. This was then pasted on a copper foil using doctor blade technique. In case of ESD derived films, no additional binder or additive is needed. $1 \mathrm{M} \mathrm{LiPF} 6$ in ethylene carbonate and diethyl carbonate $($ EC-DEC, vol./vol. = 1/1) was used as the electrolyte and Celgard 2400 was used as a separator film. Cells were arranged in an argon-filled glove box where both moisture and oxygen levels were maintained below $1 \mathrm{ppm}$.

\subsection{Results and discussion}

X-ray diffraction (XRD) analysis of the TBT@PAN nanofibers heated at $1000^{\circ} \mathrm{C}$ and $\mathrm{SnO}_{2}-$ PVP porous film heated at $900^{\circ} \mathrm{C}$ in $\mathrm{N}_{2} / \mathrm{H}_{2}$ atmosphere is shown in figure 2 . In the TBT@PAN nanofibers, PAN is pyrolyzed to carbon, which covers the tin coated with carbon (decomposed tetra butyl tin). PVP in $\mathrm{SnO}_{2}$-PVP film is decomposed to carbon and $\mathrm{SnO}_{2}$ is reduced to $\mathrm{Sn}$. XRD analysis clearly revealed the diffraction patterns of $\beta$-Sn (JCPDS, No.86-2265). No tin oxide peak was detected. All the peaks correspond only to tin, which is in agreement with other literatures [18]. 


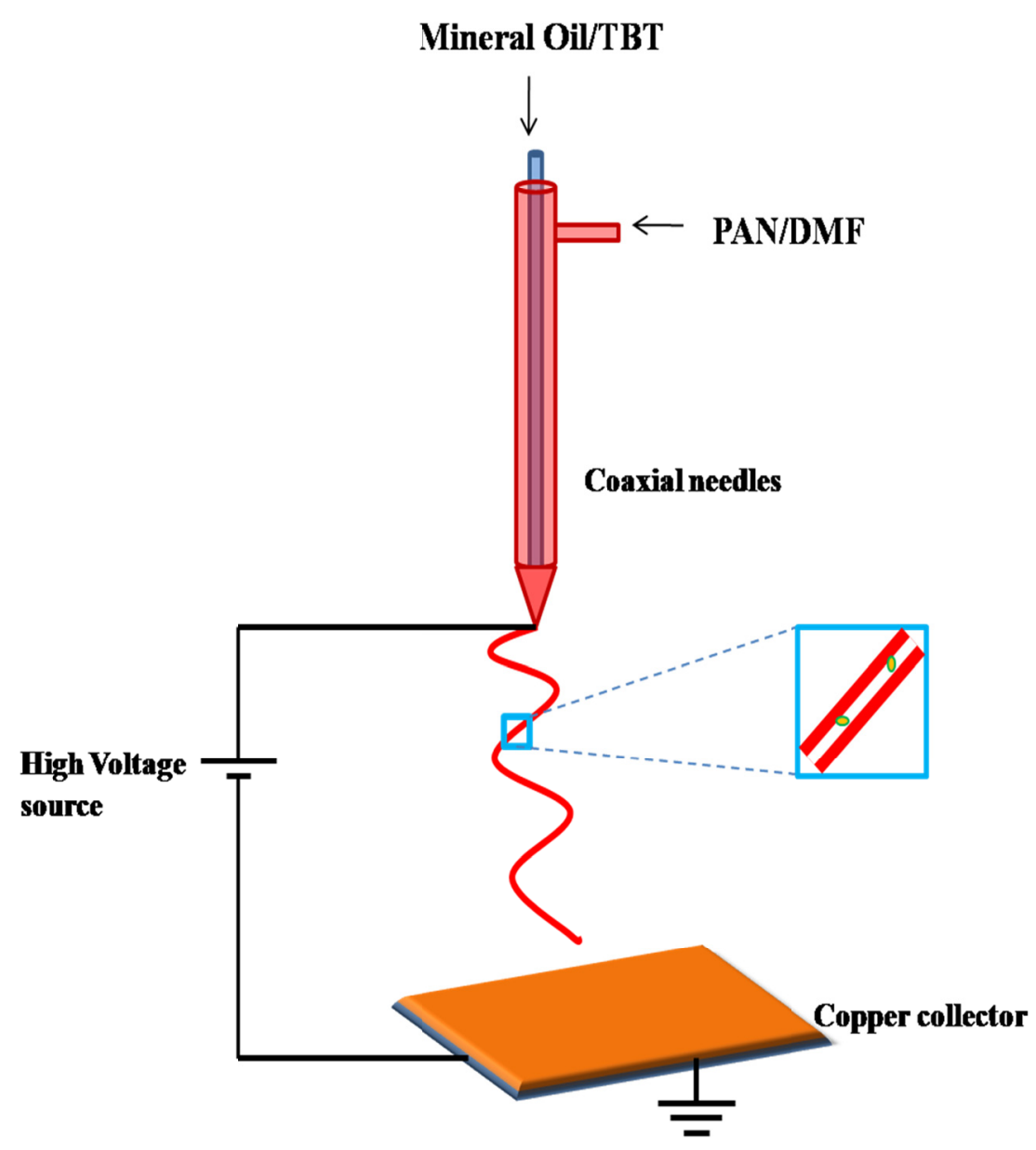

Figure 6.1 Schematic of co-axial electrospinning set-up

SEM image of as-collected TBT/PAN nanofibers from electrospinning (Figure 6.3a) show uniform continuous fibers with diameters of $200 \pm 50 \mathrm{~nm}$. The $\mathrm{SnO}_{2} / \mathrm{PVP}$ porous film in figure $6.3 \mathrm{~b}$ was deposited by using electrostatic spray deposition. The sizes of the pores are can be subdivided into the following categories: 1) big pores with diameter $10 \sim 13 \mu \mathrm{m}, 2$ ) Pores with diameter 5 7 $\mu \mathrm{m}, 3)$ Smaller pores in the range of 1 2 $\mu \mathrm{m}$ and $2 \sim 5 \mu \mathrm{m}$. These pores follow a particular pattern with the largest pores forming the ring structure. Medium and small pores lie within this big ring. These reticular structures are formed from the evaporation of the solvent molecules upon reaching the heated substrate. Therefore, the 
morphology of the ESD derived films depends on the substrate temperature and the boiling point of the solvent used in the precursor solution. If the substrate temperature is less than the boiling point of solvent, there is an increased chance for the formation of a dense film. However, if the substrate's temperature is much greater than the solvent's boiling point, it is likely that a discontinuous film or particles will form.

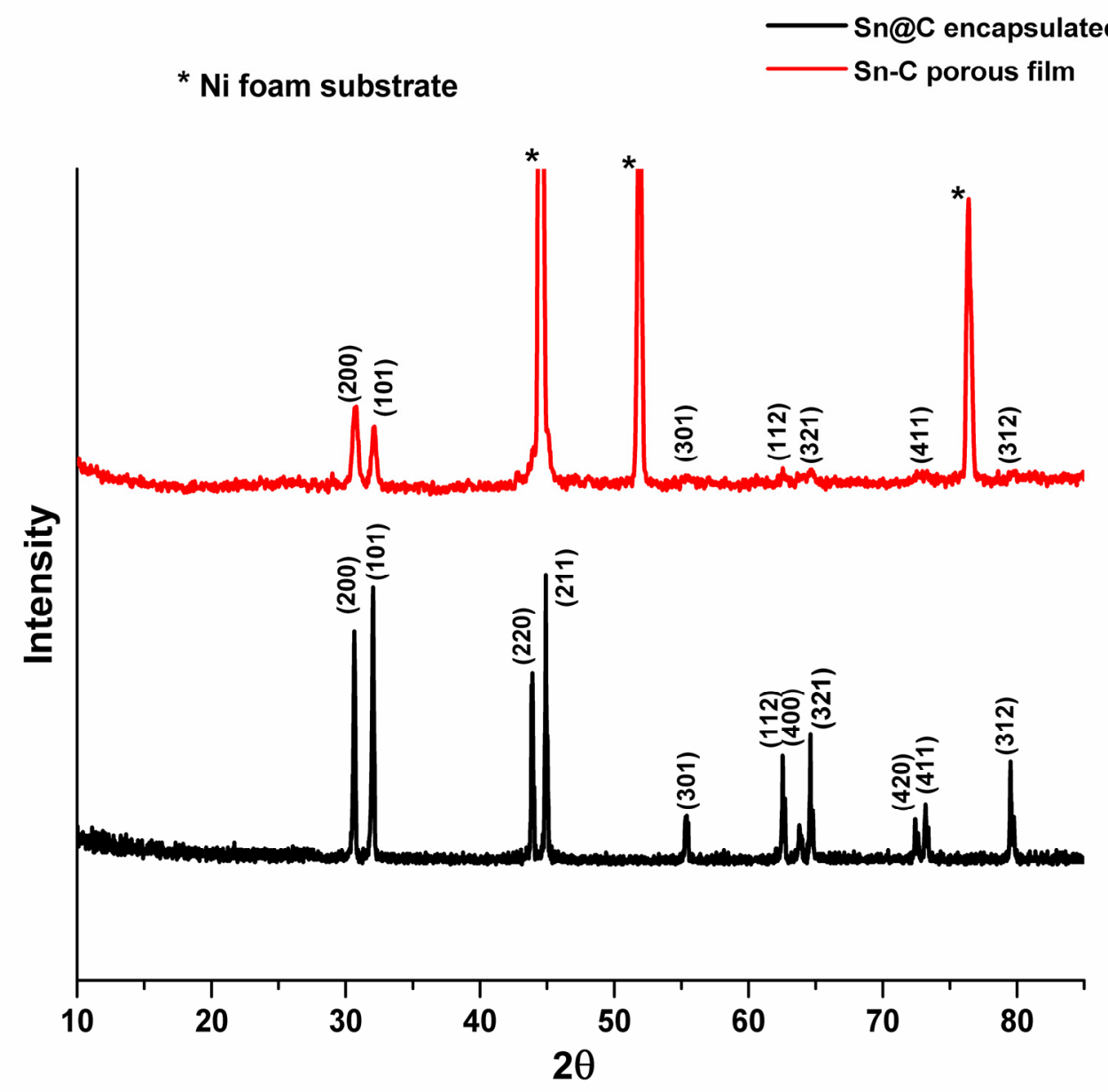

Figure 6.2 XRD patterns of Sn-C porous film and Sn@C encapsulated in C hollow fiber prepared by ESD and electro spinning, respectively. 
The substrate temperature should be maintained slightly above the boiling point of the solvent to achieve a reticular porous structure [19].

Bright field zero-loss energy filtered TEM image (Figure 6.4a) of the pyrolysed samples shows tin nanoparticles encapsulated in bamboo-like hollow carbon nanofibers. The average diameter of the pyrolysed fibers was $150 \mathrm{~nm}$ after pyrolyzation. This is due to the decomposition of the organic components at high temperature. The bright field image at a higher magnification (Figure $4 b$ ) reveals metallic tin surrounded by a thin graphitic layer of about $10 \mathrm{~nm}$ thick. The outer hollow carbon fiber is about $30 \mathrm{~nm}$ in thickness.

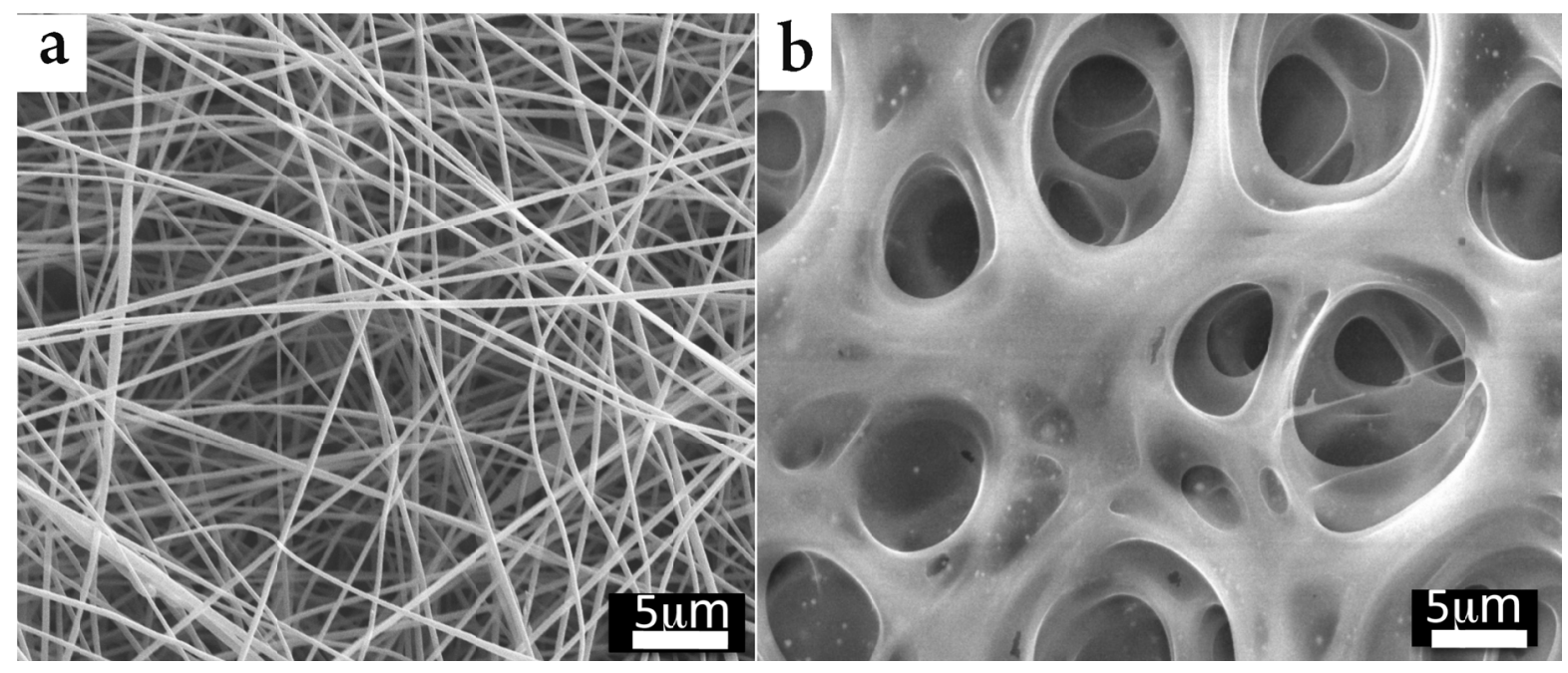

Figure 6.3 a) SEM images of as prepared TBT/PAN nanofibers b) SEM image showing porous $\mathrm{SnO}_{2} / \mathrm{PVP}$ composite. 


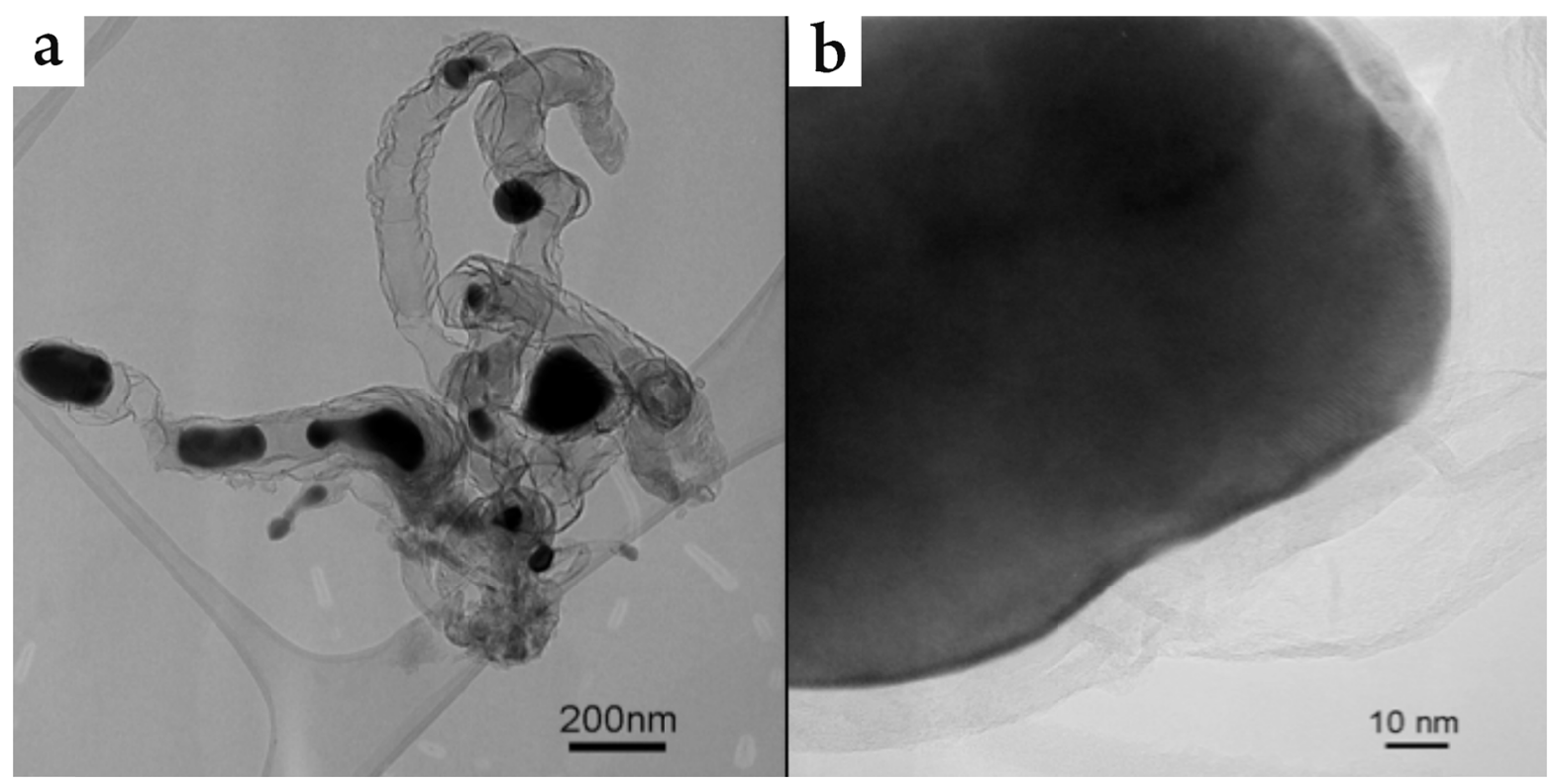

Figure 6.4 TEM of pyrolysed carbon coated tin inside hollow carbon fibers a) Bright field zero loss filtered image b) high magnification of an isolated carbon coated tin particle inside hollow carbon fiber.

Sn-C porous composites made from ESD (figure 6.5 a), exhibited a first discharge capacity of $906 \mathrm{mAh} / \mathrm{g}$ and first charge capacity of $674 \mathrm{mAh} / \mathrm{g}$, corresponding to an initial columbic efficiency of $74 \%$. The first discharge cycle of Sn@C -carbon hollow fibers showed a capacity of $1156 \mathrm{mAh} / \mathrm{g}$ compared to the theoretical $806 \mathrm{mAh} / \mathrm{g}$ (figure $6.5 \mathrm{~b}$ ). The first charge cycle exhibited a capacity of $824 \mathrm{mAh} / \mathrm{g}$. This is equivalent to a columbic efficiency of $71 \%$. The large initial capacity loss can be attributed to the thick SEI layer formation and also the $\mathrm{Li}^{+}$trapped inside the hollow fiber. 

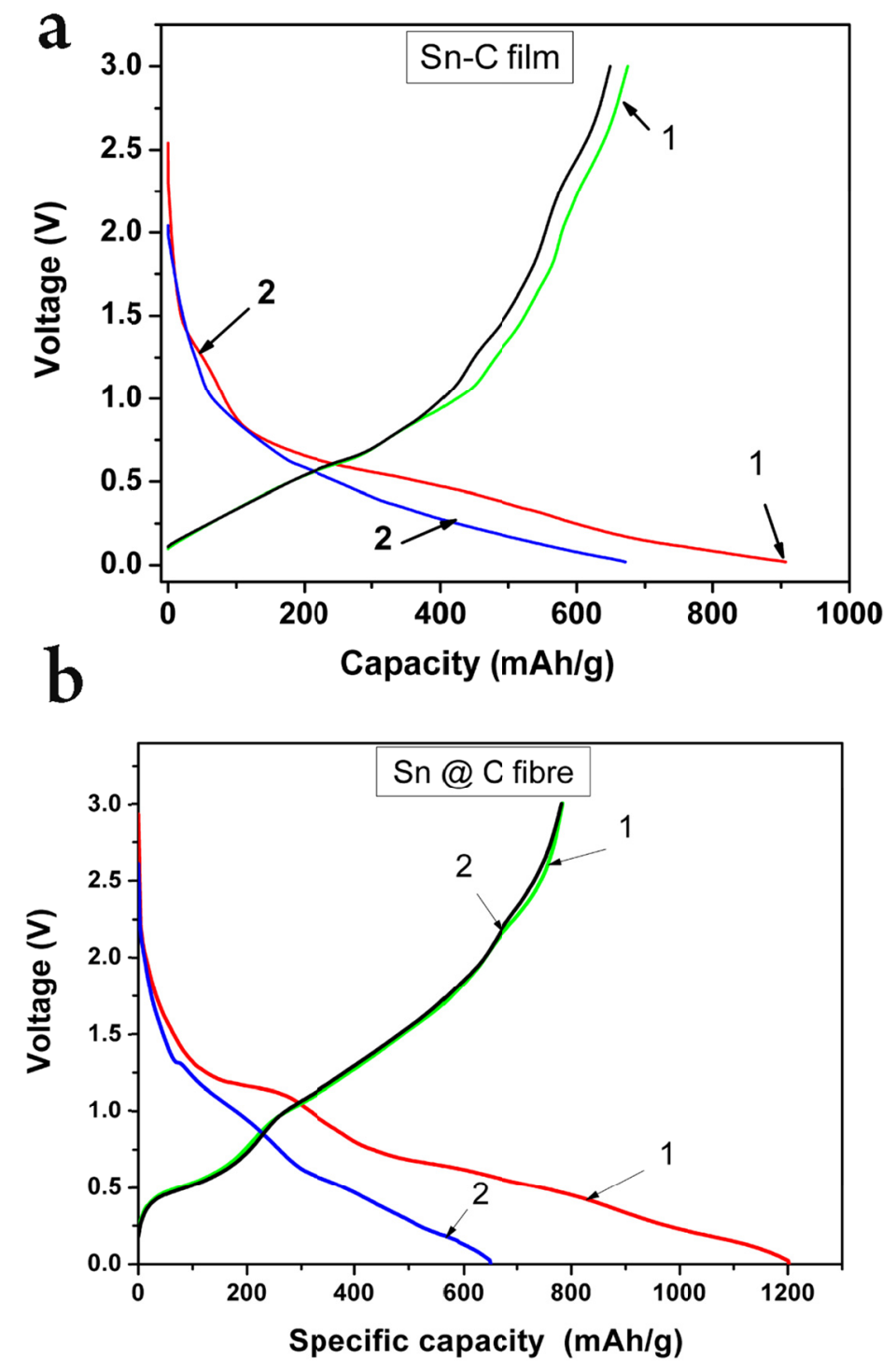

Figure 6.5 Charge-Discharge cycle of a) Porous Sn-C film at $0.2 \mathrm{~mA} / \mathrm{cm}^{2}$ in the voltage range of $0.02-3.0 \mathrm{~V}$, and b) $\mathrm{Sn} @ \mathrm{C}$ encapsulated in carbon hollow fibers anodes at $\mathrm{C} / 10$ rate in the voltage range of $0.01-3.0 \mathrm{~V}$.

Charge -discharge cycles were performed at 0.5C rate (Figure 6.6). The Sn@C carbon hollow fiber composite electrode exhibited good cycle performance with a reversible capacity of $760 \mathrm{mAh} / \mathrm{g}$ after 50 cycles. For comparative analysis, commercial Sn 
nanopowder electrode, fabricated using carbon black and binder on copper foil, was tested at $0.5 \mathrm{C}$ rate. It delivered a high capacity for the first 10 cycles, then subsequently lost its capacity drastically. This may be due to the disruption of the material. Improved performance of Sn@C - carbon hollow fiber composite can be related to the formation of a "buffer zone" due to the hollow structure; prevention of the aggregation of Sn nanoparticles due to carbon coating; and increase in the surface area which may have improved the electrical conductivity and $\mathrm{Li}$ ion diffusion rate. Sn-C porous film formed by ESD also has good cycle performance. At the end of 50 cycles, it had a discharge capacity of $686 \mathrm{mAh} / \mathrm{g}$. Porous film retained almost $75 \%$ of the initial discharge capacity whereas the Sn-C fiber retained only $65 \%$ of the initial capacity. This may be due the reduction in the diffusion path of $\mathrm{Li}^{+}$in the porous film. In the case of $\mathrm{Sn} @ \mathrm{C}-$ carbon hollow fiber, lithium ions have to travel through carbon layers to reach Sn particle. However, both morphologies showed better cyclability than the tested tin nanopowder. This can be attributed to the carbon in the composite, which can improve conductivity and also acts as a buffer matrix. 


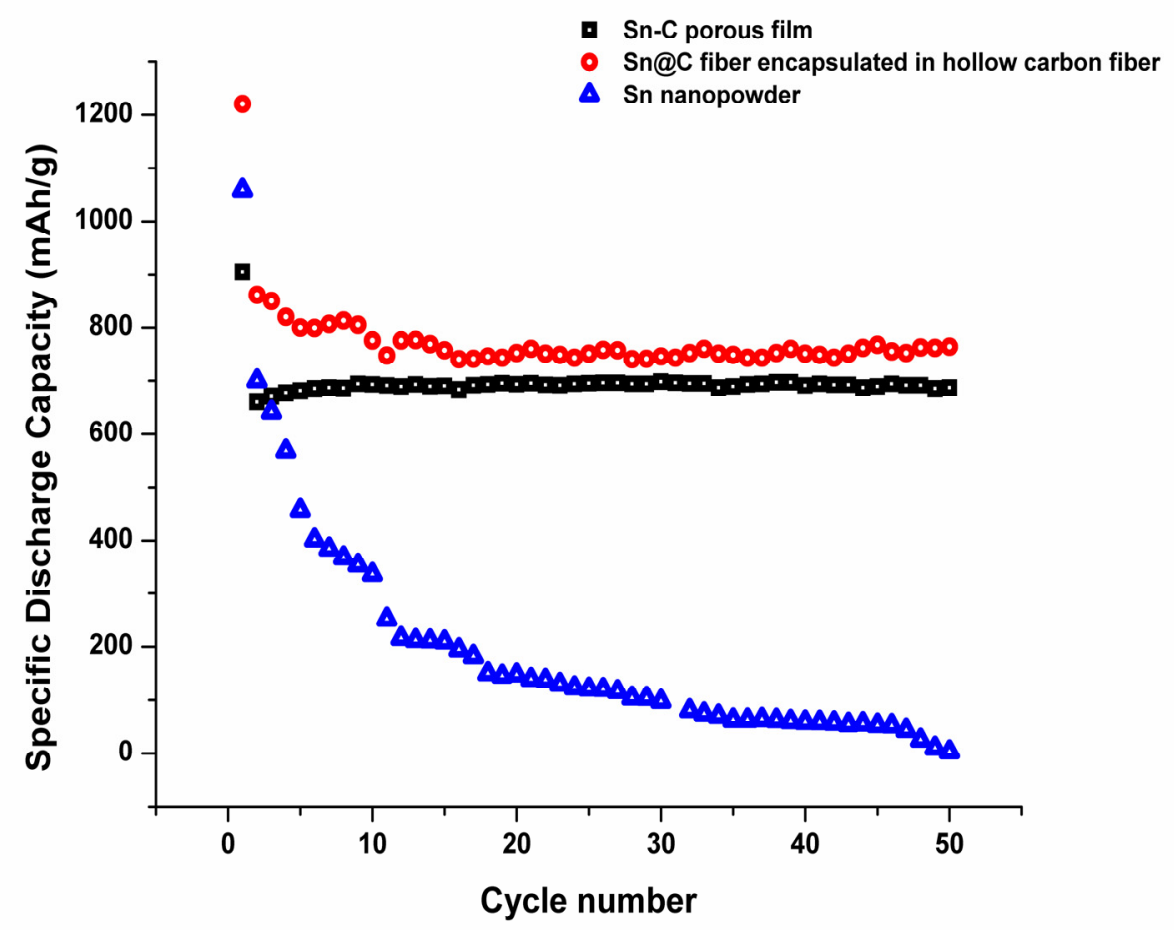

Figure 6.6. Charge-Discharge cycles of $\mathrm{Sn} @ \mathrm{C}$ encapsulated in hollow carbon fiber and commercial tin nanopowder at $0.5 \mathrm{C}$ in the voltage range of $3.0-0.01 \mathrm{~V}$. Sn-C porous film was tested between $0.02-3.0 \mathrm{~V}$ at $0.2 \mathrm{~mA} / \mathrm{cm}^{2}$.

\subsection{Conclusion}

Electrospinning and electrostatic spray deposition were used to fabricate tin -carbon composites with different morphologies such as hollow fiber and porous film. The Sn-C nanofiber anode exhibited good cycle performance with $760 \mathrm{mAh} / \mathrm{g}$ after 50 cycles at $0.5 \mathrm{C}$ between 3.0 and $0.01 \mathrm{~V}$. Sn-C porous film also showed good cyclability with $686 \mathrm{mAh} / \mathrm{g}$ at the end of 50 cycles, corresponding to a $75 \%$ capacity retention of the intial discharge capacity. Both types of anodes showed better results than the tin nanopowder. The improved performance was attributed to the hollow/porous structure, which buffers the volume 
change, and the carbon coating of Sn particles that prevents the aggregation. Sn-C composite anodes prove to be promising electrode materials for LIBs.

\subsection{References}

[1] Y. Idota, T.Kubota, A.Matsufuji, Y. Maekawa and T. Miyasaka, Science, 276, 1395 (1997).

[2] P. Poizot, S. Laruelle, S. Grugeon., L.Dupont and J.M.Tarascon, Nature, 407, 496 (2000).

[3] J. Chen, L. Xu, W. Li. and X. Gou, Adv. Mater, 17(5), 582 (2005).

[4] Y. S. Hu, L. Kienle, Y. G. Guo, and J. Maier, Adv. Mater., 18 (11), 1421 (2006).

[5] M.Winter. G.H. Wrodnigg, J.O.Besenhard and P. Novak, J. Electrochem.Soc,, 147, $2427(2000)$.

[6] M.Winter and J.O. Besenhard, Electrochim. Acta, 45, 3 (1999).

[7] D.Larcher, S. Beattie, M. Mathieu Morcrette, K. Kristina Edstrom, J.C.Jean-Claude Jumas, and J.M. Tarascon, J. Mat.Chem.,17, 3759(2007).

[8] I.A.Courtney and J.R.Dahn, J. Electrochem. Soc., 144, 2943(1997).

[9] E. Shembel, R. Apostolova, V.Nagirny, I. Kirsanova, Ph.Grebenkin, and P. Lytvyn, J. Solid St. Electrochem., 9, 96 (2005) .

[10] J. O. Besenhard, J. Yang, and M. Winter, J. Power Sources, 68, 87 (1997).

[11] J. Y. Lee, R .Zhang and Z. Liu, Electrochem. Solid-State Lett., 3, 167, (2000).

[12] G. L., Cui, Y. S. Hu, L. J. Zhi, D. Q Wu, I. Frieberwirth, J. Maier, and K. Müllen, Small, 3, 2066 (2007).

[13] Z. W. Zhao, Z. P. Guo, P. Yao and H. K. Liu, J. Mater. Sci \& Tech., 24, 657 (2008).

[14] W.M.Zhang, J.S. Hu, Y.G. Guo,, S. F. Zheng, L.S. Zhong, W.G. Song, and L.J.Wan, Adv. Mater., 20, 1160 (2008).

[15] D. Deng,and J.Y Lee, Angew. Chem. Int. Ed., 48(9), 1660 (2009).

[16] N. Li and C.Martin, J. Electrochem. Soc., 148, A164, (2001).

[17] M.Wachtler, M. R. Wagner, M. Schmied, M. Winter and J.O Besenhard, J. Electroanal. Chem., 510, 12 (2001). 
[18] C.M. Park and H.J Sohn, Electrochim. Acta, , 54(26), 6367, (2009).

[19] J.L. Shui, Y.Yu, and C.H. Chen, Appl. Surf. Sci., 253, 2379, (2006). 


\section{SUMMARY AND FUTURE WORK}

\subsection{Summary}

This dissertation presents the fabrication, and evaluation of tin oxide based composites for lithium ion battery anodes. The ESD technique was used to fabricate the anode materials. The anodes prepared using this method can be tested directly without any addition of binders. The pure tin oxide electrodes showed relatively low specific capacity. However, the addition of the CNT increases the capacity of composite anodes due to the synergetic effect. The effect of the percentage of the CNT content in the tin oxide/CNT composites was studied. The capacity was initially found to increase with the increase in the CNT content. However, with further increase in CNT ratio (from 30 to $40 \mathrm{wt} \%$ ), the capacity did not increase because of the relative decreasing contribution from $\mathrm{SnO}_{2}$ in the composite. Though the capacities retained by the composites after 50 cycles were less than the initial capacities, they are significantly higher than the commercial graphite anodes. The effect of the deposition temperature of anodes on the electrochemical performance was also investigated. It should be noted that though the deposition temperatures influence the morphology of the samples, a significant effect was not observed. Comparing the influence of temperature and CNT content, composites with $30 \% \mathrm{CNT}$ deposited at $250{ }^{\circ} \mathrm{C}$ showed high specific capacity whereas $20 \% \mathrm{CNT}$ deposited at $250{ }^{\circ} \mathrm{C}$ exhibited better capacity retention than the control samples as well as other tin oxide/CNT composites studied.

In another part of this dissertation, we examined the electrochemical impedance spectroscopy of the tin oxide/CNT composite anodes in order to understand the underlying mechanism of the contribution of CNT to the stability of the anodes. The change in the resistances of $\mathrm{SnO}_{2} / \mathrm{CNT}$ s anodes at different depths of charge/discharge upon cycling due 
to the formation of surface film was investigated. The values of the surface film resistances were found by fitting the raw data to an equivalent circuit. Change in the surface film resistance on the composite during cycling was lower than that of the pure $\mathrm{SnO}_{2}$. This can be attributed to the addition of CNT. The higher the CNT content in the composite, lower the change in surface film resistance at certain voltage upon cycling. The surface resistance increased with the depth of discharge and decreased slightly at fully lithiated state.

In another approach to improve the capacity of tin oxide anodes, we added graphene to fabricate the composite anodes. The anodes were prepared using ESD technique. Some of the samples were post-heat treated to study the influence of heat treatment. The electrodes show better capacity than the tin oxide/CNT composites as it was shown by various electrochemical testing techniques. Post-heat treated composites (tin oxide/graphene @280 ${ }^{\circ} \mathrm{C}$ ) showed better performance than as-deposited samples (tin oxide/graphene $@ 195{ }^{\circ} \mathrm{C}$ ). The possible reason for this may be the removal of the impurities from the decomposition reaction at high temperature. The maximum energy density was observed in post-heat treated composites were in the range of $3 \mathrm{kwh} / \mathrm{kg}$ in the initial cycles and reduced to 1.7 $\mathrm{kWh} / \mathrm{kg}$.

In the final part of this dissertation, tin based composites were studied. Tin has a higher theoretical capacity than tin oxide but pure tin metal anodes have problem with cyclability. It is shown that this can be alleviated by fabricating composites and also by modifying the morphology. Sn-C composites were prepared by ESD and electrospinning with different morphologies-porous thin film and $\mathrm{Sn}$ encapsulated carbon fiber. Sn-C nanofiber anode exhibited good cycle performance with $760 \mathrm{mAh} / \mathrm{g}$ after 50 cycles at $0.5 \mathrm{C}$ and Sn-C porous film also showed good cyclability with $686 \mathrm{mAh} / \mathrm{g}$ at the end of 50 cycles. 
Comparing all the anodes studied in this dissertation, the specific capacities and energy densities (at the end of 50 cycles) of tin oxide/graphene @ $280{ }^{\circ} \mathrm{C}$ is relatively high, followed by Sn/C porous film, tin oxide/graphene @ $195{ }^{\circ} \mathrm{C}, \mathrm{Sn} @$ encapulated carbon fiber, and tin oxide/ 30\% CNT @ $250{ }^{\circ} \mathrm{C}$, in that order.

\subsection{Future Work}

In this dissertation, we investigated thin film tin oxide based composites prepared using electrostatic spray deposition technique. The tin oxide based composites still have room for improvement that can be achieved by novel design of the electrodes. It is possible to use ESD method to fabricate solid state batteries for applications in micro-devices. The study of underlying mechanism of the synergetic effect due to the addition of CNT or graphene to tin oxide anodes will help to improve the overall performance of the electrode. In the electrochemical impedance spectroscopy investigation, further studies on the low frequency region are needed to understand the evolution of the phase transformation resistance. Studying the kinetics of lithium ion transport in these composites will help better the design of the electrodes. In the tin oxide/graphene composites, the effect of the $\mathrm{NaCl}$ impurities on the performance has to be studied. The future research should be focused on the fabrication of full-cells, which will reveal the possibility of scaling-up of the electrodes for higher energy requirements. 
VITA

ABIRAMI DHANABALAN

Bachelor of Technology in Chemical \& Electrochemical Engineering (2002-2006), Central ElectroChemical Research Institute (CECRI), Karaikudi, India

PhD candidate in Materials Engineering (2007-Present), Florida International University (FIU), Miami, FL

\section{PUBLICATIONS}

1. X. Li, W. Chen, A. Dhanabalan, and C. Wang, "Prospects of nanomaterials in Li-ion battery applications", Applications of Nanomaterials, American Scientific Publishers Editors: Ramesh S. Chaughule and R.V. Ramanujan, 2012 by American Scientific Publishers, ISBN: 1-58883-181-7

2. A.Dhanabalan, Y. Yu, X. Li, W. Chen, K. Bechtold, L. Gu, and C. Wang, "Porous $\mathrm{SnO}_{2} / \mathrm{CNTs}$ Composite Anodes: Influence of Composition and Deposition Temperature on the Electrochemical Performance", J. Mater Res. 2010, 25, 1554. DOI: 10.1557/jmr.2010.0200.

3. A.Dhanabalan, Y. Yu, and X. Li, "Fabrication of tin-carbon composite anode material by electrospinning and electrostatic spray deposition for lithium rechargeable battery", Proc. SPIE 2010, 7679, 76792I. DOI: 10.1117/12.852450.

4. X. Li, A.Dhanabalan, K. Bechtold, and C. Wang, "Binder-free porous core-shell structured $\mathrm{Ni} / \mathrm{NiO}$ configuration for application of high performance lithium ion batteries", Electrochem. Comm.2010,12,1222. DOI: 10.1016/j.elecom.2010.06.024.

5. X. Li, A. Dhanabalan and C. Wang, "Enhanced Electrochemical Performance of Porous NiO-Ni Nanocomposite Anode for Lithium Ion Batteries”, J. Power Source 2011, 196 , 9625. DOI: 10.1016/j.jpowsour.2011.06.097.

6. X. Li, A. Dhanabalan, K. Bechtold, and C.Wang, "Three-Dimensional Porous CoreShell Sn@Carbon Composite Anodes for High-Performance Lithium-Ion Battery Applications", Adv Ener Mater, 2012, 2, 238. DOI: 10.1002/aenm.201100380 
7. Y. Yu, L. Gu, A. Dhanabalan, C.H. Chen, and C. Wang, "Three-dimensional porous amorphous $\mathrm{SnO}_{2}$ thin films as anodes for Li-ion batteries", Electrochim Acta, 2009, 54, 7227. DOI: $10.1016 /$ j.electacta.2009.07.028.

8. W. Chen, Z. Fan, A. Dhanabalan, C. Chen, and C. Wang, "Mesoporous Si Anodes Prepared by Manesiothermic Reduction for Lithium Ion Batteries", J. Electrochem. Soc. 2011, 158, A1055. DOI: 10.1149/1.3611433.

9. T. K. Kim, C. Chen, A. Dhanabalan, and C. Wang, "Electrochemical performance of porous NiO films as anode material for lithium ion batteries", ECS Transactions Montreal, QC, Canada, Nanostructured Materials for Energy Storage and Conversion, 35, 2011.

10. Y. Yu, L. Gu, C. Wang, A. Dhanabalan, P. A. van Aken, and J. Maier, "Encapsulation of Sn@carbon Nanoparticles in Bamboo-like Hollow Carbon Nanofibers as Anode for Lithium Ion Batteries Applications", Angew Chem Int Edit, 2009, 48, 6485. DOI: 10.1002/ange.200901723.

11. X. Li, L. Gu, K. Bechtold, A. Dhanabalan, and C. Wang, "Nanoporous tree-like $\mathrm{SiO}_{2}$ films fabricated by sol-gel assisted electrostatic spray deposition", Micropor Mesopor Mat., 2012, 151, 488. DOI: 10.1016/j.micromeso.2011.09.003

12. Y. Yu, A. Dhanabalan, L. Gu, and C.Wang, "Hierarchically Macro-Mesoporous Spongy-like $\mathrm{Fe}_{3} \mathrm{O}_{4}$ Thin Film Electrode for Application in Li-ion Batteries, Nanosci. Nanotechnol. Lett., 2012, 4,1.

13. A. Dhanabalan, X. Li , Y. Yu, and C. Wang, "Impedance Spectroscopy of Porous $\mathrm{SnO}_{2} / \mathrm{CNTs}$ Composite Anodes for Lithium Ion Batteries", J. Electrochem Soc. (to be submitted).

14. Dhanabalan, X. Li, Y. Yu, and C. Wang, "Fabrication and electrochemical characterization of tin oxide/graphene electrodes as anode material for Li-ion battery", J. Power sources (to be submitted).

15. Y. Yu, L. Gu, A. Dhanabalan, and C. Wang, "Encapsulation of Silicon Nanoparticles in Carbon Nanofibers for Li-ion Batteries Application”(to be submitted). 


\section{CONFERENCE PRESENTATIONS}

1. A. Dhanabalan, X. Li, and C. Wang, "Fabrication and electrochemical characterization of tin oxide/graphene electrodes as anode material for Li-ion battery", MRS Spring 2012, Apr 9-13, San Francisco, CA.

2. Dhanabalan, K.Gharibi, and C. Wang, " $\mathrm{Fe}_{3} \mathrm{O}_{4} /$ Graphene Composites as Anode for High Performance Lithium Ion Batteries”, MRS Spring 2012, Apr 9-13, San Francisco, CA.

3. Dhanabalan, X. Li, Y. Yu, W. Chen, and C. Wang, "In situ Raman Spectroscopy studies of $\mathrm{SnO}_{2} / \mathrm{CNTs}$ composite thin film Li-ion Batteries anodes", MRS Fall 2010, Nov 29Dec 3, Boston, MA.

4. Dhanabalan, X. Li, Y. Yu, and C. Wang, "Impedance Spectroscopy of SEI on Porous $\mathrm{SnO}_{2} /$ CNTs Composite Anodes for Li-ion Batteries", 2009 MRS Fall meeting, Nov 30Dec 4, Boston, MA.

5. Dhanabalan, $\mathrm{Y}$. Yu, and $\mathrm{C}$. Wang, "Preparation and Characterization of Porous $\mathrm{SnO}_{2}$ /CNTs Thin Films as Anodes for Li-ion Batteries", NSF CMMI Research and Innovation Conference 2009, CMMI, June 22-25, 2009, Honolulu, Hawaii.

6. Dhanabalan, Y. Yu, X. Li, and C. Wang, "SnO ${ }_{2}-\mathrm{CNT}$ Thin Film Composites as Anode Materials for Li-ion Batteries", 215th ECS Meeting, May 24-29, 2009, San Francisco, CA.

7. Dhanabalan, Y. Yu, and C. Wang, "Preparation and Characterization of Porous $\mathrm{SnO}_{2}$ CNT Thin Films as Anodes for Li-ion Batteries, 2008 MRS Fall Meeting, Dec 1-5, 2008, Boston, MA.

8. Y. Yu, A. Dhanabalan, K. Bechtold, and C. Wang, "Fabrication of Silicon Nanoparticles Implanted in Carbon Nanofibers by Electrospinning Technique", 215th ECS Meeting, May 24-29, 2009, San Francisco, CA.

9. X. Li, A. Dhanabalan, K. Bechtold, and C. Wang, "Porous Sn/C composite Anode for Li-ion Batteries", 215th ECS Meeting, May 24-29, 2009, San Francisco, CA.

10. Y. Yu, A. Dhanabalan, K. Bechtold, and C. Wang, "Encapsulation of Silicon Nanoparticles in Carbon Nanofibers for Li-ion Batteries Application”, 2009 MRS Spring meeting, April 13-17, San Francisco, CA.

11. X. Li, A. Dhanabalan, K. Bechtold, Y. Yu and C. Wang, "Porous $\mathrm{SnO}_{2} / \mathrm{Ag}$ Composites as Anode Materials for Li-ion Batteries, 2009 MRS Spring meeting, April 13-17, San Francisco, CA. 
12. Y. Yu, V. Penmatsa, A. Dhanabalan, and C. Wang, "Micro/Nano Hierarchical Porous Tin Oxide Thin Film as Anode for Li-ion Batteries", 2008 MRS Fall Meeting, Dec 1-5, 2008, Boston, MA.

13. Y. Yu, M. Beidaghi, V. Penmatsa, A. Dhanabalan, and C. Wang, "Fabrication of Nano Fractal Electrodes for On-Chip Supercapacitors", DARPA MEMS PI Review Meeting, July 23-25, 2008, Vail, CO. 